Florida International University

FIU Digital Commons

FIU Electronic Theses and Dissertations

University Graduate School

$2-14-2020$

\title{
Understanding, Quantifying, and Reducing Bias in Fisheries- independent Visual Surveys
}

James Kilfoil

jkilf001@fiu.edu

Follow this and additional works at: https://digitalcommons.fiu.edu/etd

Part of the Biology Commons, Population Biology Commons, and the Terrestrial and Aquatic Ecology Commons

\section{Recommended Citation}

Kilfoil, James, "Understanding, Quantifying, and Reducing Bias in Fisheries-independent Visual Surveys" (2020). FIU Electronic Theses and Dissertations. 4445.

https://digitalcommons.fiu.edu/etd/4445

This work is brought to you for free and open access by the University Graduate School at FIU Digital Commons. It has been accepted for inclusion in FIU Electronic Theses and Dissertations by an authorized administrator of FIU Digital Commons. For more information, please contact dcc@fiu.edu. 


\title{
FLORIDA INTERNATIONAL UNIVERSITY
}

Miami, Florida

\section{UNDERSTANDING, QUANTIFYING, AND REDUCING BIAS IN FISHERIES- INDEPENDENT VISUAL SURVEYS}

\author{
A dissertation submitted in partial fulfillment of \\ the requirements for the degree of \\ DOCTOR OF PHILOSOPHY \\ in \\ BIOLOGY \\ by \\ James Patrick Kilfoil
}

2020 
To: Dean Michael R. Heithaus

College of Arts, Sciences and Education

This dissertation, written by James Patrick Kilfoil, and entitled Understanding, Quantifying, and Reducing Bias in Fisheries-independent Visual Surveys, having been approved in respect to style and intellectual content, is referred to you for judgment.

We have read this dissertation and recommend that it be approved.

Michael R. Heithaus

Joel C. Trexler

Wei Zeng

Matthew D. Campbell

Yuying Zhang, Major Professor

Date of Defense: February 14, 2020

The dissertation of James Patrick Kilfoil is approved.

Dean Michael R. Heithaus

College of Arts, Sciences and Education

Andrés G. Gil

Vice President for Research and Economic Development and Dean of the University Graduate School

Florida International University, 2020 
(C) Copyright 2020 by James Patrick Kilfoil

All rights reserved. 


\section{DEDICATION}

Dedicated to the loving memory of James O. Kilfoil and William H. Berkley. 


\section{ACKNOWLEDGMENTS}

My former lab mate Robert Nowicki (now Dr. Nowicki) told me when I began my studies at Florida International University (FIU) that, "it takes a village to write a dissertation" and time has proven him correct. Reflecting back on my graduate work, I have so many people to thank that made this project possible. First and foremost, I would thank my major advisor, Dr. Yuying Zhang. Yuying constantly challenged me while supporting me, and guided me while allowing me the flexibility to pursue my own interests. I am constantly amazed by your work ethic, analytical mind, and willingness to help others. Under your advisement, I have grown from a young field biologist into a well-rounded scientist, and for that I will always be grateful.

In addition to my major advisor, I had the privilege of being supported by a number of faculty and staff during my graduate studies. I would like to thank Dr. Michael Heithaus, who served as a committee member and an informal second advisor for my graduate research. Mike, you invited me to collaborate with your lab and made me feel a like a part of the Heithaus family. I am in awe of your productivity, support of your students, and constant humor. Thank you for everything. Thank you to Dr. Joel Trexler for our frequently meetings to discuss ecological theory, and for always reminding me to relate my research back to these principals. To Dr. Matthew Campbell, you were instrumental in developing the focus of my dissertation research, and your expertise with visual surveys was invaluable. I cannot thank you enough. I would like to extend my gratitude to Dr. Wei Zeng, who helped me to learn many concepts of computer vision and helped to provide a unique perspective on my research topics. In addition to my committee, I would like to thank Drs. Jeremy Kiszka and Mark Bond who constantly 
offered their support and were key collaborators in the development of my research. I would like to extend my gratitude to Dr. Aaron Wirsing from the University of Washington for his help with all aspects of my research, from writing, to fund raising, to hard work in the field. You are and will always be, the BRUV Master General. Kirk Gastrich also deserves many, many, thanks for his guidance and help in the field with all things Tetiaroa. Without providing your hard work, great conversation, and perhaps most importantly, excellent music, it is very likely that none of this work would have been completed. I would be remiss if I did not acknowledge all the help and support from members of the Fisheries and Ecosystem Assessment Lab and Heithaus Lab. Thank you to Nan, Rob, Sonja, Camila, Beth, Valeria, Bradley, Frances, Courtney, and all members of the FIU graduate community for your contributions, conversations, and friendship. With that, I would also like to say a special thanks to Ivan Rodriguez-Pinto for his help with aspects of computer vision used in my dissertation research, and more importantly for his friendship and collaboration throughout our graduate studies.

I would also like to thank all of my family for their constant love, support, and for always believing in me. To my parents Mike and Thresa, you instilled the importance of education in me at a young age, and helped me to become both the man and scientist I am today. To my sister Katie, thank you for always providing a kind ear, a perspective on what is really important, and for not making fun of me too much anytime I complained about my "work...on a boat...in Tahiti." I would also like to say thanks to my nephews Carson, Kellen, and Corbin whose interest in wildlife and conservation inspires me, and gives me hope for future generations. Lastly, I need to thank my wife Lisa (Dr. Lisa Ailloud to be more precise). You gave me the courage to pursue marine sciences, and 
have always been my greatest supporter. Thank you for dropping everything to come help me in the field for a month, for counting more sea cucumbers than you than you probably thought possible, and for our late night talks about all things fish. For your relentless optimism, your humor, love, patience, and kindness, I can't thank you enough.

Lastly, I would like to extend my sincerest gratitude to all the funding sources that made this project possible. Funding for this research was provided by generous donations from the Seeley Family and J. Hirota. Additional funding was provided by the Save Our Seas Foundation, the Guy Harvey Scholarship Fund, and the FIU Dissertation Year Fellowship. I thank the editors of the Marine Ecological Progress Series for granting permission for the use of Chapter Two in this dissertation. And to anyone who I undoubtedly forgot to mention, just know that I am in your debt (and that there is a page limit for the acknowledgements). For all these reasons and more, thank you everyone. 


\title{
ABSTRACT OF THE DISSERTATION \\ UNDERSTANDING, QUANTIFYING, AND REDUCING BIAS IN FISHERIES- INDEPENDENT VISUAL SURVEYS
}

\author{
by \\ James Patrick Kilfoil \\ Florida International University, 2020 \\ Miami, Florida \\ Professor Yuying Zhang, Major Professor
}

Understanding spatiotemporal changes in populations is vital for conservation managers to assess current recovery efforts, determine future conservation priorities, and forms the basis to explore complex ecological questions. In fisheries, these data have traditionally been collected using fisheries-independent surveys that rely on extractive sampling practices (e.g., longlines, gillnets, trawls). However, with the growing availability of low-cost, high-definition cameras, researchers are increasingly using visual surveys as a non-invasive alternative. Camera surveys have a number of advantages including their archivable data, and offer insights into species habitat use and behavior. However, the use of cameras has a number of inherent biases. Understanding, quantifying, and mitigating against these biases is critical if camera systems are to be used to inform management and policy. In the present dissertation, potential biases were explored for two commonly used visual survey methods; baited remote underwater videos (BRUV), and unmanned aerial vehicles (UAV). Specifically, our objectives were to answer: (1) Are metrics of relative abundance derived from BRUVs linearly related to true changes in abundance for elasmobranchs, (2) Are these same metrics sensitive to 
changes in density-independent factors, and (3) Can UAVs be used to replace or supplement traditional diver transects for marine invertebrate species? Using a combination of standard and full-spherical camera BRUV deployments, Chapter Two found that tradition BRUVs likely undercount sharks in high density environments, while also having lower probability of detection than full-spherical cameras. Using a spatiallyexplicit, individual-based-model, Chapter Three revealed that metrics of relative abundance derived from BRUVs are also highly sensitive to factors unrelated to changes in abundance (e.g., swimming speed, current strength, and movement patterns). Lastly, using paired snorkeler-UAV transect sampling, Chapter Four found counts derived from UAV transects did not significantly differ from divers, and offered a number of advantages over traditional techniques (shorter sampling times, larger surveyed area, and automation). Furthermore, we found that UAVs can improve sampling designs used to quantify invertebrates, by estimating their distribution within a study region prior to initiating transect sampling. Collectively, these works improve our understanding and interpretation of video survey results that are used for management across the globe. 


\section{TABLE OF CONTENTS}

CHAPTER

PAGE

I. INTRODUCTION ................................................................................... 2

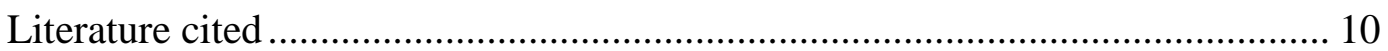

II. BAITED REMOTE UNDERWATER VIDEO SURVEYS UNDERCOUNT SHARKS AT HIGH DENSITIES: INSIGHTS FROM FULL-SPHERICAL

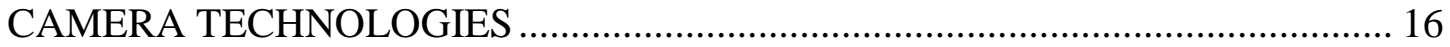

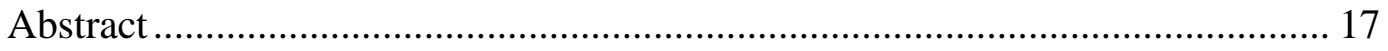

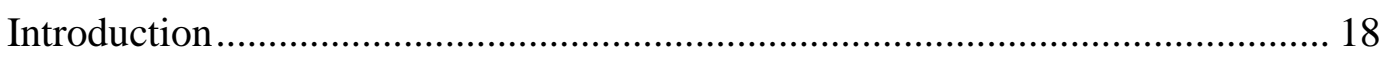

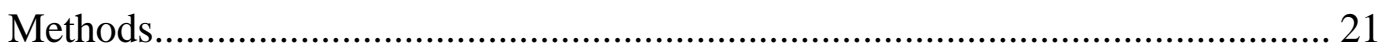

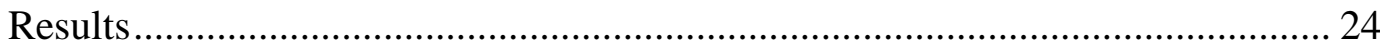

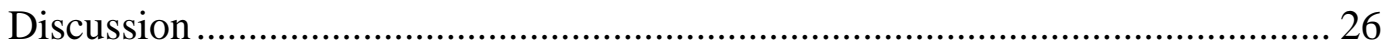

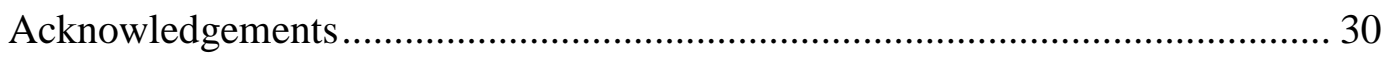

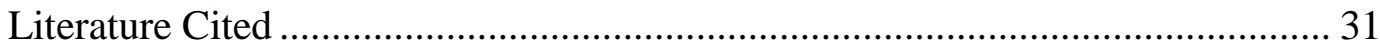

III. INFLUENCE OF SHARK BEHAVIOR AND ENVIRONMENTAL CONDITIONS ON BAITED REMOTE UNDERWATER VIDEO SURVEY

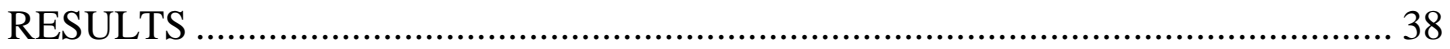

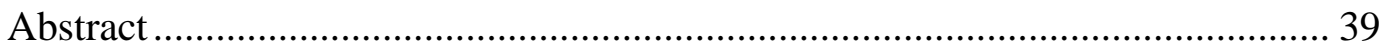

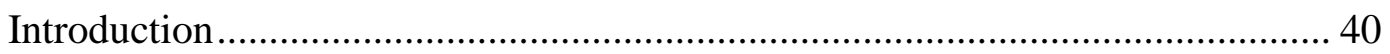

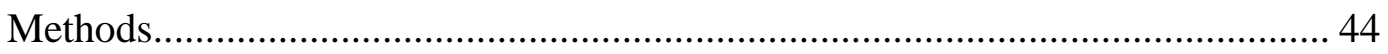

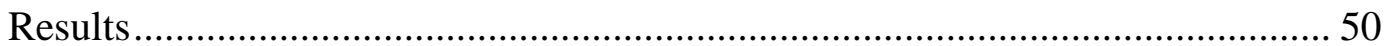

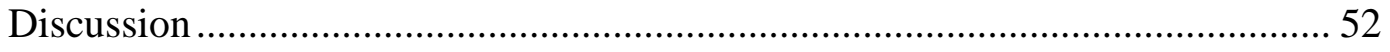

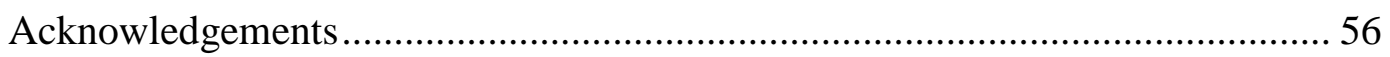

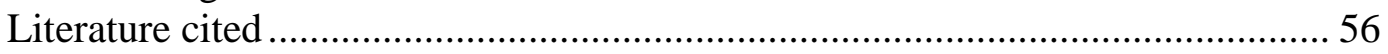

IV. USING UNMANNED AERIAL VEHICLES AND MACHINE LEARNING TO IMPROVE SEA CUCUBMER DENSITY ESTIMATION IN SHALLOW

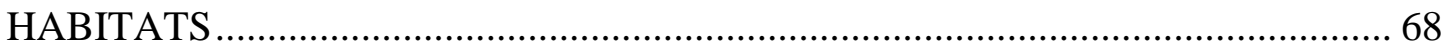

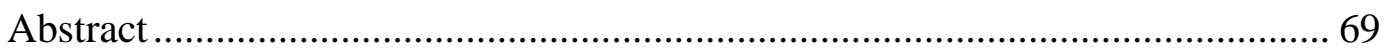

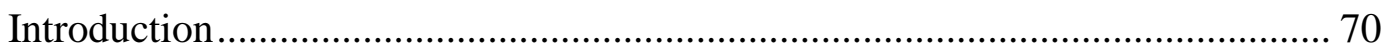

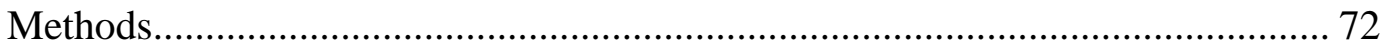

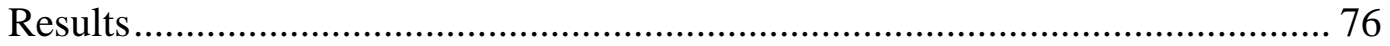

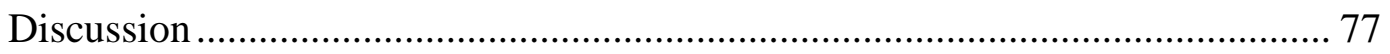

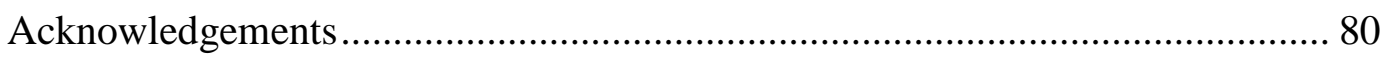

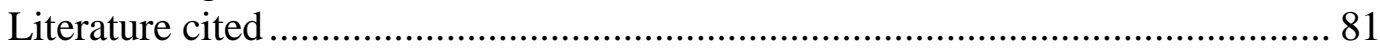

V. CONCLUSIONS AND FUTURE DIRECTIONS............................................. 90

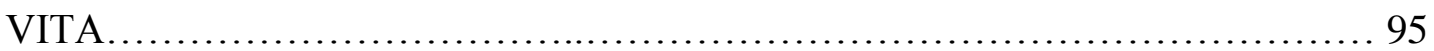




\section{LIST OF TABLES}

CHAPTER

PAGE

\section{CHAPTER III}

Table 1.

Parameter description and value range when varied, as well as fixed value when not varied for each simulation scenario. 


\section{LIST OF FIGURES}

CHAPTER

PAGE

\section{CHAPTER II}

Figure 1.

Baited Remote Underwater Visual Full-spherical $\left(\mathrm{BRUV}^{\mathrm{fs}}\right.$ ) array deployed in Tetiaroa, French Polynesia (July $17^{\text {th }}$ to August $8^{\text {th }}, 2017$ ). Red inset depicts GoPro F360 mounting used to later generate full-spherical videos, with its location on the BRUV ${ }^{\mathrm{fs}}$ also highlighted with a red square. Orange inset depicts the single Hero4 GoPro used as the mono camera comparison, with its location on the $\mathrm{BRUV}^{\mathrm{fs}}$ highlighted with a corresponding orange square.

Figure 2.

Still images extracted from stitched full-spherical (left panel) and mono (right panel) BRUV deployments in Tetiaroa, French Polynesia (August, 2016). Red dots indicate elasmobranch species that could be identified (left panel, $\mathrm{N}=8$; right panel, $\mathrm{N}=2$ ) at the same point in time.

Figure 3.

A) Relationship between site abundance (assumed to be equivalent to the full-spherical count) and estimates of MaxN from mono camera (upper panel), as well as catchability (q) of the mono camera (lower panel). Blacktip reef sharks (Carcharhinus melanopterus) are represented by black X marks, whereas sicklefin lemon sharks (Negaprion acutidens) are represented by open grey squares. Data points with both $X$ and open grey squares represent both sicklefin lemon and blacktip reef sharks. Dashed lines represent what relationship would be typically assumed for MaxN (upper panel; $y=x$ ), and catchability (lower panel; q=1.0). B) Relationship between site abundance (assumed to be equivalent to full-spherical count) and estimates of MeanCount from mono camera (upper panel), as well as catchability (q) of the mono camera (lower panel). Data are aggregated across both sicklefin lemon and blacktip reef sharks and represented by open circles. Dashed lines represent what relationship would be typically assumed for MeanCount (upper panel; $\mathrm{y}=\mathrm{x}$ ), and catchability (lower panel; $\mathrm{q}=1.0$ ).

\section{CHAPTER III}

Figure 1.

Simulated bait odor particle locations (indicated by small black dots) following five minutes of dispersal from the center $(500,500)$ of the study system with a constant current speed of 1.5 meters per second. Odor particle locations were used to create a smoothed raster of particle concentrations of 
1.0 (highest concentration, indicated by pink) to 0.0 (lowest concentration, indicated by grey).

Figure 2.

A) Resulting shark movement tracks (indicated by black lines) for a simulated baited remote underwater video deployment, with a mean swimming speed of 1.5 meters per second. B) Zoomed image of the same shark movement tracks, highlighting track patterns once the shark is in contact with the bait plume (indicated by color gradient of pink to light orange).

Figure 3.

Figure illustrating full-spherical and standard camera detection ranges for simulated baited remote underwater video survey deployments. Red circle represents both camera types, with yellow shading used to indicate restricted field of view $\left(120^{\circ}\right)$ for standard camera. Standard camera is oriented to the direction of the simulated current flow, and detection probability for both cameras (indicated in blue shading) reduces a function of distance from the camera. Inside the lower visibility (LV) region, cameras have a $100 \%$ probability of detection for sharks, and outside the upper visibility (UV) region cameras have a $0 \%$ detection probability. All sharks (represented by small black circle) cast a $5^{\circ}$ degree visual shadow, behind which subsequent sharks cannot be detected by either camera.

Figure 4.

Relationship between shark density $\left(1-125 / \mathrm{km}^{2}\right)$ and resulting MaxN (upper panel) and MeanCount (lower panel) estimates from simulated baited remove underwater video system deployment. Black circles represent estimates derived assuming a full-spherical $\left(360^{\circ}\right)$ field of view, while grey dots assume a standard $\left(120^{\circ}\right)$ view. White dashed lines represent a fitted linear model using the geom_smooth function in R's ggplot2 package.

Figure 5.

Comparison of MaxN (upper panels) and MeanCount (lower panels) estimates' relative bias in relation to: A) Mean swimming speed B) Relative attraction strength to bait (alpha) C) Directedness of movement patterns (directionality), D) Camera visibility range, E) Bait plume size $\left(\mathrm{km}^{2}\right)$. White dashed lines represent a fitted linear model using the geom_smooth function in R's ggplot2 package.

Figure 6.

Standardized coefficient estimates for all highly significant factors in generalized linear models created for MaxN using full-spherical cameras (FS_MaxN; light-grey circle), MeanCount using full-spherical cameras (FS_MeanCount; medium-grey diamonds), MaxN using standard cameras 
(Standard_MaxN; light-grey squares) and MeanCount using standard cameras (Standard_MeanCount; dard-grey triangles). Values have been scaled to their mean values to aid in comparison. Surrounding each parameter estimate is the assumed normal distribution with $95 \%$ confidence intervals.

\section{CHAPTER IV}

Figure 1.

All unmanned aerial vehicle (UAV) transects for this study were flown in sandflat habitats of Tetiaroa (French Polynesia) of less than 2 meters in depth, from 22-25 July 2018. Lower inset depicts nearby islands of the Society Archipelago; Tahiti and Moorea. Upper inset highlights northern region of lagoon where UAV transects were flown.

Figure 2.

Example images of UAV data flown over snorkeler transects used in Tetiaroa, French Polynesia. Snorkeler transects are highlighted by weighted PVC and connected lines to ease comparison between divers and UAV. A) Image after being processed by observer using Visual Counter software. Sea cucumbers identified by the observer one are represented by small purple squares, while observer two markings are indicated in blue. B) Image of sea cucumber counts processed by two independent observers, with areas of agreement (represented by small orange squares) and disagreement (represented by small red squares) identified using MATLAB color channel filtering in the $\mathrm{L}^{*} \mathrm{a}^{*} \mathrm{~b}$ color space.

Figure 3.

Left panel: Results from linear regression of sea cucumber counts estimated by manual review of UAV images (black circles) and via the employed convolution neural network model (CNN; grey triangles) as compared to mean count obtained by divers for the same transect. Small dashed line represents a perfect correlation, with the range in diver estimates illustrated by grey shadowing. Larger dashed lines represent an fitted polynomial of the manual review (black) and CNN (grey) estimates to aid in pattern visualization using the geom_smooth function in ggplot. Right panel: Boxplot for counts estimates derived from CNN, Divers, and Manual review of UAV data. Median values are indicated by center box line, with the integral quartile range represented by boxes, and minimum/maximum quartile ranges indicated by extended lines.

Figure 4.

Photomosaic map of study region in Tetiaroa, French Polynesia generated by stitching 56 overlapping, geo-referenced images using the application Pix4DCapture. Inset highlights zoomed in portion of image with sea cucumbers manually marked using Visual Counter. 
Figure 5.

Sample variance from simulated transects (1-100) in relation to the number of transects sampled, based on sea cucumber locations taken from UAV generated photomosaic of the study region in Tetiaroa, French Polynesia. A total of 1,000 simulations were run for each number of simulated transects sampled. 


\section{PREFACE}

The following chapter has been accepted for publication and has been formatted for that volume.

\section{CHAPTER II}

Kilfoil, J. P., A. J. Wirising, M. D. Campbell, J. J. Kiszka, K. R. Gastrich, M. R. Heithaus, Y. Zhang, and M. E. Bond. 2017. Baited Remote Underwater Video surveys undercount sharks at high densities: Insights from full-spherical camera technologies. Marine Ecological Progress Series, 585: 113-121.

Permission has been granted by the editors of this volume to print Chapter II of this dissertation. 
CHAPTER I

INTRODUCTION 
A fundamental goal of fisheries research, and more broadly ecology itself, is to provide accurate estimates of species abundances. These estimates are used to measure the success of current management actions, identify species and regions that are in need of future protections, and form the basis for exploration of complex ecological processes. In fisheries, the data used to provide these estimates have historically been collected using a combination of fishing gears such as longlines, gillnets, and trawls (Shipman et al. 2001). Though important tools, the extractive properties of these methodologies have a number of disadvantages, including potential high rates of mortality for sampled individuals (Skomal 2007), and destruction of habitat critical for some species (Wheeler et al. 2005). Accordingly, an increasing amount of fisheries data are being gathered using minimally invasive, visual survey approaches (Struthers et al. 2015).

Underwater visual surveys (UVS), sometimes referred to as underwater visual censuses, are a group of fisheries-independent sampling techniques used to quantify species richness, abundance, distribution, and size structure of aquatic populations around the globe (Edgar et al. 2004). Though used in a variety of environments, UVS are primarily employed in shallow, temperate, coral reef ecosystems, due to visibility requirements of the technique (Caldwell et al. 2016). Historically, UVS have been limited to using either snorkeler or SCUBA observers to count species of interest over a specified period of time (Sale and Douglas 1981), and could be further classified as either stationary point counts (SPC) or belt transect counts (BTC). In SPCs, the underwater observer stays in the same spot and provides counts for a fixed area over a specified time (Bohnsack and Bannerot 1986), whereas in BTCs the observer will swim in a straight line at constant speed over a given distance, and provide counts of organisms within a certain 
transect width (Brock 1954), while sometimes providing estimates of the distance to each organism (Thomas et al. 2010). Each technique has its own advantages and shortcomings, and researchers must carefully consider the study questions as well as the species of interest before determining which method may be most appropriate (Smith 1989; Kulbicki et al. 2010). However, a universal limitation of UVS has been the use of human observers in the field. As a result of safety concerns, underwater observers have been constrained by depth and the amount of time in which they can be deployed, thus restricting their ability to sample certain habitats. Additionally, the mere presence of observers has been shown to attract some species while repelling others (Dearden et al. 2010), which can severely bias survey results. Limited dive times coupled with the mobile nature of many fish species may also bias observers' counts as they struggle to rapidly identify, estimate the size of, and distance to observed fishes. Though some studies have attempted to estimate the effects these types of biases may have on survey results, (e.g., potential of SCUBA diver bubbles as an attractant or repellant; Lindfield et al. 2006), the vast majority simply ignore their potential impacts, either explicitly or implicitly. Given the impact of human observers on UVS, along with their limited depth and duration capabilities, a growing number of UVS are replacing human observers with camera systems.

Video cameras have been used in fisheries research since the introduction of the first videotape recorder in 1951 (Bellis 2004). Early iterations of underwater camera systems were used to study fish behavior, benthic organisms, plankton, and interactions with fisheries gear (Barnes 1951; Brawn 1960; Livingstone 1962; Richard 1968). The first seafloor mounted camera observation systems were designed by Kumpf and 
Lowenstein (1962) and Stevenson and Myrberg (1996) to estimate species diversity and abundances, while also providing insights into species-specific behaviors and interactions (Steinberg et al. 1965; Myrberg et al. 1969). Though incredibly important for advancing the use of cameras in fisheries research, these early designs were impracticable for widespread use given their large size, high cost, and need for customized underwater housings (Struthers et al. 2015). However, as frequently occurs in the technological sector, increased consumer demand for video systems coupled with advances in optical technologies has resulted in the development of a variety of small, inexpensive, highdefinition cameras capable of being deployed underwater (e.g., GoPro ${ }^{\mathrm{TM}}$ ). Since their commercial emergence in the 1990s, these type of action cameras have been used to assess fish habitat (Carleton and Done 1995; Heithaus et al. 2002), estimate fish size (Harvey et al. 2002; Costa et al. 2006) assess community structure (Booth and Beretta 2002; Cooke and Schreer 2002), validate foraging models (Hughes et al. 2003), and document fish behavior (Heithaus et al. 2002; Michel et al. 2002). Given that these camera systems are used for a variety of research purposes, it is not surprising that there are a number of accepted methodologies and platforms used to deploy them in the marine environment (Murphy and Jenkins 2010). Of these, two of the most commonly used platforms are Baited Remote Underwater Video Systems (BRUV or BRUVS) and Unmanned Aerial Vehicles (UAVs).

Baited Remote Underwater Video Systems, sometimes referred to as Baited Remote Underwater Video Surveys, are a group of survey tools used to generate SPCs. Though BRUVS can vary in their complexity (e.g., pelagic, vertically oriented, or stereo BRUVS) they are generally comprised of a relatively simple platform (e.g, rebar cage; 
Bond et al. 2012), with a single camera that is mounted in front of a bait source. The platform is typically lowered to the seafloor by hand, with the camera and bait arm oriented in the direction of the current flow to attract fishes to the BRUVS. Deployment times vary between studies, however, BRUVS are typically deployed for a minimum of 60 minutes before being retrieved (Murphy and Jenkins 2010; Whitmarsh et al. 2017). Their low cost and ease of use have helped BRUVS to become one of the most popular UVS methods using cameras over the last two decades (Whitmarsh et al. 2017), and are utilized for a wide variety of scientific studies ranging from investigating species specific-behaviors (Santana-Garcon et al. 2014), to habitat associations (Harvey et al. 2012; Espinoza et al. 2014) and community analyses (Whitmarsh et al. 2014). However, the most common use of BRUVS is to monitor and assess how populations of fishes are changing across space and time (Whitmarsh et al. 2017). In particular, their nonextractive nature has made them widely used to study Marine Protected Areas (MPAs), where they are frequently used to study larger mobile predators such as sharks (Colton 2010). However, the same non-extractive property of BRUVS that has made them so widely used, also presents unique challenges not found in traditional sampling techniques.

In general terms, BRUVS work by attracting fishes in front of the camera's field of view (FOV) using a bait plume, where they can later be identified and counted from the video footage (Cappo et al. 2007). However, enumerating fishes from these video data is not a straight forward process. As a result of the non-invasive sampling of BRUVS, coupled with the limited FOV of cameras, fishes have the potential to be repeatedly counted as they swim in and out of the camera's FOV. If not accounted for, 
this limitation can result in artificially inflated abundance estimates derived from BRUV data (Cappo et al. 2007). In an attempt to alleviate these concerns, a number of alternative methods have been developed to quantify fishes from BRUV footage. By far, the most commonly used of these methods are MaxN and MeanCount approaches (Campbell et al. 2015; Whitmarsh et al. 2017). The metric MaxN is defined as a species-specific count of the maximum number of individuals observed on any single video frame across the entire BRUV deployment (Ellis and Demartinin 1995), while MeanCount is calculated by averaging the count of individuals observed on sub-sample of video frames taken at specified sampling intervals (e.g., 10s, 15s, 30s, or 60s; Bacheler et al. 2013; Schobernd et al. 2014; Campbell et al. 2015). Despite being widely used (e.g., Willis and Babcock 2000, Stoner et al. 2008; Schnobernd et al. 2014), and reducing issues of inflated counts, these metrics have recently been criticized as the relationship between each and true population changes are not well understood under certain conditions (Schobernd et al. 2014; Campbell et al. 2015; Kilfoil et al. 2017). Failure to understand these relationships can lead to hyperdepleted or hyperinflated indices of relative-abundance generated from these data, whereby true populations are changing while indices remain constant. Furthermore, almost no studies to date have explored how MaxN and MeanCount estimates may be influenced by factors unrelated to changes in abundances such as the size of the bait plume and the speed of surveyed species, despite recommendations for such works to be carried out (Taylor et al. 2013).

In addition to underwater survey methods, action cameras are now being utilized to supplement and replace data collection for aerial surveys. In particular, pairing small camera technology with unmanned aerial vehicles (UAVs, commonly referred to as 
drones), has dramatically increased over the last decade (Bryson and Williams 2015; Ivošević et al. 2015). As a wildlife monitoring tool, UAVs has been used to study a wide range of species and taxa, both in terrestrial and marine environments (Anderson and Gaston 2013; Colefax et al. 2017). In particular, UAVs have proved useful for gathering data on species and habitats that are difficult or dangerous to access directly with human observers, or whose presence may disrupt the objectives of the study such as identifying orangutan nests (Koh and Wich 2012), estimating the size and abundance of nesting birds (Goebel et al. 2015), and investigating the nesting behavior of crocodiles (Evans et al. 2015). However, one of the most pervasive uses of UAVs today is to replace costlier and more dangerous manned aerial surveys (Colefax et al. 2017). The majority of this work to date has focused on large marine vertebrate such as dolphins (Hodgson et al. 2010; Fettermann et al. 2019;), dugongs (Hodgson et al. 2013; Maire et al. 2013), manatees (Martin et al. 2012), whales (Hodgson et al. 2017), sea turtles (Bevan et al. 2015; Rees et al. 2018), sea birds (McClelland et al. 2016; Brisson-Curadeau et al. 2017), and sharks (Kiszka et al. 2016; Rieucau et al. 2018). An as of yet unexplored application of UAVs is their ability to supplement or replace underwater survey methods. In particular, their ability to fly slow speeds, at low altitudes, over complex and repeatable flight patterns could make them an invaluable tool for surveying shallow water environments that divers and underwater vehicles have difficulty accessing.

The goal of my dissertation is to investigate potential sources of biases for both BRUVs and UAV surveys used in fisheries research. Furthermore, I seek to not only identify and quantify potential sources of biases, but to also reduce their impacts on survey results through technological innovations. In Chapter Two, I begin by exploring 
the relationship between MaxN and MeanCount with true changes in local abundances, focusing on the application of BRUVS to study elasmobranch species. By pairing BRUV deployments with traditional cameras and newly developed full-spherical cameras (capable of recording in $360^{\circ}$ horizontal by $360^{\circ}$ vertical FOVs), I go on to explore how these relationships may change in relation to the camera's FOV. Furthermore, by pairing these camera systems, I am able to quantify detection probability for each using a Bayesian approach. In Chapter Three, I build off the initial findings of Chapter Two, and investigate if MaxN and MeanCount are sensitive to changes in factors unrelated to changes in localized shark densities. To answer this question, I developed a spatially explicit individual-based-model to test for the impact of species speed, movement patterns, attraction strength to bait, size of bait plume, and water visibility on resulting estimates of MaxN and MeanCount for standard and full-spherical BRUV platforms. Lastly, in Chapter Four I investigated the potential of UAVs to replace traditional diver BTCs for invertebrate species in shallow water environments. By pairing diver survey counts of sea cucumbers (class Holothuroidea) with manual and automated review of UAV transects over the same area and time, I was able to compare each method in terms relative accuracy and survey effort required. Overall, this work advances our understanding of biases inherent in currently used visual survey methods, while also improving the accuracy and interpretation of survey results. 
Literature cited

Anderson, K., Gaston, K. J. 2013. Lightweight unmanned aerial vehicles will revolutionize spatial ecology. Frontiers in Ecology and the Environment, 11: 138146.

Bacheler,N.M., Schobernd, C.M., Schobernd, Z.H., Mitchell, W.A., Berrane, D.J., Kellison, G.T., Reichert, M.J. 2013. Comparison of trap and underwater video gears for indexing reef fish presence and abundance in the southeast United States. Fish Res, 143: 81-88.

Barnes, H. 1952. Under-water television and marine biology. Nature, 169: 477-479.

Bellis, M. 2004. History of the digital camera. Available: inventors. about.com/library/inventors/bldigitalcamera.htm.

Bevan, E., Wibbels, T., Najera, B. M., Martinez, M. A., Martinez, L. A., Martinez, F. I., Cuevas, J.M., Anderson, T., Bonka, A., Hernandez, M.H., Pena, L. J. 2015. Unmanned aerial vehicles (UAVs) for monitoring sea turtles in near-shore waters. Marine Turtle Newsletter, 145: 19-22.

Bohnsack, J.A., Bannerot, S.P. 1986. A stationary visual census technique for quantitatively assessing community structure of coral reef fishes. NOAA Technical Report NMFS 41. US Department of Commerce, Springfield, VA, USA, 15 pp.

Bond, M.E., Babcock, E.A., Pikitch, E.K., Abercrombie, D.L., Lamb, N.F., Chapman, D.D. 2012. Reef sharks exhibit site-fidelity and higher relative abundance in marine reserves on the Mesoamerican Barrier Reef. PLOS ONE 7:e32983

Booth, D.J., Beretta, G.A. 2002. Changes in a fish assemblage after a coral bleaching event. Marine Ecology Progress Series, 245: 205-212.

Brawn, V.M. 1960. Underwater television observations of the swimming speed and behaviour of captive herring. Journal of the Fisheries Board of Canada 17: 689698.

Brisson-Curadeau, É., Bird, D., Burke, C., Fifield, D.A., Pace, P., Sherley, R.B., Elliott, K.H. 2017. Seabird species vary in behavioural response to drone census. Scientific reports, 7(1): 17884.

Brock, V.E. 1954. A preliminary report on a method of estimating reef fish populations. Journal of Wildlife Management, 18: 297-308.

Bryson, M., Williams, S. 2015. Review of Unmanned Aerial Systems (UAS) for Marine Surveys. Australian Centre for Field Robotics, University of Sydney. 
Caldwell, Z.R., Zgliczynski, B.J., Williams, G.J., Sandin, S.A. 2016. Reef fish survey techniques: assessing the potential for standardizing methodologies. PLOS ONE 11(4): e0153066 DOI 10.1371/journal.pone.0153066.

Campbell, M.D., Pollack, A.G., Gledhill, C.T., Switzer, T.S., DeVries, D.A. 2015. Comparison of relative abundance indices calculated from two methods of generating video count data. Fisheries Research, 170: 125-133.

Cappo, M., Harvey, E., Shortis, M. 2007. Counting and measuring fish with baited video techniques - an overview. In: Lyle JM, Furlani DM, Buxton CD (eds) Cutting edge technologies in fish and fisheries science. Australian Society for Fish Biology Workshop Proceedings, 28-29 August 2006, Hobart, p 101-114.

Carleton, J.H., Done, T.J. 1995. Quantitative video sampling of coral reef benthos: largescale application. Coral Reefs, 14: 35-46.

Colefax, A.P., Butcher, P.A., Kelaher, B.P., Browman, H. 2017. The potential for unmanned aerial vehicles (UAVs) to conduct marine fauna surveys in place of manned aircraft. ICES Journal of Marine Science, 75: 1-8.

Colton, M., Swearer, S. 2010 A comparison of two survey methods: differences between underwater visual census and baited remote underwater video. Marine Ecological Progress Series, 400: 19-36.

Cooke, S.J., Schreer, J.F. 2002. Determination of fish community composition in the untempered regions of a thermal effluent canal - the efficacy of a fixed underwater videography system. Environmental Monitoring and Assessment, 73:109-129.

Costa, C., Loy, A., Cataudella, S., Davis, D., Scardi, M. 2006. Extracting fish size using dual underwater cameras. Aquacultural Engineering, 35: 218-227.

Dearden, P., Theberge, M., Yasué, M. 2010. Using underwater cameras to assess the effects of snorkeler and SCUBA diver presence on coral reef fish abundance, family richness, and species composition. Environmental Monitoring and Assessment, 163: 531-538.

Edgar, G.J., Barrett, N.S., Morton, A.J. 2004. Biases associated with the use of underwater visual census techniques to quantify the density and size-structure of fish populations. Journal of Experimental Marine Biology and Ecology, 308: 269290.

Ellis, D.M., DeMartini, E.E. 1995. Evaluation of a video camera technique for indexing abundances of juvenile pink snapper, Pristipomoides filamentosus, and other Hawaiian insular shelf fishes. Fisheries Bulletin, 93: 67-77. 
Espinoza, M., Cappo, M., Heupel, M.R., Tobin, A.J., Simpfendorfer, C.A. 2014. Quantifying shark distribution patterns and species-habitat associations: implications of marine park zoning. PloS one, 9(9), e106885.

Evans, I.J., Jones, T.H., Pang, K., Evans, M.N., Saimin, S., Goossens, B. 2015. Use of drone technology as a tool for behavioral research: a case study of crocodilian nesting. Herpetology Conservation Biology, 10: 90-98.

Fettermann, T., Fiori, L., Bader, M., Doshi, A., Breen, D., Stockin, K. A., Bollard, B. 2019. Behaviour reactions of bottlenose dolphins (Tursiops truncatus) to multirotor Unmanned Aerial Vehicles (UAVs). Scientific Repoirts, 9: 8558.

Goebel, M.E., Perryman, W.L., Hinke, J.T., Krause, D.J., Hann, N.A., Gardner, S., LeRoi, D.J. 2015. A small unmanned aerial system for estimating abundance and size of Antarctic predators. Polar Biology, 38: 619-630.

Harvey, E., Fletcher, D., Shortis, M. 2002. Estimation of reef fish length by divers and by stereo-video: a first comparison of the accuracy and precision in the field on living fish under operational conditions. Fisheries Research, 57: 255-265.

Harvey, E.S., Butler, J.J., McLean, D.L., Shand, J. 2012. Contrasting habitat use of diurnal and nocturnal fish assemblages in temperate Western Australia. Journal of Experimental Marine Biology and Ecology, 426: 78-86.

Heithaus, M.R., Dill, L.M, Marshall, G., Buhleier, B.M. 2002. Habitat use and foraging behavior of Tiger Sharks (Galeocerdo cuvier) in a seagrass ecosystem. Marine Biology, 140: 237-248.

Hodgson, A.J., Noad, M., Marsh, H., Lanyon, J., Kniest, E. 2010. Using unmanned aerial vehicles for surveys of marine mammals in Australia: test of concept. Final Report to the Australian Marine Mammal Centre, 30.

Hodgson, A., Peel, D., Kelly, N. 2017. Unmanned aerial vehicles for surveying marine fauna: assessing detection probability. Ecological Applications, 27: 1253-1267.

Hodgson, A., Kelly, N., Peel, D. 2013. Unmanned aerial vehicles (UAVs) for surveying marine fauna: a dugong case study. PloS one, 8(11): e79556.

Hughes, N.F., Hayes, J.W., Shearer, K.A., Young, R.G. 2003. Testing a model of driftfeeding using three-dimensional videography of wild Brown Trout, Salmo trutta, in a New Zealand river. Canadian Journal of Fisheries and Aquatic Sciences, 60: $1462-1476$.

Ivošević, B., Han, Y.G., Cho, Y., Kwon, O. 2015. The use of conservation drones in ecology and wildlife research. Ecology and Environment, 38: 113-188. 
Kilfoil, J.P., Wirsing, A.J., Campbell, M.D., Kiszka, J.J., Gastrich, K.R., Heithaus, M.R., Zhang, Y., Bond, M.E. 2017. Baited Remote Underwater Video surveys undercount sharks at high densities: insights from full-spherical camera technologies. Marine Ecology Progress Series, 585: 113-121.

Kiszka, J.J., Mourier, J., Gastrich, K., Heithaus, M.R. 2016. Using unmanned aerial vehicles (UAVs) to investigate shark and ray densities in a shallow coral lagoon. Marine Ecology Progress Series, 560: 237-242.

Kulbicki, M., Cornuet, N., Vigliola, L., Wantiez, L., Moutham, G., Chabanet, P. 2010. Counting coral reef fishes: interaction between fish life-history traits and transect design. Journal of Experimental Marine Biology and Ecology, 387:15-23.

Kumpf, H.E., Lowenstein, J.M. 1962. Undersea observation station. Sea Frontiers, 8:1 98-206.

Koh, L.P., Wich, S.A. 2012. Dawn of drone ecology: low-cost autonomous aerial vehicles for conservation. Tropical Conservation Science, 5: 121-132.

Lindfield, S.J., Harvey, E.S., McIlwain, J.L., Halford, A.R. 2014. Silent fish surveys: bubble-free diving highlights inaccuracies associated with SCUBA-based surveys in heavily fished areas. Methods in Ecology and Evolution, 5: 1061-1069.

Livingstone, R. 1962. Underwater television observations of Haddock (Melanogrammus aeglefinus) in the cod-end. ICES Journal of Marine Science, 27: 43-48.

Maire, F., Mejias, L., Hodgson, A., Duclos, G. 2013. Detection of dugongs from unmanned aerial vehicles. IEEE/RSJ International Conference on Intelligent Robots and Systems, 2750-2756.

Martin, J., Edwards, H.H., Burgess, M.A., Percival, H.F., Fagan, D.E., Gardner, B.E., ..., Rambo, T.J. 2012. Estimating distribution of hidden objects with drones: From tennis balls to manatees. PLoS One, 7: e38882.

McClelland, G.T., Bond, A.L., Sardana, A., Glass, T. 2016. Rapid population estimate of a surface-nesting seabird on a remote island using a low-cost unmanned aerial vehicle. Marine Ornithology, 44: 215-220.

Myrberg, A.A., Banner, A., Richard, J.D. 1969. Shark attraction using a video-acoustic system. Marine Biology, 2: 264-276.

Michel, A.M., Croff, K.L., McLetchie, K.W., Irish, J.D. 2002. A remote monitoring system for open ocean aquaculture. Proceedings of the 2002 Oceans MTS/IEEE symposium, Biloxi, Mississippi. 
Murphy HM, Jenkins GP. 2010 Observational methods used in marine spatial monitoring of fishes and associated habitats: a review. Marine and Freshwater Research. 61: 236-252.

Rees, A.F., Avens, L., Ballorain, K., Bevan, E., Broderick, A. C., Carthy, R. R., Christianen, M. J., Duclos, G., Heithaus, M. R., Johnston, D. W., Mangel, J. C., Paladino, F., Pendoley, K., Reina R. D., Robinson, N. J., Robert, R., SykoraBoide, S. T., Tilley, D., Varela, M.R., Whitman, E. R., Whittock, P. A., Wibbels, T., Godley, B. J. 2018. The potential of unmanned aerial systems for sea turtle research and conservation: a review and future directions. Endangered Species Research, 35: 81-100.

Richard, J.D. 1968. Fish attraction with pulsed low-frequency sound. Journal of the Fisheries Board of Canada, 25: 1441-1452.

Rieucau, G., Kiszka, J.J., Castillo, J.C., Mourier, J., Boswell, K.M., Heithaus, M.R. 2018. Using unmanned aerial vehicle (UAV) surveys and image analysis in the study of large surface-associated marine species: a case study on reef sharks Carcharhinus melanopterus shoaling behaviour. Journal of Fish Biology, 93: 119-127.

Sale, P.F., Douglas, W.A. 1981. Precision and accuracy of visual census technique for fish assemblages on coral patch reefs. Environ Biol Fish, 6: 333-339.

Santana-Garcon, J., Leis, J., Newman, S., Harvey, E. 2014 Presettlement schooling behaviour of a priacanthid, the Purplespotted Bigeye Priacanthus tayenus (Priacanthidae: Teleostei). Environ. Biol. Fishes, 97: 277-283.

Schobernd, Z.H., Bacheler, N.M., Conn, P.B. 2014. Examining the utility of alternative video monitoring metrics for indexing reef fish abundance. Canadian Journal of Fisheries and Aquatic Sciences, 71: 464-471.

Shipman, S.T., Braun, E., Carnahan, D., Koza, L., Schoenung, B., Keller, D., Stefanavage, T. 2001. Manual of fisheries survey methods. Indiana Department of Natural Resources. Division of Fish and Wildlife. Indianapolis, Indiana.

Skomal, G. 2007. Evaluating the physiological and physical consequences of capture on post release survivorship in large pelagic fishes. Fish Manag Ecol, 14: 81-89.

Steinberg, J.C., Cummings, W.C., Brahy, B.D., Macbain, J.Y. 1965. Further bio-acoustic studies off the west coast of North Bimini, Bahamas. Bulletin of Marine Science, 15: 942-963.

Stevenson, R.A., Myrberg A.A, Jr. 1966. Behavior of the bi- color Damselfish, Eupomacentrus partitus, in the field and in the aquarium. American Zoologist, 6:516. 
Stoner, A.W., Laurel, B.J., Hurst, T.P. 2008. Using a baited camera to assess relative abundance of juvenile Pacific cod: field and laboratory trials. Journal of Experimental Marine Biology and Ecology, 354: 202-211.

Struthers, D.P., Danylchuk, A.J., Wilson, A.D., Cooke, S.J. 2015. Action cameras: bringing aquatic and fisheries research into view. Fisheries, 40: 502-512.

Taylor, M.D., Baker, J., Suthers, I.M. 2013. Tidal currents, sampling effort and baited remote underwater video (BRUV) surveys: are we drawing the right conclusions? Fisheries. Research, 140: 96-104.

Thomas, L., Buckland, S.T., Rexstad, E.A., Laake, J.L., Strindberg, S., Hedley, S.L., Bishop, J.B., Marques, T.A., Burnham, K.P. 2010. Distance software: design and analysis of distance sampling surveys for estimating population size. Journal of Applied Ecology, 47: 5-14.

Willis, T.J., Babcock, R.C. 2000. A baited underwater video system for the determination of relative density of carnivorous reef fish. Marine and Freshwater research, 51: 755-763.

Wheeler, A.J., Bett, B.J., Billett, D.M., Masson, D.G., Mayor, D.J. 2005. The impact of demersal trawling on northeast Atlantic deepwater coral habitats: the case of the Darwin Mounds, United Kingdom. In American Fisheries Society Symposium, 41: 807-818.

Whitmarsh, S., Fairweather, P., Brock, D., Miller, D. 2014 Nektonic assemblages determined from baited underwater video in protected versus unprotected shallow seagrass meadows on Kangaroo Island, South Australia. Marine Ecological Progress Series, 503: 205-218.

Whitmarsh, S.K., Fairweather, P.G., Huveneers, C. 2017. What is Big BRUVver up to? Methods and uses of baited underwater video. Rev. Fish Biol. Fish, 27: 53-73. 
CHAPTER II

BAITED REMOTE UNDERWATER VIDEO SURVEYS UNDERCOUNT SHARKS AT HIGH DENSITIES: INSIGHTS FROM FULL-SPHERICAL CAMERA TECHNOLOGIES 
This article is reproduced in the thesis under license from the copyright holder, InterResearch, with the following restriction: The complete article may not be further copied or distributed from this source separately from the copying and distribution of the thesis. This restriction ends on December 27, 2022.

\section{Abstract}

Video surveys are an essential tool for monitoring marine communities. Their use to study elasmobranch populations has dramatically increased over the last decade. However, the restricted field-of-view of traditional cameras in these surveys may bias abundance estimates in a number of ways, including saturation at high densities, and low detection probability for rare or cryptic species. This study investigated these potential biases using newly developed full-spherical (FS) camera technology. A comparison of 35 Baited Remote Underwater Video Surveys (BRUVs), using both FS and traditional cameras, was conducted from July-August 2016 in shallow waters (0.4-8.5m) of Tetiaroa, French Polynesia. Both blacktip reef (Carcharhinus melanopterus) and sicklefin lemon sharks (Negaprion acutidens) were quantified from traditional cameras using MaxN and MeanCount methods. These estimates were then regressed against FS cameras counts, which were assumed to more accurately represent site abundance, to test for gear saturation. Detection probabilities of the traditional and FS cameras were assessed using a Bayesian binomial model, with uninformed-uniform priors. Results indicated a significant effect of gear saturation for standard BRUVs as counts on FS cameras increased, regardless of the metric used. Furthermore, traditional cameras had a significantly lower detection probability $(69.88 \pm 0.008 \%$ mean $\pm 2 \mathrm{SD})$ than FS cameras $(81.20 \pm 0.007 \%)$. Our findings show that traditional cameras are unlikely to adequately discriminate differences in shark relative abundance at high densities. Therefore, standard 
BRUV techniques that use restricted FOV cameras are likely limited in their ability to provide accurate information to managers once populations have reached particular thresholds of abundance.

\section{Introduction}

Over the last few decades many elasmobranch populations have experienced dramatic population declines (Ferretti et al. 2010; Worm et al. 2013; Dulvy et al. 2014). Though the magnitude of these declines varies considerably across species and ecosystems, an increasing number of shark and ray populations are in need of conservation and management actions (Dulvy et al. 2014; Dulvy et al. 2017). Effective elasmobranch conservation efforts rely on our ability to assess spatial and temporal variation in the abundance of populations, which is critical for identifying conservation priorities and assessing the progress of current recovery efforts (Cortés et al. 2015). Unfortunately, nearly half of all known elasmobranch species remains 'data deficient' (Dulvy et al. 2014), posing a significant obstacle to their future conservation.

Traditionally, elasmobranch population data have been gathered through a combination of fisheries-independent and dependent sources, employing gears such as longlines, gill nets, and trawls from which Catch per unit of Effort (CPUE) data are used to estimated relative abundance. Though useful tools, these methods have limitations, including an inability to survey high complexity habitats such as coral reefs (Williams et al. 2010), high levels of physiological stress (Mandelman et al. 2009; Kneebone et al. 2013; Gallagher et al. 2014) and increased post-release mortality for a number of species (Morgan \& Carlson 2010; Dapp et al. 2017; Kilfoil et al. 2017). Video surveys have 
emerged as a potential way to address the deficiencies of traditional sampling methods, while also reducing current data gaps.

Video surveys are increasingly used to assess the diversity and relative abundance of marine species across the globe (Whitmarsh et al. 2017). They are particularly suitable for the study of elasmobranchs because of their non-extractive nature (Cappo et al. 2006) and ability to sample previously 'inaccessible' environments (Whitmarsh et al. 2017). Though gathering data on sex, size, and individual recapture rates is more difficult with these methods as compared to traditional fishing gears, they provide a number of advantages including: a permanent record of the data (Harvey et al. 2013), insights on species behavior and habitat use (Langlois et al. 2010; Bacheler et al. 2013), and reduced issues with size (Wells et al. 2008) and species (Bacheler et al. 2013) selectivity to fishing gears. For elasmobranchs, one of the most common video survey approaches is the use of Baited Remote Underwater Video Surveys (BRUVs; e.g., Bond et al. 2012; Clarke et al. 2012; Santana-Garcon et al. 2014). A BRUV consists of a single, aka. mono, camera deployed behind a bait source and provides stationary point counts for species of interest that swim into the camera's field-of-view (FOV) over a specified duration. To eliminate multiple counting of fishes swimming in and out of the FOV, one of two relative abundance metrics are often used: $\operatorname{MaxN}$ (Ellis \& Demartini 1995) or MeanCount (Conn 2011). MaxN is defined as the maximum number of a species observed on any frame of a video (Ellis \& Demartini 1995), whereas MeanCount provides an average count of the species observed over a sub-sample of video frames (Conn 2011). Although widely used (e.g., Willis \& Babcock 2000; Stoner et al. 2008; Schobernd et al. 2013), these metrics have recently been criticized due to their inability to account for non- 
uniform spatial distributions of species around the camera (Campbell et al. 2015), and they may also result in biased estimates in high density environments because of issues stemming from FOV saturation.

A fundamental assumption required to use indices of relative abundance $(I)$ to monitor populations, is that they be linearly related to the true site abundance $(N)$ given a constant catchability coefficient $(q)$ :

$$
I=q N
$$

If this assumption is violated or invalid, the metric of relative abundance may overestimate (hyperstable) or underestimate (hyperdepleted) abundance, resulting in imprecise indices which in turn will compromise the integrity of management decisions (Cooke \& Beddington 1984). In the case of video surveys, simulation work has shown that this fundamental assumption may not hold true for teleost fishes due to limited FOVs failing to capture the non-uniform spatial distribution of fishes around the camera (Campbell et al. 2015). However, no work has addressed this issue specifically for elasmobranchs. For large-bodied fishes, including many elasmobranchs, a further hindrance may be the saturation of cameras in high density environments. Under these conditions, cameras may not be able to detect increases in abundance beyond some maximum observable threshold, resulting in a hyperstable relationship whereby catchability decreases as true site abundance increases. Furthermore, cameras with a restricted FOVs may reduce detection probabilities for elasmobranchs, which will in turn impact standardized indices of relative abundance through inflated zero counts (Campbell et al. 2015; Cortés et al. 2015). Given that one of the greatest challenges currently facing elasmobranch stock assessments is generating accurate and precise indices of relative 
abundance (Cortés et al. 2015), these issues must be resolved if video surveys are to be used to monitor these populations. Recently developed full-spherical (FS) underwater video platforms may offer a means to test these concerns regarding the use of video surveys to monitor elasmobranchs. In this manuscript, we used this newly developed technology to conduct the first FS video survey of elasmobranchs. Specifically, our objectives were to determine: (1) if the catchability $(q)$ of reduced FOV (mono) cameras derived from estimates of MaxN and MeanCount is constant across a range of site densities as estimated from FS cameras; and (2) the detection probability for mono and FS cameras.

\section{Methods}

\section{Data collection}

All video data were collected from July $17^{\text {th }}$ to August $8^{\text {th }}, 2016$, in Tetiaroa; a small French Polynesian atoll in the Society Archipelago. Sampling locations were chosen haphazardly throughout the atoll's inner lagoon in depths ranging from 0.4 to 8.5 m. All deployments were conducted on sandy sediment, with a single BRUV deployed at any one time. At each sampling site, a small aluminum frame was deployed with approximately $1 \mathrm{~kg}$ of crushed sardines inside a wire mesh container that was attached to a bait arm (Fig. 1). The aluminum frame, hereafter referred to as BRUV $V^{\mathrm{fs}}$, was equipped with both a single GoPro camera (hereafter referred to as 'mono camera') as well as six GoPro cameras mounted above the frame in a GoPro freedom360 (F360) ${ }^{\mathrm{TM}}$ housing (collectively referred to as a FS camera). To correct for light refraction underwater, dome port lenses were applied to all cameras in the F360. Although mono and FS cameras were set at 30 frames per second, FS cameras had additional setting requirements needed to 
synchronize and stitch FS videos correctly (see supplemental material S1). To ensure units were not deployed on top of live reef habitat, they were set by snorkelers who could visually confirm the location and orientation of the frame for each deployment. Once settled on the sea floor, cameras soaked for approximately 60 min. Following deployment, depth and GPS coordinates of each site were recorded. Following video synchronization and stitching of video files, FS and mono videos were reviewed and annotated by trained, independent observers who estimated MaxN as well as MeanCount (derived from images sequenced every 10s) beginning once the frame was securely on the sea floor. To reduce issues with observer bias, MaxN and MeanCount were estimated by different individuals for each video.

\section{Relationship between video counts and site abundance}

Two metrics were used to enumerate elasmobranchs from video data: MaxN and MeanCount. To examine the relationship between counts derived from mono cameras and site density, we assumed that the corresponding estimates derived from FS cameras (both MaxN and MeanCount) represented a site's true abundance (as the abundance of

each site could not be independently estimated), and that the volume of area sampled did not change between sites. Given these assumptions, and substituting for Eq. (1):

$$
\text { Mono }_{\text {Est }}=q * F S_{\text {Est }}
$$

which when rearranged gives

$$
q=\frac{M o n o_{E s t}}{F S_{E s t}}
$$

where $q$ denotes the catchability coefficient, Mono Est represents the count derived from the mono camera, and $F S_{E s t}$ is the FS camera estimate. Under the assumption that 
estimates derived from mono cameras exhibit a consistent linear relationship to true site abundance over a range of site densities, we would expect $q$ to remain relatively constant. To test this assumption, $q$ of each estimate was plotted against the FS estimate, and a linear model was developed to test for any relationship between $q$ (response variable) and site abundance (predictor variable) using the base 'lm' function in R (R core team 2015).

\section{Detection probability}

To estimate the detection probability for both mono and FS cameras, we examined the probability of detection at two scales: (1) a single image, and (2) the video as a whole. At the single image scale, detection histories for each camera type were categorized for every image as either both detected an elasmobranch $(1,1)$, the mono camera detected an elasmobranch whereas the FS camera did not $(1,0)$, the mono camera did not detect an elasmobranch but the FS camera did $(0,1)$, or neither camera detected an elasmobranch $(0,0)$. For each image, a 'true presence' was determined based on these catch histories, with $(0,0)$ indicating absence and any other indicating presence. For each video, data were aggregated to elucidate the total number of images, the number of images in which a shark was present, the number of images in which a shark was detected by the FS camera, and the number of images a shark was detected by the mono camera. Detection probability for each camera was then estimated within a Bayesian framework using the 'rjags' package (Plumer 2013) in R (R core team 2015). Under this Bayesian framework, rather than assuming that a catch history of $(0,0)$ is always indicative of true absence, we modeled the probability of occurrence as a Bernoulli process with an uninformed-uniform prior between zero and one. The detection probabilities of the mono and FS cameras were modeled using a binomial distribution, 
also using uninformed-uniform priors between zero and one. Models were run for 100,000 iterations, with a the first 10,000 iterations disregarded. To examine detection probability for the video as a whole, similar catch histories were developed as previously described (e.g., $(0,1)$ indicates a shark was observed on the FS but not on the mono camera), but from the entire video rather than an individual image. Again, a species was considered absent only for a catch history of $(0,0)$. The probability of a false negative (reporting a catch of 0 , when it was truly present) was then calculated for both camera types and all observed elasmobranch species by summing their respective catch histories, divided by the total number of videos that the species was present.

\section{Results}

We deployed the BRUV ${ }^{\text {fs }}$ platform 43 times at a variety of locations throughout Tetiaroa, French Polynesia, and during those deployments turbidity ranged from a scale of one (clear) to five (visibility less than 1m). Eight deployments had camera issues and or short recording times $(<40 \mathrm{~min})$ and were thus excluded from analyses, resulting in a total of 35 samples. Although a large diversity of reef fish species was observed on the collected videos, only two shark species were detected: blacktip reef (Carcharhinus melanopterus) and sicklefin lemon sharks (Negaprion acutidens). Accordingly, all MaxN (maximum count on any one frame) analyses pertaining to video data focused on these two species separately. However, resulting sequenced images had a number of partial sharks present (i.e., only snout or portion of the caudal fin visible), which reduced the ability of observers to distinguish between these two species. To account for this limitation, all counts of shark species present on a particular image were aggregated for subsequent analyses pertaining to MeanCount (average count over a subsample of 
frames). Slight differences in recording times between sets resulted in small variations in MeanCount sample sizes (395.49 \pm 139.01 ; mean $\pm \mathrm{SD})$. Average MaxN estimates from mono cameras for blacktip reef $(5.06 \pm 4.17)$ and sicklefin lemons $(1.94 \pm 2.42)$ were lower than those provided by FS cameras (6.62 \pm 6.04 - blacktip reef; $2.03 \pm 2.64$-sicklefin

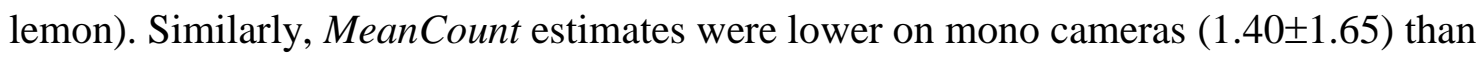
FS cameras (3.25 \pm 3.69$)$. Furthermore, a higher rate of images with zero counts was observed on the mono camera $(n=3,930)$ compared to the FS camera $(n=2,120)$.

\section{Relationship between catchability and true site abundance}

Full-spherical cameras provided a substantial increase in FOV, which often resulted in higher shark counts compared to the standard mono camera (Fig.2). Regardless of the relative abundance metric used, catchability of mono cameras decreased linearly as abundance on the FS camera increased (Fig. 3). For estimates of $\operatorname{MaxN}$, this relationship held true for both the sicklefin lemon and the blacktip reef sharks ( $p<0.05$ for both species; Fig. 3A). However, for sicklefin lemon sharks, which were detected in lower abundances, the negative correlation between catchability and site abundance was heavily influenced by two data points, with all others showing no relationship. Consistent with these findings, catchability derived from MeanCount estimates also showed a significant negative relationship with site abundance $(\mathrm{p}<0.001$; Fig. 3B).

\section{Detection probability}

Results from the Bayesian binomial model indicated a significant difference between detection probabilities for FS $(81.20 \pm 0.007 \%)$ and mono cameras 
$(69.88 \pm 0.008 \%)$. Despite this disparity, there was no difference between the two cameras in their probability of false negatives on the entire video (reporting a species as absent, when it is truly present), with neither detecting a shark when the other did not.

\section{Discussion}

By simultaneously sampling with FS and mono cameras, we were able to demonstrate how limited FOVs may reduce the effectiveness of these optical technologies in monitoring shark populations, particularly in regions where abundances are relatively high. Our field sampling efforts revealed that catchability estimates derived from MaxN had a significant negative correlation with site abundance. These findings support previous simulation efforts, which revealed $\operatorname{MaxN}$ to be non-linearly related to site abundance (Schobernd et al. 2013; Campbell et al. 2015). MaxN’s hyperstable relationship with site abundance is believed to be due to its basis as a maximum order statistic, whereby only the maximum count is considered. This limitation may result in estimates reaching a maximum threshold at which they plateau due to camera saturation or issues with spatial distribution of sharks around the cameras, while true site abundance continues to increase. For these reasons, Schobernd et al. (2013) postulated that estimates of larger predators from video data (which are often less aggregated and found in lower densities than other reef fishes) would be less influenced by issues of hyperstability. While this may be true for certain species and locations, our results do not support this hypothesis, as site density frequently exceeded the catchability threshold of mono cameras for both blacktip reef and sicklefin lemon sharks. Furthermore, whereas previous works found using MeanCount may resolve issues with hyperstability (Conn 2011; Schobernd et al. 2013; Campbell et al. 2015), we also observed a significant linear 
decline in catchability derived from MeanCount as site abundance increased. It is possible that the large size of our focal species, coupled with densities higher than would occur naturally, as well as the presence of bait could have driven these results.

In addition to concerns surrounding catchability, mono cameras were found to have a significantly lower probability of detecting sharks than FS cameras at any given point in time. Namely, changing the cameras' FOV from mono to FS improved the probability of shark detection by nearly $12 \%$. However, it should be noted that neither the mono $(70 \%)$ nor the FS camera $(81 \%)$ had a $100 \%$ estimated detection probability based on the modeled probability of occurrence, which is often assumed in ecological studies (Yoccoz et al. 2001; Kellner \& Swihart 2014; Monk 2014). Failure to account for this imperfect detection can result in biased and inaccurate estimates of species distributions (Chen et al. 2013), environmental drivers of these distributions (Gu \& Swihart 2004), and trends in population dynamics (Kery \& Schmidt 2008; Buckland et al. 2011).

The results of this study have several implications for the use of video surveys to monitor elasmobranch populations. Indices of relative abundance, particularly for elasmobranchs, are frequently generated using zero-inflated models (i.e., deltageneralized linear models; Bonfil 2005; Cortés 2011; Cortés et al. 2015). These types of models rely on the ability to accurately predict if a species will be present at a particular sampling location (i.e., binomial presence/absence data), as well as providing accurate counts if a species is present (i.e., Poisson presence only data). If either component is imprecise, the resultant index of relative abundance derived from these models is also imprecise. Results from this study reveal issues surrounding both factors derived from 
traditional mono camera video surveys for elasmobranchs. Estimates of MaxN appear to be saturated around 6-7 individuals for the two shark species we examined. This hyperstable relationship between $\operatorname{MaxN}$ and true site abundance may hinder detection of changes in local population sizes through time. Imagine, for example, that a region's true site density is 12 sharks per unit area sampled by BRUVs. Given issues with saturation, as evident in this study, the estimated $\operatorname{MaxN}$ for this region would most likely be around 6. If this population then experience marked declines over some time period (e.g., a 50\% decrease over five years), estimates of MaxN would appear unchanged over this time interval, leading to the incorrect assessment that the population is relatively stable. Similarly, this saturation issue may prevent one from detecting spatial differences in relative abundance (e.g., site 1 has a true density of 15 sharks/area, site 2 has true density of 7 sharks/area, but both have a MaxN estimate of 7). However, it should be noted that the results of this study indicate these issues will likely only be of importance once a site density exceeds a certain threshold (i.e., 6-7 sharks for the focal species observed in this study). For species that occur at lower densities (and are thus likely below any threshold value), survey results from FS and mono cameras will not likely differ significantly. Although MeanCount has been shown to reduce hyperstability for teleost fishes (Conn 2011; Schobernd et al. 2013; Campbell et al. 2015), we did not find this benefit to be true for our focal elasmobranchs. Furthermore, detection probability on any given image was relatively low for the mono camera. This low detection probability likely drove the hyperstable relationship with true site abundance by highly inflating zero counts. This in turn would also affect the binomial component (presence/absence) of any delta model approach used to create an index of relative abundance. However, the probability of a 
false negative for the video as a whole did not appear to be affected by the FOV of the camera. It should be noted, however, that the probability of occurrence for the entire video was not modeled, and thus catch histories of $(0,0)$ were considered as a species being truly absent, when it is possible a species was present and simply not detected by either camera. Although this may bias our estimates of absolute detection probability, this bias would impact each gear type equally, and thus does not influence our resulting comparisons. When determining whether to use MaxN or MeanCount to enumerate elasmobranchs, researchers should also take into account species-specific considerations such as movement patterns and behaviors (e.g., slow moving species that have an affinity for the substrate may stay in front of the camera longer, and thus increase MeanCount estimates) that may influence which metric is more appropriate.

Despite the problems with mono cameras highlighted above, video surveys remain a viable tool for monitoring elasmobranch populations if limitations of restricted FOVs can be reduced or removed. By increasing the FOV to FS, we were able to greatly increase our instantaneous detection probability for elasmobranchs. Furthermore, increasing FOV reduced the effects of gear saturation at higher densities, and thus likely reduced the hyperstable relationship between counts derived from cameras and a site's true abundance. This issue may be particularly important for larger species of sharks, for which mono cameras would become saturated with relatively few individuals in the camera's FOV. Critically, these results demonstrate the influence of FOV on resulting video survey abundance estimates currently used by conservation managers to monitor elasmobranch populations. However, a major assumption of this study (as well as in 
previous work), is that FS cameras represent the true site abundance. Full-spherical cameras also likely experience deviations from linearity with true site abundance due to density, environmental (e.g., poor visibility), and species-specific considerations (e.g., cryptic behavior). These issues, however, should be reduced compared to standard video. Future research needs to be conducted for a variety of species, and across multiple systems to investigate the potential for regional, environmental, physical, and speciesspecific considerations that may influence resulting estimates. Following these efforts, it may be possible to develop a correction factor so that researchers can convert estimates of relative abundance from mono cameras to an equivalent FS estimate (e.g., with a linear model allowing for an asymptotic effect), and thus provide a method to incorporate historic data with estimates derived from emerging FS technology. Full-spherical camera technology continues to develop, including recent advances reducing the number of cameras required (i.e., BoxFish $360 \mathrm{VR}$; https://www.boxfish-research.com/products) as well as now allowing for stereo-camera length estimates of fishes (Campbell personal communication). As the technology continues to advance, and the associated costs continue to decline, it is likely that FS video surveys will become the new norm for video surveys of elasmobranchs and teleost fishes.

\section{Acknowledgements}

The authors would like to thank the Seeley family, the Global FinPrint Project funded by Paul G. Allen Philanthropies, and J. Hirota for funding this research. We would like to give special thanks to the Tetiaroa Society, the Brando Hotel, and Centre de Recherches Insulaires et Observatoire de l'Environnement (CRIOBE), particularly Dr. Eric Clua, for all the help and support with field work as well as coordinating the 
necessary permits to operate in French Polynesia. Lastly, we would like to thank all the interns in the Fisheries and Ecosystem Assessment Lab at FIU for help with video data extraction: J. Alvarez, A. Bass, M. Castillo, D. De Mello, J. Diaz, and M. Schlegel. This is contribution \# 64 from the Marine Education and Research Center in the Institute for Water and Environment at Florida International University.

\section{Literature Cited}

Bacheler NM, Schobernd CM, Schobernd ZH, Mitchell WA, Berrane DJ, Kellison GT, Reichert MJ (2013) Comparison of trap and underwater video gears for indexing reef fish presence and abundance in the southeast United States. Fish Res 143:81-88.

Bond ME, Babcock EA, Pikitch EK, Abercrombie DL, Lamb NF, Chapman DD (2012) Reef sharks exhibit site-fidelity and higher relative abundance in marine reserves on the Mesoamerican Barrier Reef. PLOS ONE 7: e32983.

Bonfil R (2005) 10. Fishery stock assessment models and their application to sharks. In: Management techniques for elasmobranch fisheries. Food and Agriculture Organization of the United Nations, p. 154.

Buckland ST, Studeny AC, Magurran AE, Newson SE (2011) Biodiversity monitoring: the relevance of detectability. In: Biological diversity: frontiers in measurement and assessment. Oxford: Oxford University Press, p 25-36.

Campbell MD, Pollack AG, Gledhill CT, Switzer TS, DeVries DA (2015) Comparison of relative abundance indices calculated from two methods of generating video count data. Fish Res 170: 125-133.

Cappo M, Harvey E, Shortis M (2006) Counting and measuring fish with baited video techniques-an overview. Aust Socie for Fish Biology Workshop Proceedings 1:101-114.

Chen G, Kéry M, Plattner M, Ma K, Gardner B (2013) Imperfect detection is the rule rather than the exception in plant distribution studies. J Ecol 101: 183-191.

Clarke C, Lea J, Ormond R (2012) Comparative abundance of reef sharks in the Western Indian Ocean. Proc - 12th Int Coral Reef Symp, Cairns, Australia, p. 9-13. 
Conn PB (2011) An Evaluation and Power Analysis of Fishery Independent Reef Fish Sampling in the Gulf of Mexico and US south Atlantic. NOAA Tech. Memo. NMFSSEFSC-610. Available from: https://docs.lib.noaa.gov/noaa_documents/NMFS/SEFSC/TM_NMFS_SEFSC/NMFS_S EFSC_TM_610.pdf

Cooke JG, Beddington JR (1984) The relationship between catch rates and abundance in fisheries. Math Med Biol 1: 391-405.

Cortés E (2011) An overview of approaches used to assess the status of shark populations: experiences from the USA and ICCAT in the Atlantic Ocean.

Cortés E, Brooks EN, Shertzer KW (2015) Risk assessment of cartilaginous fish populations. ICES J Mar Sci 72: 1057-1068.

Dapp DR, Huveneers C, Walker TI, Mandelman J, Kerstetter DW, Reina RD (2017) Using logbook data to determine the immediate mortality of blue sharks (Prionace glauca) and tiger sharks (Galeocerdo cuvier) caught in the commercial US pelagic longline fishery. Fish Bull 115.

Dulvy NK, Fowler SL, Musick JA, Cavanaugh RD, Kyne PM, Harrison LR, Carlson JK, Davidson LNK, Fordham SV, Francis MP, Pollock CM, Simpfendorfer CA, Burgess GH, Carpenter KE, Compagno LJV, Ebert DA, Gibson C, Heupel MR, Livingstone SR, Sanciangco JC, Stevens JD, Valenti S, White WT (2014) Extinction Risk and Conservation of the world's sharks and rays. eLife 3: e00590.

Dulvy, NK, Simpfendorfer CA, Davidson LN, Fordham SV, Bräutigam A, Sant G, Welch DJ (2017) Challenges and Priorities in Shark and Ray Conservation. Curr Biol 27: 565-572.

Ellis DM, DeMartini EE (1995) Evaluation of a video camera technique for indexing abundances of juvenile pink snapper, Pristipomoides filamentosus, and other Hawaiian insular shelf fishes. Fish Bull 93: 67-77.

Ferretti F, Worm B, Britten GL, Heithaus MR, Lotze HK (2010) Patterns and ecosystem consequences of shark declines in the ocean. Eco Lett 13: 1055-1071.

Gallagher AJ, Serafy JE, Cooke SJ, Hammerschlag N (2014) Physiological stress response, reflex impairment, and survival of five sympatric shark species following experimental capture and release. Mar Ecol Prog Ser 496: 207-218.

Gu W, Swihart RK (2004) Absent or undetected? Effects of non-detection of species occurrence on wildlife-habitat models. Biol Conserv 116: 195-203. 
Harvey E, McLean DL, Frusher S, Haywood M, Newman S, Williams A (2013) The use of BRUVs as a tool for assessing marine fisheries and ecosystems: a review of the hurdles and potential. Fisheries Research and Development Corporation and The University of Western Australia.

Kellner KF, Swihart RK (2014) Accounting for imperfect detection in ecology: a quantitative review. PLOS ONE 9: e111436.

Kery M, Schmidt BR (2008) Imperfect detection and its consequences for monitoring for conservation. Community Ecol 9: 207-216.

Kilfoil JP, Wetherbee BM, Carlson JK, Fox DA (2017) Targeted Catch-and-Release of Prohibited Sharks: Sand Tigers in Coastal Delaware Waters. Fisheries 42: 281-287.

Kneebone J, Chisholm J, Bernal D, Skomal G (2013) The physiological effects of capture stress, recovery, and post-release survivorship of juvenile sand tigers (Carcharias taurus) caught on rod and reel. Fish Res 147: 103-114.

Langlois TJ, Harvey ES, Fitzpatrick B, Meeuwig JJ, Shedrawi G, Watson DL (2010) Cost-efficient sampling of fish assemblages: comparison of baited video stations and diver video transects. Aquat Biol 9: 155-168.

Mandelman JW, Skomal GB (2009) Differential sensitivity to capture stress assessed by blood acid-base status in five carcharhinid sharks. J Comp Physiol B 179: 267.

Monk J (2014) How long should we ignore imperfect detection of species in the marine environment when modelling their distribution? Fish Fish 15: 352-358.

Morgan A, Carlson JK (2010) Capture time, size and hooking mortality of bottom longline-caught sharks. Fish Res 101: 32-37.

Plummer M (2013) rjags: Bayesian graphical models using MCMC. R package version, 3.

R Core Team (2015) R: A language and environment for statistical computing. R Foundation for Statistical Computing, Vienna, Austria. URL https://www.R-project.org/.

Santana-Garcon J, Braccini M, Langlois TJ, Newman SJ, McAuley RB, Harvey ES (2014) Calibration of pelagic stereo-BRUVs and scientific longline surveys for sampling sharks. Methods Ecol Evol 5: 824-833.

Schobernd ZH, Bacheler NM, Conn PB (2013) Examining the utility of alternative video monitoring metrics for indexing reef fish abundance. Can J Fish Aquat Sci 71: 464-471. 
Stoner AW, Laurel BJ, Hurst TP (2008) Using a baited camera to assess relative abundance of juvenile Pacific cod: field and laboratory trials. J Exp Mar Biol Ecol 354: 202-211.

Wells RD, Boswell KM, Cowan JH, Patterson WF (2008) Size selectivity of sampling gears targeting red snapper in the northern Gulf of Mexico. Fish Res 89: 294-299.

Whitmarsh SK, Fairweather PG, Huveneers C (2017) What is Big BRUVver up to? Methods and uses of baited underwater video. Rev Fish Biol Fish, 27: 53-73.

Williams K, Rooper CN, Towler R (2010) Use of stereo camera systems for assessment of rockfish abundance in untrawlable areas and for recording pollock behavior during midwater trawls. Fish Bull 108: 352-362.

Willis TJ, Babcock RC (2000) A baited underwater video system for the determination of relative density of carnivorous reef fish. Mar Freshw Res 51: 755-763.

Worm B, Davis B, Kettemer L, Ward-Paige CA, Chapman DD, Heithaus MR, Kessel ST, Gruber SH (2013) Global catches, exploitation rates, and rebuilding options for sharks. Mar Policy 40: 194-204.

Yoccoz NG, Nichols JD, Boulinier T (2001) Monitoring of biological diversity in space and time. Trends Ecol Evol 16: 446-453. 


\section{Figures}

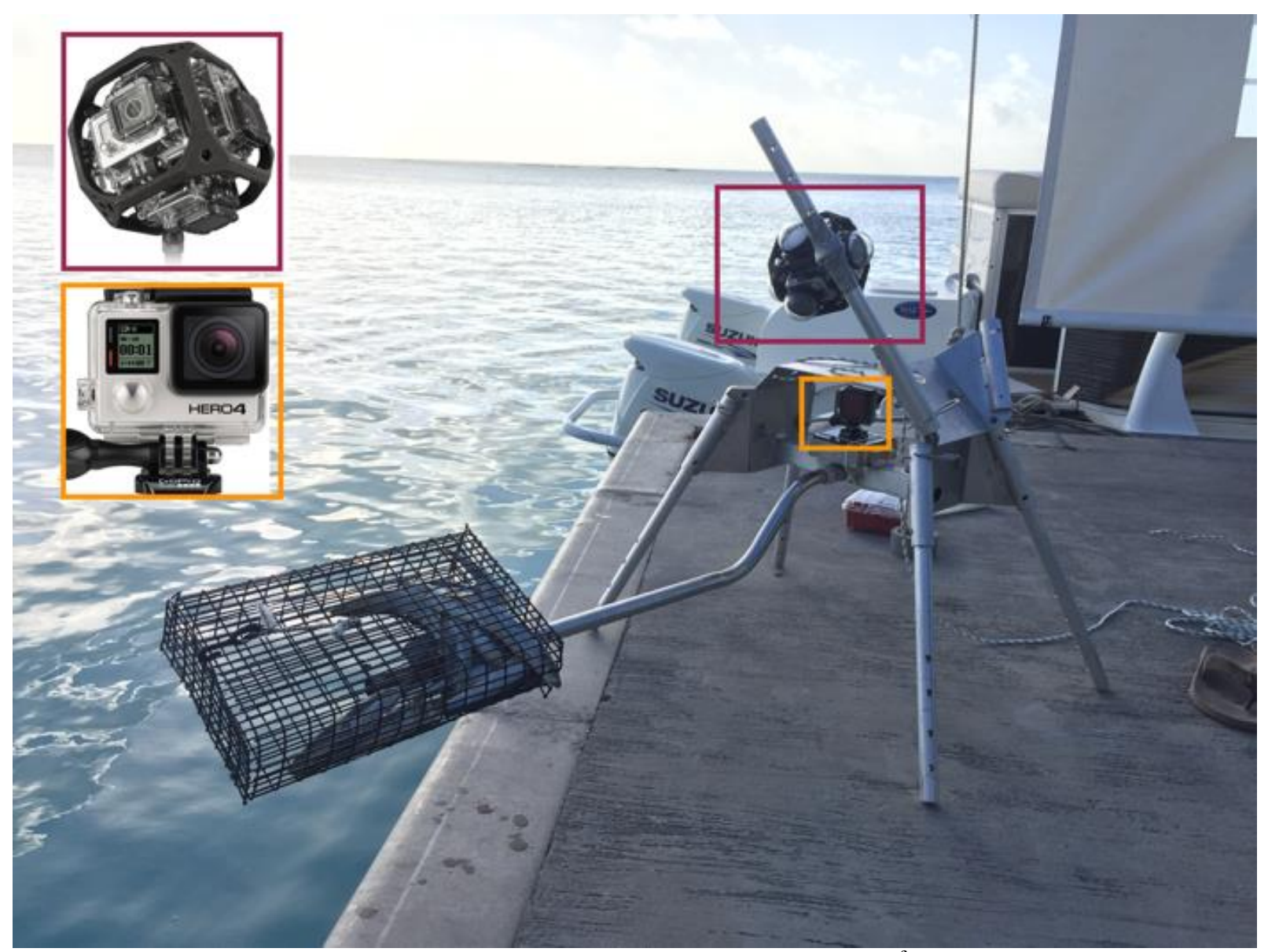

Figure 1. Baited Remote Underwater Visual Full-spherical $\left(\mathrm{BRUV}^{\mathrm{fs}}\right)$ array deployed in Tetiaroa, French Polynesia (July $17^{\text {th }}$ to August $8^{\text {th }}, 2017$ ). Red inset depicts GoPro F360 mounting used to later generate full-spherical videos, with its location on the BRUV ${ }^{\text {fs }}$ also highlighted with a red square. Orange inset depicts the single Hero4 GoPro used as the mono camera comparison, with its location on the BRUV ${ }^{\mathrm{fs}}$ highlighted with a corresponding orange square. 


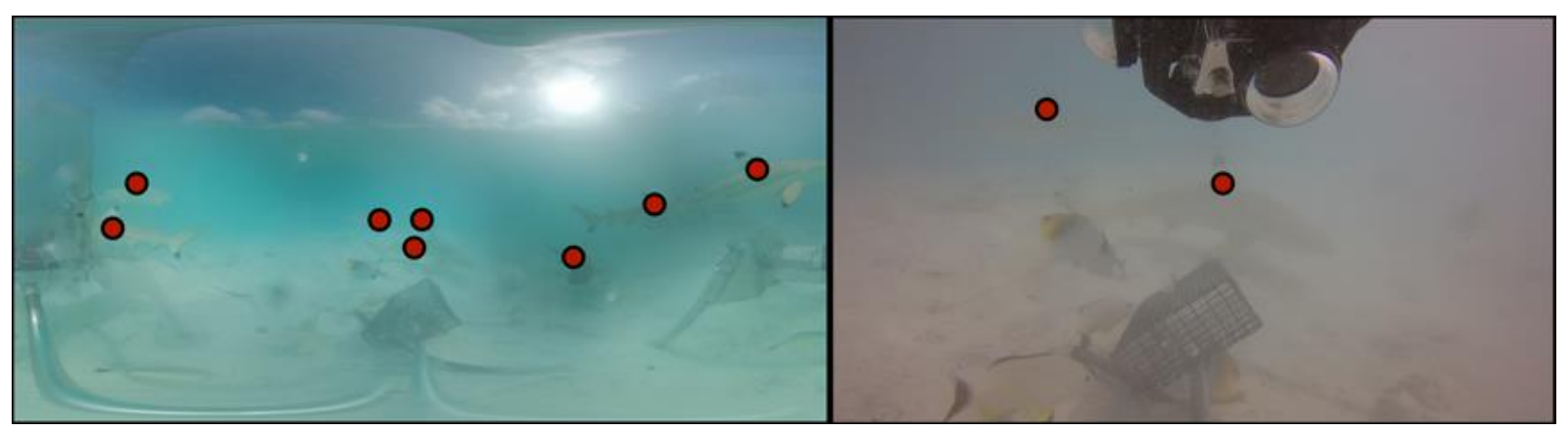

Figure 2. Still images extracted from stitched full-spherical (left panel) and mono (right panel) BRUV deployments in Tetiaroa, French Polynesia (August, 2016). Red dots indicate elasmobranch species that could be identified (left panel, $\mathrm{N}=8$; right panel, $\mathrm{N}=2$ ) at the same point in time. 

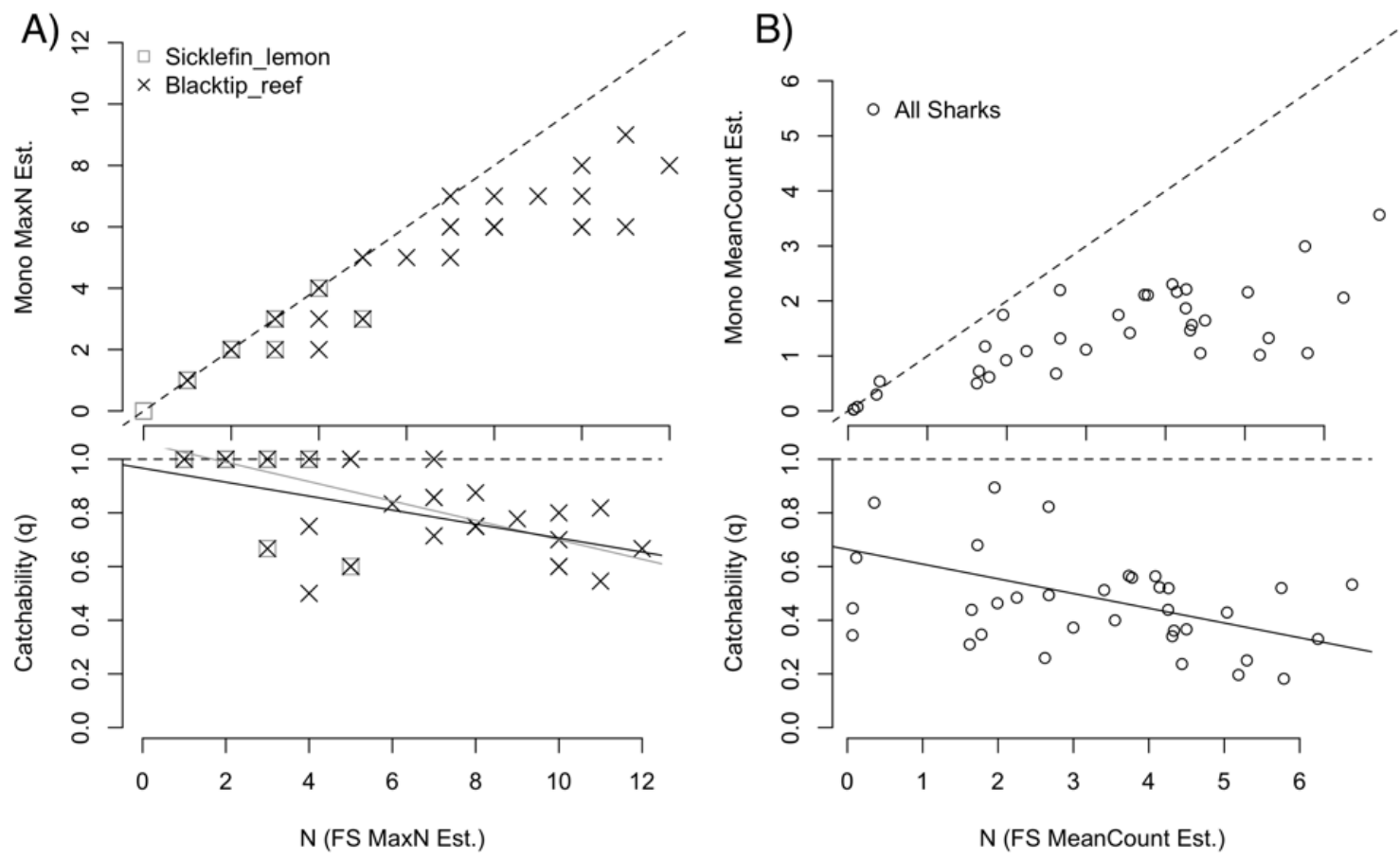

Figure 3. A) Relationship between site abundance (assumed to be equivalent to the fullspherical count) and estimates of MaxN from mono camera (upper panel), as well as catchability (q) of the mono camera (lower panel). Blacktip reef sharks (Carcharhinus melanopterus) are represented by black X marks, whereas sicklefin lemon sharks (Negaprion acutidens) are represented by open grey squares. Data points with both $\mathrm{X}$ and open grey squares represent both sicklefin lemon and blacktip reef sharks. Dashed lines represent what relationship would be typically assumed for MaxN (upper panel; $y=x$ ), and catchability (lower panel; q=1.0). B) Relationship between site abundance (assumed to be equivalent to full-spherical count) and estimates of MeanCount from mono camera (upper panel), as well as catchability (q) of the mono camera (lower panel). Data are aggregated across both sicklefin lemon and blacktip reef sharks and represented by open circles. Dashed lines represent what relationship would be typically assumed for MeanCount (upper panel; $\mathrm{y}=\mathrm{x}$ ), and catchability (lower panel; $\mathrm{q}=1.0$ ). 
CHAPTER III

INFLUENCE OF SHARK BEHAVIOR AND ENVIRONMENTAL CONDITIONS ON BAITED REMOTE UNDERWATER VIDEO SURVEY RESULTS 


\begin{abstract}
Baited remote underwater video systems (BRUVS) have become an important and frequently used tool by resource managers to monitor relative abundances for a variety of marine species. The sampling method offers a number of advantages over traditional fisheries surveys including being minimally invasive, reduced issues with sampling selectivity, and providing insights into species behavior and habitat use. As with any abundance survey method, fundamental assumptions of the technique are that counts derived from videos accurately reflect true changes to abundances, while being robust to changes in density-independent factors. We tested these assumptions using a spatially-explicit individual-based simulation model for two of the most commonly used video survey metrics of relative abundance; MaxN and MeanCount. Simulating a 1-km² area over a 60-min BRUV deployment targeting elasmobranch species, we evaluated how resulting estimates of each metric were influenced by swimming speed, relative directness of movement patterns, relative attraction strength to bait, bait plume size, and water visibility. By simulating both standard $\left(120^{\circ}\right)$ and full-spherical (FS; $\left.360^{\circ}\right)$ fields of view, we were also able to explore if newly developed FS cameras could help reduce the influence of these density-independent factors. Each simulation scenario, whereby one factor varies within a range of values while all others are held constant, was repeated 1,000 times. An additional simulation scenario, where all factors were allowed to vary across their respective ranges simultaneously, was repeated 1,000 times and was used to develop a generalized linear model (GLM) for each video survey metric and camera combination. Allowing for main effects of all factors, GLM results indicated that both density and density-independent factors were highly significant in predicting metric
\end{abstract}


values, regardless of the camera type used. Simulations indicated that the relative bias in MaxN and MeanCount estimates were not constant across the range of values used for the density-independent factors tested. The direction and the shape of relationships were similar across metrics and camera types, however, MaxN estimators with FS cameras showed the lowest bias overall. Despite the lower bias for the FS cameras they showed higher variability in the bias estimates themselves. These findings highlight how current video survey metrics are sensitive to factors unrelated to changes in density. Given that these trends held true for both FS and standard cameras, future efforts should focus on developing robust video survey metrics of relative abundance.

\section{Introduction}

The use of baited remote underwater video systems (BRUVS) to study fish communities in the marine environment has dramatically increased over the last two decades (Cappo et al. 2001; Cappo et al. 2006; Harvey et al. 2013; Whitmarsh et al. 2017). The popularity of the method stems from its ease of use, low cost, minimal invasiveness, and because of the insights into species behavior and habitat use that it provides (Bacheler et al. 2013; Klages et al. 2014; Roberts et al. 2016; Whitmarsh et al. 2017). Although there is no single accepted protocol, BRUVS generally involve deploying a camera mounted to a platform with an attached bait source for an extended period of time (i.e., 60 mins; Cappo et al. 2006; Whitmarsh et al. 2017). One critical assumption of this method is that individuals who come in contact with the bait plume will search for and encounter the bait source at some point during the deployment, where they can be 'sampled' by the camera (Cappo et al. 2006). The non-extractive property of 
BRUVS makes them a preferred method to study many depleted species and populations, but also presents unique challenges not found in fishing-based surveys. Chiefly, fishes have the potential to be observed multiple times in a single deployment, and thus simply recording raw counts would likely artificially inflate abundance estimates (Cappo et al. 2006). Accordingly, various methods have been developed to enumerate species observed on BRUVS.

Methods to quantify fishes from BRUVS include time in - time out, time at first occurrence $\left(\mathrm{T}^{\mathrm{st}}\right)$, MeanCount, and MaxN. Time in - time out is calculated by monitoring both the time of entry and exit for each animal observed on the BRUV video data and is most commonly used for behavioral studies (Schobernd et al. 2014). Similarly, $\mathrm{T}^{\text {st }}$ refers to the first time a species is observed on a video, and can be used to get an idea of the distance the animal was from the bait source and/or the strength of attraction to bait for that species (Campbell et al. 2015). To monitor the relative abundance of species through time and space, either MeanCount or MaxN is typically employed (Campbell et al. 2015; Whitmarsh et al. 2017). Of these two, MaxN is the most commonly used method, and is simply defined as the maximum number of individuals for a species of interest observed on any single video frame (Ellis and Demartini 1995). By limiting counts to this conservative approach, researchers prevent the possibility of counting the same individual multiple times. MeanCount calculates a mean estimate of abundance over the duration of the BRUV by averaging the counts for each species of interest on every frame taken at a specified sampling interval (i.e., every 5,10,30, or 60s; Bacheler et al. 2013; Schobernd et al. 2014; Campbell et al. 2015). 
As with any survey index, metrics of relative abundance derived from video data have a number of inherent biases. However, what distinguishes camera systems from traditional survey techniques, is these biases can be readily explored rather than simply ignored. Understanding, acknowledging, and mitigating these biases is essential for implementing video surveys, and enabling the correct interpretation of survey results for assessment purposes. In particular, the relationship between the calculated metric and true changes to local population sizes, aka density, must be understood. Typically in fisheries, this relationship is assumed to be linear (Maunder and Starr 2003), despite many indices exhibiting non-linear relationships with the true abundance (Hilborn and Walters 1992; Erisman et al. 2014). Failing to understand these relationships can lead to hyperstability or hyperdepletion, whereby survey metrics remain constant even as the actual abundance is changing. MeanCount was developed in response to concerns that MaxN had a non-linear relationship with true abundance (Schobernd et al. 2014) and has been shown, through simulations and empirical data, to reduce issues of non-linearity under certain conditions (Schobernd et al. 2014; Campbell et al. 2015). However, this improved linearity was not observed for large elasmobranch species, for which both MaxN and MeanCount were shown to be ineffective at reflecting changes in abundance at high densities (Kilfoil et al. 2017; Sherman et al. 2019). These findings highlight that no single count method is consistently superior for all research purposes, species, or environments. Furthermore, it is possible that these count methods are theoretically sound, but are simply limited by the camera technology often employed. For example, advances in full-spherical (FS) cameras have demonstrated that by increasing the observed field of view (FOV), both MaxN and MeanCount can maintain a linear 
relationship with true abundance across a wider range of localized densities (Campbell et al. 2015; Kilfoil et al. 2017; Campbell et al. 2018; Whitmarsh et al. 2018).

In addition to preserving a linear relationship with changes in abundance, survey metrics must also be robust to fluctuations in factors independent of changes to local densities (e.g., abiotic conditions). If this relationship does not hold true for a chosen metric, it becomes difficult to determine if changes detected by a survey are caused by true changes in species densities, or are instead a byproduct of unrelated variables. Although it is widely accepted that density-independent factors such as swimming speed (Ward-Paige et al. 2008), movement patterns (Watson et al. 1995; Fewster et al. 2008), and environmental conditions (Gruss et al. 2017) can influence survey metrics, it is often assumed (either implicitly or explicitly) that these biases are negligible and/or constant, thus having a minimal impact on survey results. Further obscuring our understanding of the potential impacts of density-independent factors on survey results is the inability of researchers to isolate the effects of any one variable. This is particularly true for large bodied species such as sharks, for which laboratory experiments are often logistically impractical. Given that BRUVS are frequently used to study and inform management decisions for elasmobranch species (e.g., Bond et al. 2012; Goetze and Fullwood, 2013; Murray et al. 2019; Winter et al. 2019), there remains a need to understand how densityindependent factors may influence metrics of relative abundance for this group. Accordingly, we explored these questions within a simulated spatially-explicit, individual-based modelling approach. Specifically, our objects were to determine how density-independent factors - including swimming speed, directedness of movement patterns, species attraction strength to bait, bait plume size and visibility - influence 
relative bias for estimates of MaxN and MeanCount for BRUVS. Moreover, we explored how these relationships varied between standard and FS cameras. Although we limited the scope of our study to elasmobranch species, the results have broad applications to BRUVS and other underwater video surveys used to gather fisheries-independent data.

\section{Methods}

To simulate a BRUV survey aimed at enumerating elasmobranchs, we constructed an individual-based model (IBM) within the $\mathrm{R}$ core environment ( $\mathrm{R}$ Core Team, 2018). For simplicity, our IBM simulation represented a featureless twodimensional space, having an origin in the lower left quadrant $(0,0 ; \mathrm{X}, \mathrm{Y})$ and an upper bound of 1000 for each axis, representing a $1-\mathrm{km}^{2}$ area. Every simulation occurred in discrete time steps representing one second intervals and was comprised of three primary components: bait plume, shark movement, and camera detection field.

\section{Bait plume}

To generate bait plumes in our two-dimensional space, we used a simple bait odor particle dispersal model developed by Vabø et al. (2004). Following this general procedure, an odor source was placed in the center of the study site $(500,500 ; \mathrm{X}, \mathrm{Y})$, with a large number of initial odor particles $\left(S_{0}\right)$ randomly placed within a small region representing a bait bag $(\mathrm{BB})$. At each time step the leaching rate $(\lambda)$ determined how many particles were released from the BB using the equation:

$$
S_{t}=\frac{S_{0}}{(1+\lambda \times t)}
$$

where $S_{t}$ represents the amount of odor particles remaining in the BB at time step $t$. These released odor particles $(O P)$ then moved through the simulated space based on 
their previous XY position, a current vector $(U)$ which was assumed to be constant throughout the study region, and a small degree of diffusion with random movement. Specifically, at any time step the $\mathrm{XY}$ position of each particle $\left(O P_{X_{t}}\right.$ and $O P_{Y_{t}}$ respectively) was defined by the equations:

$$
\begin{aligned}
& O P_{X_{t}}=\left(O P_{X_{t-1}}+U_{x}\right)+(D \times \sqrt{D F}) \\
& O P_{Y_{t}}=\left(O P_{Y_{t-1}}+U_{y}\right)+(D \times \sqrt{D F})
\end{aligned}
$$

where $D$ denotes a random error with a uniform distribution between a positive and negative displacement parameter $(D S P)$, and $D F$ represents a constant diffusion rate. This process was repeated for 300 time steps, representing a 'burn in' period for BRUV surveys whereby researchers do not review footage. This 'burn in' period is typically used to allow for sediment to resettle, the FOV to clear, and to reduce the impact of potential attraction or avoidance behaviors of fishes to the platform. Although rarely considered, it is also likely that during this time the gear effected area of the BRUV has its largest variation as the bait plume disperses through the water column. The current vector (direction) was set to be held constant for all simulation runs, and by varying the speed of the current vector we were able to generate bait plumes of varying sizes and shapes. Odor particle point data were then smoothed at the end of the 'burn in' to give a more realistic odor gradient by converting to raster data using a high bandwidth (bandwidth $=15$ ) kernel density estimation procedure in the Kernsmooth package (Wand, 2015). These resulting raster data were then rescaled with the highest value equal to one, and the total number of raster cells containing positive odor particle values used to calculate bait plume sizes (Fig. 1). 


\section{Shark movement}

Swimming behaviors for simulated sharks were also modelled using an individual-based approach. Each simulated shark's movement properties and behavioral rules were tracked and generally defined in relation to common foraging strategies (i.e., scavenging), whereby each simulated shark had a total length of one meter. At the initial time step $\left(T_{0}\right)$ a total number of sharks $\left(N_{\text {sharks }}\right)$ were randomly populated within the study region and given a random heading from $0-360^{\circ}$. At each time step, every shark determined the odor particle concentration of the raster cell associated with its XY location, which was used to assign the shark to one of four behavioral states; plume search, bait search, near bait, and bait found. Each behavioral state had its own set of rules that determined how each shark moved by influencing their selected step length (a.k.a., distance moved) and heading choice.

Plume search behavior was assigned when the shark had yet to detect any odor particles within its current cell. Under plume search behavior, the shark selects a step length from a normal distribution defined by a mean $\left(\mu_{\text {speed }}\right)$ and variance $\left(\sigma_{\text {speed }}^{2}\right)$. Its heading options were then limited to either any three cells in front of their of their current heading (representing a range of $-45^{\circ}, 0^{\circ}$, or $+45^{\circ}$ ), with an equal probability of selection initially assumed. However, the probability of selecting its current heading was then multiplied by a directionality strength parameter $(D S)$, which varied from 1-10, where 1 would indicate no directedness of movements, while 10 would be considered a highly directed movement pattern as it was 10x more likely to move in the same direction that to choose a neighboring cell. All sharks were also assigned a spatial-memory of their last 25 
time-steps, whereby a shark would not select a cell previously selected within this tabu list.

If a shark detected an odor particle concentration of greater than zero within its raster cell, it moved from plume search to bait search behavior, and would not re-enter plume search for the remainder of the simulation. While in bait search, a shark's step length was selected from the same normal distribution as defined in plume search, but with its mean parameter doubled to simulate an excited response to bait by increasing swimming speed. Its heading options were again restricted to its previous heading or either adjacent cell, with an assumed equal probability of selection for each. However, the odor values for each potential heading were evaluated by the shark prior to selection, with the highest having its probability of selection multiplied by an attraction strength parameter $(a)$, that could vary from 1-10. If however, this value was less than $95 \%$ of the shark's current cell value (across a smoothed raster surface), the shark would then determine that it was likely moving away from the source of the bait and instead picked a random heading in the another direction (i.e., $90^{\circ}, 135^{\circ}, 180^{\circ}, 225^{\circ}$, or $270^{\circ}$ relative to current heading).

If the shark moved to a raster cell adjacent to the $B B$, its movements were governed by near bait behavioral rules. These movement rules were very similar to bait search behavior, but reduced the mean value defining the step length distribution to half of its initial value, thus slowing the sharks down by roughly half as they approached the bait source (determined from personal observations of sharks interacting with bait bag from BRUV footage). 
Lastly, if a shark was in contact with $B B$ (meaning in the same raster cell), its movements were then governed by bait found behavioral rules. The rules governing this behavior were very similar to the previously described near-bait behavior. The shark used the same step length distribution and heading selection rules but had a $50 \%$ probability of implementing its chosen step length, and a $50 \%$ probability of selecting a step length of 0 instead (thus remaining in contact with the bait).

In an addition to these behavioral types, shark movements are dictated by a set of rules which are held universal. To maintain a constant shark density throughout the simulation, the study site is considered to be a closed system, meaning sharks cannot go outside the $\mathrm{X}$ and $\mathrm{Y}$ axis bounds. If a shark's selected heading and step length go outside these bounds, the shark will instead choose a random heading that does not go outside the study region. Secondly, each raster cell has a maximum of 4 sharks allowed at any time step in its represented $1-\mathrm{m}^{2}$ area. If sharks' movements result in having more than 4 individuals in any one raster, $n$ sharks will be randomly selected to move into adjacent cells $(n=N-4$, where $\mathrm{N}$ is the total number of sharks found in the cell at the beginning of the time step). The resulting shark tracks generated by the IBM (Fig. 2) were then visually compared to shark tracks gathered in previous empirical (Heithaus et al. 2002) and simulated (Ward-Paige et al. 2008) studies to verify whether the movement patterns were biologically realistic.

\section{Camera detection field}

For each simulation, we modeled a BRUV deployment with two simultaneous camera recording systems. The first camera assumed a $120^{\circ} \mathrm{FOV}$ (referred to as standard camera), while the second assumed $360^{\circ}$ (referred to as full-spherical). Cameras were 
fixed at the center of the study area $(500,500)$ for the whole duration of the simulation. Cameras were oriented in the same direction as the current vector for each simulated deployment. Both cameras were assigned two visibility parameters (Fig. 3). The first, lower visibility $(L V)$, defined the distance (meters) within which a camera could detect a shark $100 \%$ of the time, given the shark was within the camera's FOV. The second, upper visibility $(U V)$, was set to $1.5 \mathrm{LV}$ and defined the distance behind which sharks could not be detected by the cameras. A linear decline in detection probability was assumed between $L V$ and $U V$, resulting in steeper declines in detection rates for lower visibility environments. If a shark was detected within a camera's FOV, it cast a $5^{\circ}$ visual shadow, behind which subsequent sharks could not be detected by the camera. For each simulation run, the number of sharks detected by each camera type was reported at every time step.

\section{Simulation scenarios and analyses}

To determine which and how factors impact MaxN and MeanCount estimates, 6 variables were considered. These variables included aspects of shark behavior (swimming speed, attraction strength to bait, directedness of movement patterns), environmental conditions (visibility, bait-plume size), and density. To test the individual effects of each of these factors, a simulation scenario was established for each, where the variable of interest was made to vary over a range of biologically acceptable values (e.g., burst swimming for Carcharhinus leucas of $5.3 \mathrm{~ms}^{-1}$; Gray 1971) while all other parameters were held constant (Table 1). Each scenario was run for 3600 time steps (representing a 60-min deployment) and replicated 1000 times. For each simulation run, the estimated MaxN and MeanCount (using a 10s sampling interval) were noted for each 
camera. Using these estimates, a measure of relative bias for each metric was calculated at the end of every simulation run using the equation:

$$
\text { Relative bias }=\left(M_{c}-N\right) / N
$$

where $M_{c}$ denotes the metric derived count, and $\mathrm{N}$ represents the true number of sharks in our simulated space.

Lastly, a simulation scenario was conducted where all parameter values were allowed to vary between their lower and upper bounds, and was replicated 1,000 times. From this scenario output, we created a generalized linear model (GLM) trying a variety of appropriate distributions (i.e., Poisson, Gamma, Negative-binomial, Tweedie) with video survey metrics of relative abundance for each camera type modeled using all factors as predictor variables, allowing for main effects. From these, the best model was selected using AIC with the MASS package stepAIC function (Venables and Ripley, 2002).

\section{Results}

A total of 6,000 simulation runs were conducted, consisting of 1000 runs for each simulation scenario. The baseline run, whereby density was varied while all other parameter values were held constant, indicated that our simulated BRUVS were capable of detecting changes in localized abundance. For FS cameras, both MaxN and MeanCount demonstrated a linear relationship with site abundance (Fig. 4). However, similar to previous empirical work (i.e., Kilfoil et al. 2017; Sherman et al. 2019), standard cameras had an apparent saturation effect after the number of sharks present exceeded approximately 25, after which FS and standard camera counts began to diverge (Fig.4). 
When density is held constant, the null assumption often made by researchers is that the relative bias introduced by density-independent factors would be constant over a wide range of potential values. In contrast to this null expectation, nearly all of tested variables introduced bias into our estimates of relative abundance, regardless of the camera type or metric used. More importantly, these relative biases were not constant over a range of each parameters' respective values (Fig. 5). When considering all parameters together, relative bias showed the highest variability when MaxN and FS cameras were used as compared to MeanCount and Standard Cameras. However, the MaxN with FS cameras consistently showed lower relative bias in comparison with MeanCount and standard cameras across all parameters and all parameter values. Although it should also be noted that FS and standard cameras had very similar relationships between parameters and relative biases. The exact relationship between a density-independent factor's parameter value and introduced bias did vary from one parameter to another. Swimming speed had the most complicated relationship with bias. As speed of individuals increased, the amount of relative bias declined in a linear fashion, until a speed of $2.0 \mathrm{~ms}^{-1}$ was reached. After this apparent threshold, relative bias increased as speed went up. Attraction strength to bait also demonstrated a linear decline in bias as its value increased to 2.5, after which no apparent pattern exists. Both directionality strength and visibility had a linear decline in relative bias as their parameter value increased. Interestingly, the size of the bait plume within the study area had no apparent relationship with the amount of bias introduced into either metric of relative abundance, regardless of the camera used. 
The GLM was parameterized with a number of different error distributions, but ultimately Poisson and Gamma were deemed most appropriate for MaxN and MeanCount estimation respectively, regardless of camera type. The results of each GLM indicated that while density was the most influential factor in predicting metric values, all densityindependent factors were also found to be highly significant $(\mathrm{P}<0.001$; Fig. 6).

Furthermore, the estimated coefficient of each parameter was similar across all metrics and camera types. Following density, visibility had the greatest influence on estimated metric values, followed by speed and/or attraction strength to bait, and lastly plume size and directedness of movements (Fig. 6).

\section{Discussion}

The results of the present study quantified the potential influence of environmental factors and aspects of species behavior on two of the most widely used video survey metrics of relative abundance, MeanCount and MaxN. Overall, our simulations highlighted that factors unrelated to changes in abundance can significantly impact video survey results. Outside of density, visibility had the strongest influence on counts derived from video data, suggesting that if not accounted, differences in visibility may lead to a misinterpretation of BRUV survey results. Researchers should therefore make it standard practice to quantify the approximate visibility range over the survey period (i.e., examining surface visibility via Secchi disk) or even quantifying how visibility may change over the course of the BRUV deployment using stereo-camera systems. Additionally, speed had a very complicated relationship in influencing counts derived from video data, with high relative bias occurring at both high and low speeds. Previous research has found similar results; whereby highly mobile fishes are over- 
counted in underwater visual censuses (Ward-Paige et al. 2010). Given that speed is highly correlated with the size/age of elasmobranchs, this pattern with bias could lead to inaccurate assessments of local population size/age structures, whereby juveniles have a lower probability of being sampled than larger adults. Furthermore, similar issues could arise if researchers attempt to compare animals and species with differing speeds, mobility and behavioral patterns in habitat use. The same issues apply when trying to compare individuals or species which differ in their relative attraction towards bait, as well as the directedness of their movement patterns, both of which were associated with increased bias as their respective values decreased.

The popularity of MaxN and MeanCount as metrics of relative abundance is likely because of their ease of use, relatively short processing times, ability to compare results to previously published literature using the same techniques, and their conservative methodology which prevents inflating abundance estimates via double counting individuals (Willis and Babcock 2000; Cappo et al. 2010). However, to be a viable means for monitoring populations, estimates must not only be conservative, but ideally maintain a linear relationship with true abundance, or at the very least have this relationship be clearly understood. Previous research using simulations and empirical data have indicated that this assumption likely does not hold true under certain conditions for either MaxN (Campbell et al. 2015; Kilfoil et al. 2017; Sherman et al. 2018) or MeanCount (Kilfoil et al. 2017). Reasons for this divergence from linearity are not well understood, but could be caused by species exhibiting non-uniform spatial distribution around BRUVS (Campbell et al. 2015), or saturation of the camera under high densities (Kilfoil et al. 2017). Not surprisingly, researchers have found that by increasing the 
camera FOV used in video surveys, both MaxN and MeanCount can preserve a linear relationship with true abundance over a wider range of values (Campbell et al. 2015; Kilfoil et al. 2017; Campbell et al. 2018; Sherman et al. 2018). Our simulation results support these previous findings, with MaxN and to a lesser extent, MeanCount deviating from linearity as local abundance increases using the standard view camera. However, it should be noted that the deviation from linearity did not occur until very high densities were reached (approximately 20 sharks/km2), and thus may not be of great concern when sampling relatively low density environments. By increasing the simulated FOV to mimic newly developed full-spherical (FS) cameras, both metrics proved capable of maintaining a linear relationship with true abundance. Unfortunately, this advantage for FS cameras did not extend to reducing the influence of density-independent factors on metric estimates. MeanCount and MaxN estimates from both FS and standard cameras were highly sensitive to changes in factors unrelated to density, including swimming speed, attraction to bait, directness of movements, and distance at which you can positive identify fish from camera footage (camera visibility range). Furthermore, the bias introduced by these density-independent factors appears to show greater variability for FS cameras over the range of each parameters' value. Importantly, this trend is likely a result of FS cameras showing lower bias than standard cameras across all parameters and all parameter levels tested. Though optical technologies are constantly improving and will likely provide solutions to many issues facing visual surveys (e.g., multispectral imaging to increase camera visibility range), researchers should also simultaneously work to develop more robust metrics of relative abundance that can be derived from these data. 
As with any simulation, our IBM model attempted to simplify inherently complex biological and ecological processes to improve our understanding of how these factors may interact with one another in situ. Though relatively simple, additional complexities could be integrated into our model, depending on the research questions one wishes to answer. Though not the intended focus of the present study, future iterations could explore how results may vary under different models of species movement patterns (i.e., levy vs. correlated random walks), additional sources of attraction (i.e., visual, acoustic), predatory strategies (i.e., lie-and-wait vs. roving predators), interactions effects between density-independent variables and density, and added complexities to the simulation's spatial structure (i.e., adding a third dimension or incorporating habitat complexity). Furthermore, though the aim of this paper was to cover a potential parameter values for a wide range of shark species, researchers could use this simulation framework to test similar questions focusing on specific species or environments. Additionally, further efforts should explore the potential influence of bait-plum size on survey metrics and animal behavioral responses. Interestingly, our simulation results indicated that baitplume size had a relatively small, but significant, negative impact on estimates of relative abundance. This is in contrast to previous studies (Harvey et al. 2007; Heagney et al. 2007; Bernard and Gotz, 2012; Dorman et al. 2012), and may be caused by the closedsystem structure of our IBM. By restricting the survey to a $1-\mathrm{km}^{2}$ area, it is possible that the effects of relatively large bait plumes are dampened, since their greatest impact may be caused by attracting sharks from farther away than this limit.

Overall, our simulation study indicates that the density-independent factors can significantly affect metrics of relative abundance derived from video data. Given that 
BRUVS are frequently used by resource managers to monitor populations trends (Barord et al. 2014), gain insights on species richness (Mallet et al. 2014; Andradi-Brown et al. 2016), and to evaluate the effectiveness of marine protected areas (Sanguinetti, 2013; Bond et al. 2017), it is critical that researchers understand how their survey results may be impacted by factors unrelated to density. Baited Remote Underwater Video Systems are still a viable survey method, capable of detecting and tracking changes to local population sizes with minimal impact on the animals and habitats in which they are employed. However, until more robust metrics of relative abundance are developed and tested, or the biases of current metrics are further explored and accounted for, researchers must carefully evaluate if differences observed in video data are driven by differences in population size, or some other unrelated factors.

\section{Acknowledgements}

The authors thank the Florida International University Dissertation Year

Fellowship for funds contributing towards this research.

Literature cited

Andradi-Brown, D. A., Macaya-Solis, C., Exton, D. A., Gress, E., Wright, G., Rogers, A. D. 2016. Assessing Caribbean shallow and mesophotic reef fish communities using baited-remote underwater video (BRUV) and diver-operated video (DOV) survey techniques. PLoS One, 11: e0168235.

Bacheler, N. M., Schobernd, C. M., Schobernd, Z. H., Mitchell, W. A., Berrane, D. J., Kellison, G. T., Reichert, M. J. 2013. Comparison of trap and underwater video gears for indexing reef fish presence and abundance in the southeast United States. Fisheries Research, 143: 81-88. 
Barord, G. J., Dooley, F., Dunstan, A., Ilano, A., Keister, K. N., Neumeister, H., Preuss, T., Schoepfer, S., Ward, P. D. 2014. Comparative population assessments of Nautilus sp. in the Philippines, Australia, Fiji, and American Samoa using baited remote underwater video systems. PLoS One, 9: e100799.

Bernard, A. T. F., Götz, A. 2012. Bait increases the precision in count data from remote underwater video for most subtidal reef fish in the warm-temperate Agulhas bioregion. Marine Ecology Progress Series, 471: 235-252.

Bond, M. E., Babcock, E. A., Pikitch, E. K., Abercrombie, D. L., Lamb, N. F., Chapman, D. D. 2012. Reef sharks exhibit site-fidelity and higher relative abundance in marine reserves on the Mesoamerican Barrier Reef. PloS one, 7: e32983.

Campbell, M.D., Pollack, A.G., Gledhill, C.T., Switzer, T.S., DeVries, D.A., 2015. Comparison of relative abundance indices calculated from two methods of generating video count data. Fisheries Research, 170: 125-133.

Campbell, M.D., Salisbury, J., Caillouet, R., Driggers, W.B., Kilfoil, J.P. 2018. Camera field-of-view and fish abundance estimation: a comparison of individual-based model output and empirical data. Journal of Experimental Marine Biology and Ecology, 501: 46-53.

Cappo, M., Harvey, E., Shortis, M. 2006. Counting and measuring fish with baited video techniques-an overview. In Australian Society for Fish Biology Workshop Proceedings, 1: 101-114. Australian Society for Fish Biology.

Cappo, M., 2010. Development of a Baited Video Technique and Spatial Models to Explain Patterns of Fish Biodiversity in Inter-reef Waters. James Cook University, Townsville, Australia.

Dorman, S.R., Harvey, E.S., Newman, S.J. 2012. Bait Effects in Sampling Coral Reef Fish Assemblages with Stereo-BRUVs. PLoS ONE, 7: e41538.

Ellis, D.M., DeMartini, E.E., 1995. Evaluation of a video camera technique for index-ing abundances of juvenile pink snapper, Pristipomoides filamentosus, and other Hawaiian insular shelf fishes. Fisheries Bulletin, 93: 67-77.

Erisman, B.E., Allen, L.G., Claisse, J.T., Pondella, D.J., Miller, E.F., Murray, J.H. 2011. The illusion of plenty: hyperstability masks collapses in two recreational fisheries that target fish spawning aggregations. Canadian Journal of Fisheries and Aquatic Science, 68: 1705-1716.

Fewster, R. M., Southwell, C., Borchers, D. L., Buckland, S. T., Pople, A. R. 2008. The influence of animal mobility on the assumption of uniform distances in aerial linetransect surveys. Wildlife Research, 35: 275-288. 
Goetze, J. S., Fullwood, L. A. F. 2013. Fiji’s largest marine reserve benefits reef sharks. Coral Reefs, 32: 121-125.

Gray, J. 1971. How fishes swim; Moore JR, ed. San Francisco California: W.H. Freeman and Co. pp 228-234.

Gruss, A., Thorson, J. T., Sagarese, S. R., Babcock, E. A., Karnauskas, M., Walter III, J. F., Drexler, M. 2017. Ontogenetic spatial distributions of red grouper (Epinephelus mono) and gag grouper (Mycteroperca microlepis) in the US Gulf of Mexico. Fisheries Research, 193: 129-142.

Harvey, E., McLean, D., Frusher, S., Haywood, M., Newman, S. J., \& Williams, A. 2013. The use of BRUVs as a tool for assessing marine fisheries and ecosystems: a review of the hurdles and potential. University of Western Australia.

Heagney, E. C., Lynch, T. P., Babcock, R. C., Suthers, I. M. 2007. Pelagic fish assemblages assessed using mid-water baited video: standardising fish counts using bait plume size. Marine Ecology Progress Series, 350: 255-266.

Heithaus, M., Dill, L., Marshall, G., Buhleier, B. 2002. Habitat use and foraging behavior of tiger sharks (Galeocerdo cuvier) in a seagrass ecosystem. Marine Biology, 140: 237-248.

Hilborn, R., Walters, C.J. 1992. Quantitative Fisheries Stock Assessment: Choice, Dynamics and Uncertainty. Chapman and Hall, New York.

Kilfoil, J. P., Wirsing, A. J., Campbell, M. D., Kiszka, J. J., Gastrich, K. R., Heithaus, M. R., Zhang, Y., Bond, M. E. 2017. Baited Remote Underwater Video surveys undercount sharks at high densities: insights from full-spherical camera technologies. Marine Ecology Progress Series, 585: 113-121.

Klages, J., Broad, A., Kelaher, B. P., Davis, A. R. 2014. The influence of gummy sharks, Mustelus antarcticus, on observed fish assemblage structure. Environmental biology of fishes, 97: 215-222.

Langlois, T. J., Harvey, E. S., Fitzpatrick, B., Meeuwig, J. J., Shedrawi, G., Watson, D. L. 2010. Cost-efficient sampling of fish assemblages: comparison of baited video stations and diver video transects. Aquatic biology, 9: 155-168.

Maunder, M.N., Starr, P.J., 2003. Fitting fisheries models to standardized CPUE abundance indices. Fisheries Research. 63: 43-50. 
Murray, R., Conales Jr, S., Araujo, G., Labaja, J., Snow, S. J., Pierce, S. J., Songco, A., Ponzo, A. 2019. Tubbataha Reefs Natural Park: the first comprehensive elasmobranch assessment reveals global hotspot for reef sharks. Journal of AsiaPacific Biodiversity, 12: 49-56.

R Core Team. 2018. R: A language and environment for statistical computing. $\mathrm{R}$ Foundation for Statistical Computing, Vienna, Austria. URL. https://www.Rproject.org/.

Roberts, L., Pérez-Domínguez, R., Elliott, M. 2016. Use of baited remote underwater video (BRUV) and motion analysis for studying the impacts of underwater noise upon free ranging fish and implications for marine energy management. Marine pollution bulletin, 112: 75-85.

Sanguinetti, C. A. V. 2013. Patterns in reef fish assemblages as determined by baited remote underwater video (BRUV) along the western side of False Bay: effects of site, depth and protection status. Doctoral dissertation, University of Cape Town.

Schobernd, Z.H., Bacheler, N.M., Conn, P.B. 2014. Examining the utility of alternative video monitoring metrics for indexing reef fish abundance. Canadian Journal of Fisheries and Aquatic Science, 71: 464-471.

Sherman, C. S., Chin, A., Heupel, M. R., Simpfendorfer, C. A. 2018. Are we underestimating elasmobranch abundances on baited remote underwater video systems (BRUVS) using traditional metrics?. Journal of experimental marine biology and ecology, 503: 80-85.

Vabø, R., Huse, G., Fernö, A., Jørgensen, T., Løkkeborg, S., \& Skaret, G. 2004. Simulating search behaviour of fish towards bait. ICES journal of Marine Science, 61: 1224-1232.

Venables, W. N. Ripley, B. D. 2002. Modern Applied Statistics with S. Fourth Edition. Springer, New York. ISBN 0-387-95457-0.

Wand, M. 2015. KernSmooth: Functions for Kernel Smoothing Supporting Wand \& Jones (1995). R package version 2.23-15.https://CRAN.Rproject.org/package $=$ KernSmooth

Ward-Paige, C., Flemming, J.M., Lotze, H.K. 2010. Overestimating Fish Counts by NonInstantaneous Visual Censuses: Consequences for Population and Community Descriptions. PLoS ONE 5: e11722.

Watson, R. A., Carlos, G. M., Samoilys, M. A. 1995. Bias introduced by the non-random movement of fish in visual transect surveys. Ecological Modelling, 77: 205-214. 
Whitmarsh, S.K., Fairweather, P.G., Huveneers, C. 2017. What is Big BRUVver up to? Methods and uses of baited underwater video. Reviews in Fish Biology and Fisheries, 27: 53-73.

Whitmarsh, S. K., Huveneers, C., Fairweather, P. G. 2018. What are we missing? Advantages of more than one viewpoint to estimate fish assemblages using baited video. Royal Society open science, 5: 171993.

Winter, H. V., de Graaf, M. 2019. Diversity, abundance, distribution and habitat use of reef-associated sharks in the Dutch Caribbean: Field studies using Baited Remote Underwater Video (BRUV) and acoustic telemetry; as part of the DCNA 'Save Our Sharks' project (Nationale Postcode Loterij) (No. C105/18). Wageningen Marine Research.

Willis, T.J., Babcock, R.C., 2000. A baited underwater video system for the determination of relative density of carnivorous reef fish. Marine and Freshwater Research, 51: 755-763. 
Figures and Tables

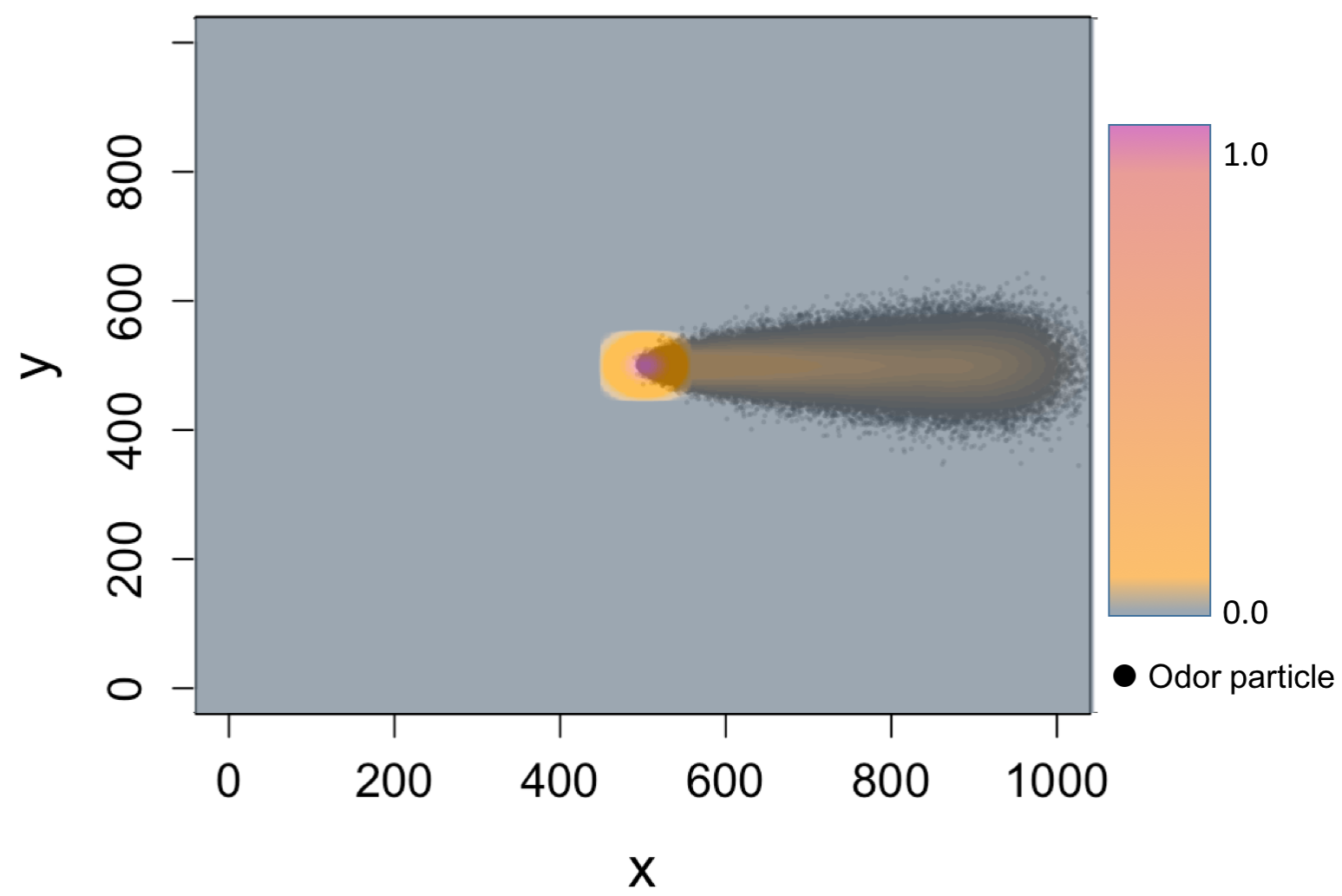

Figure 1. Simulated bait odor particle locations (indicated by small black dots) following five minutes of dispersal from the center $(500,500)$ of the study system with a constant current speed of 1.5 meters per second. Odor particle locations were used to create a smoothed raster of particle concentrations of 1.0 (highest concentration, indicated by pink) to 0.0 (lowest concentration, indicated by grey). 

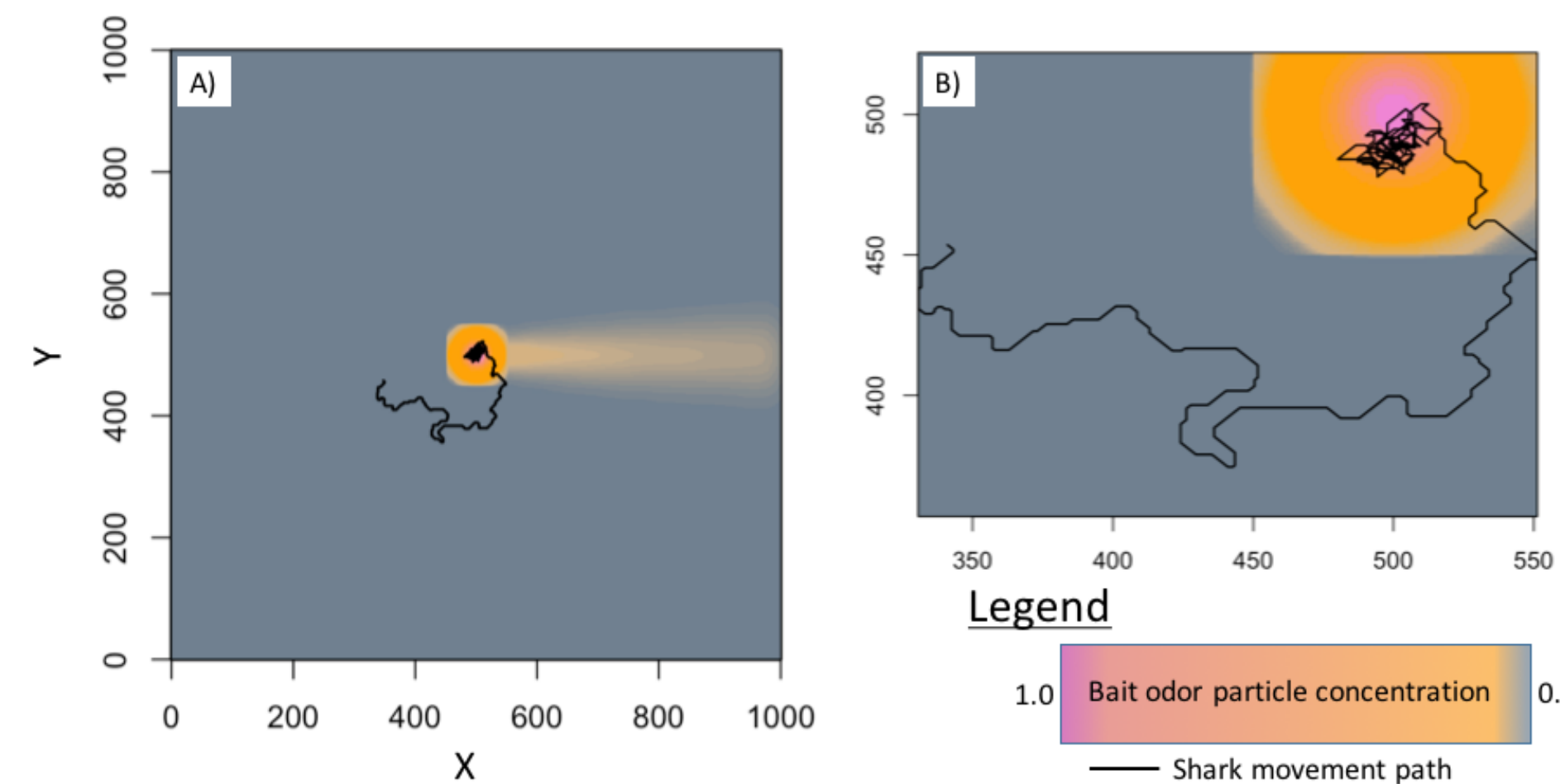

Figure 2. A) Resulting shark movement tracks (indicated by black lines) for a simulated baited remote underwater video deployment, with a mean swimming speed of 1.5 meters per second. B) Zoomed image of the same shark movement tracks, highlighting track patterns once the shark is in contact with the bait plume (indicated by color gradient of pink to light orange). 


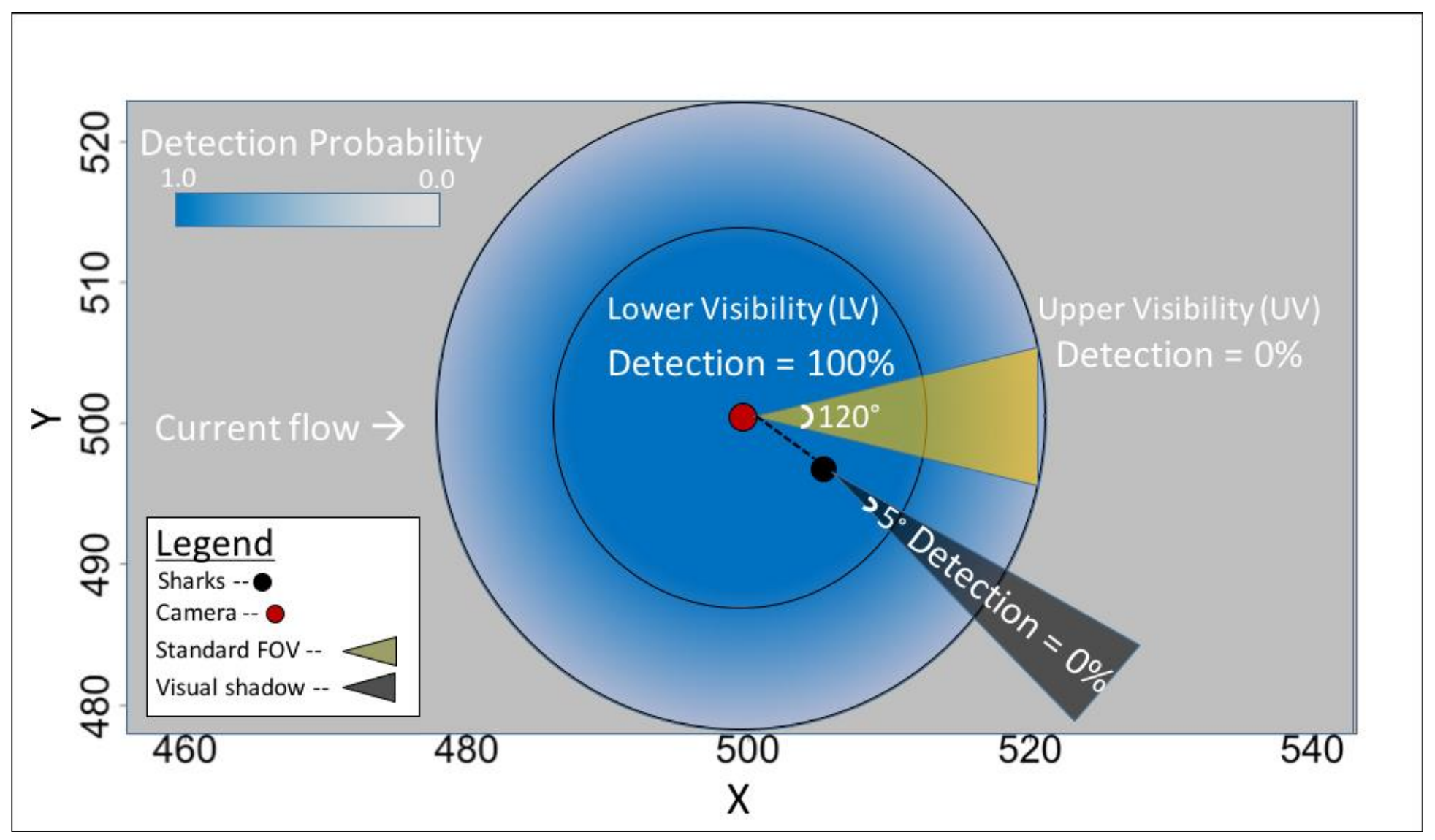

Figure 3. Figure illustrating full-spherical and standard camera detection ranges for simulated baited remote underwater video survey deployments. Red circle represents both camera types, with yellow shading used to indicate restricted field of view $\left(120^{\circ}\right)$ for standard camera. Standard camera is oriented to the direction of the simulated current flow, and detection probability for both cameras (indicated in blue shading) reduces a function of distance from the camera. Inside the lower visibility (LV) region, cameras have a $100 \%$ probability of detection for sharks, and outside the upper visibility (UV) region cameras have a $0 \%$ detection probability. All sharks (represented by small black circle) cast a $5^{\circ}$ degree visual shadow, behind which subsequent sharks cannot be detected by either camera. 


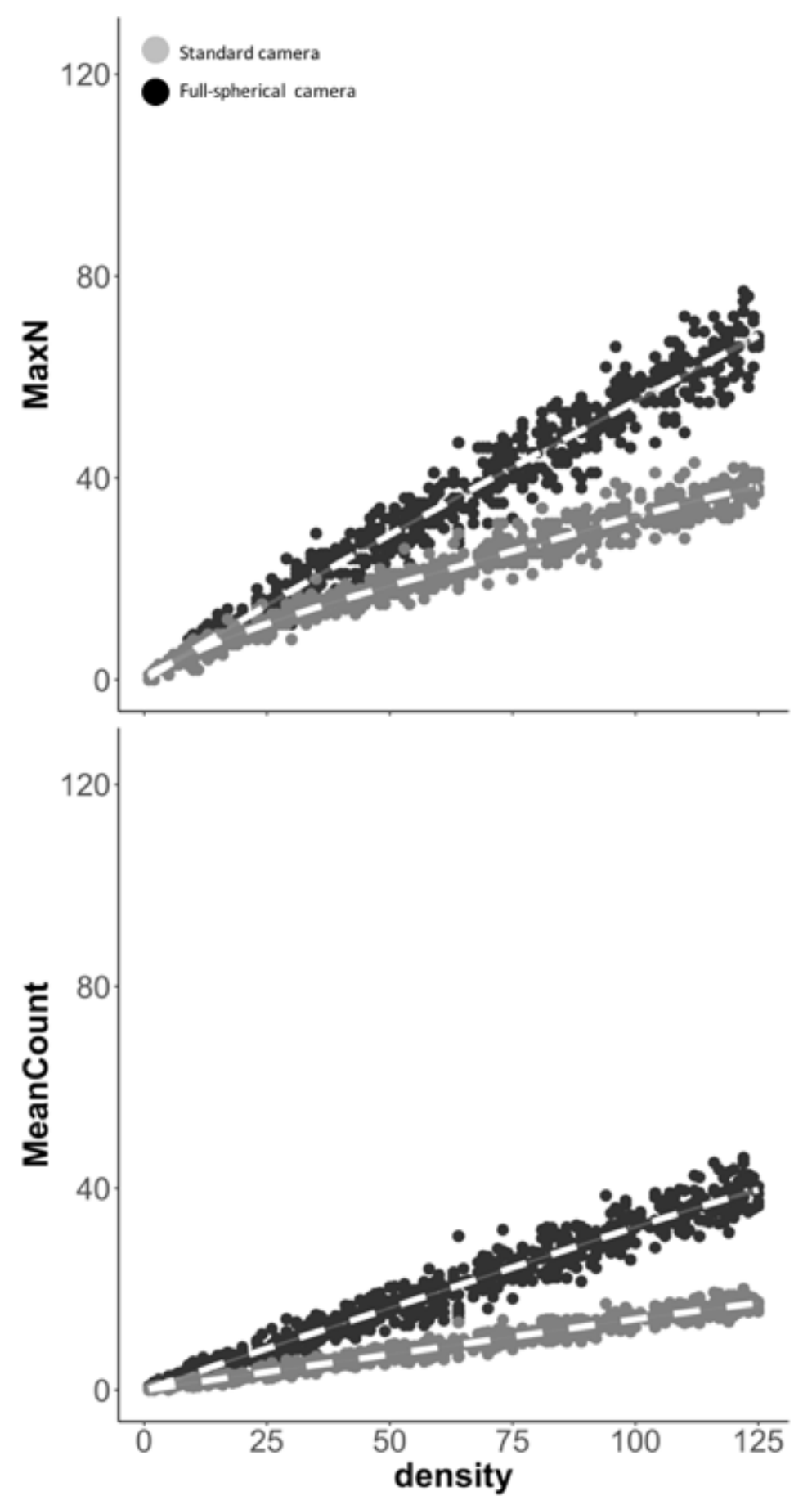

Figure 4. Relationship between shark density $\left(1-125 / \mathrm{km}^{2}\right)$ and resulting MaxN (upper panel) and MeanCount (lower panel) estimates from simulated baited remove underwater video system deployment. Black circles represent estimates derived assuming a fullspherical $\left(360^{\circ}\right)$ field of view, while grey dots assume a standard $\left(120^{\circ}\right)$ view. White dashed lines represent a fitted linear model using the geom_smooth function in R's ggplot2 package 


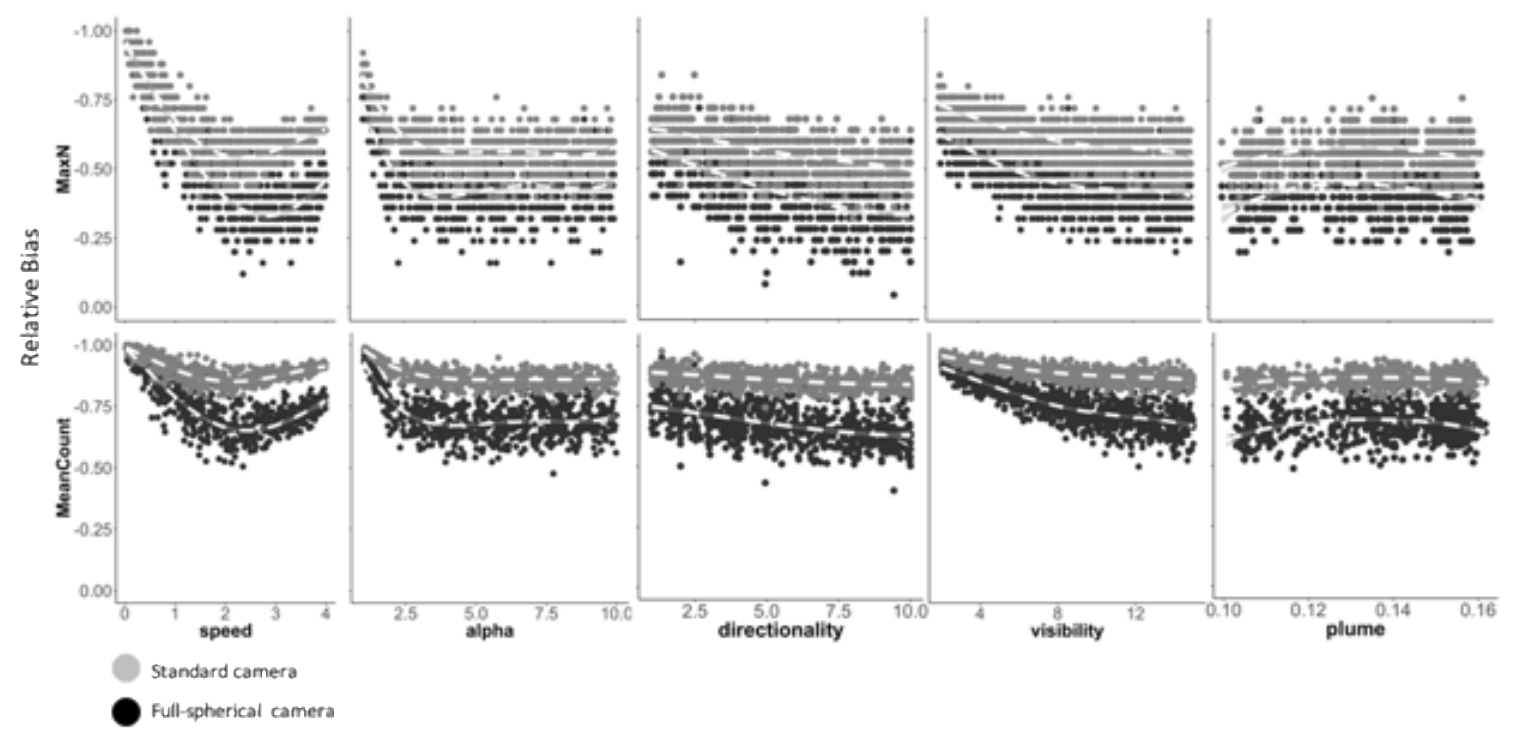

Figure 5. Comparison of MaxN (upper panels) and MeanCount (lower panels) estimates' relative bias in relation to: A) Mean swimming speed B) Relative attraction strength to bait (alpha) C) Directedness of movement patterns (directionality), D) Camera visibility range, E) Bait plume size $\left(\mathrm{km}^{2}\right)$. White dashed lines represent a fitted linear model using the geom_smooth function in R's ggplot2 package. 


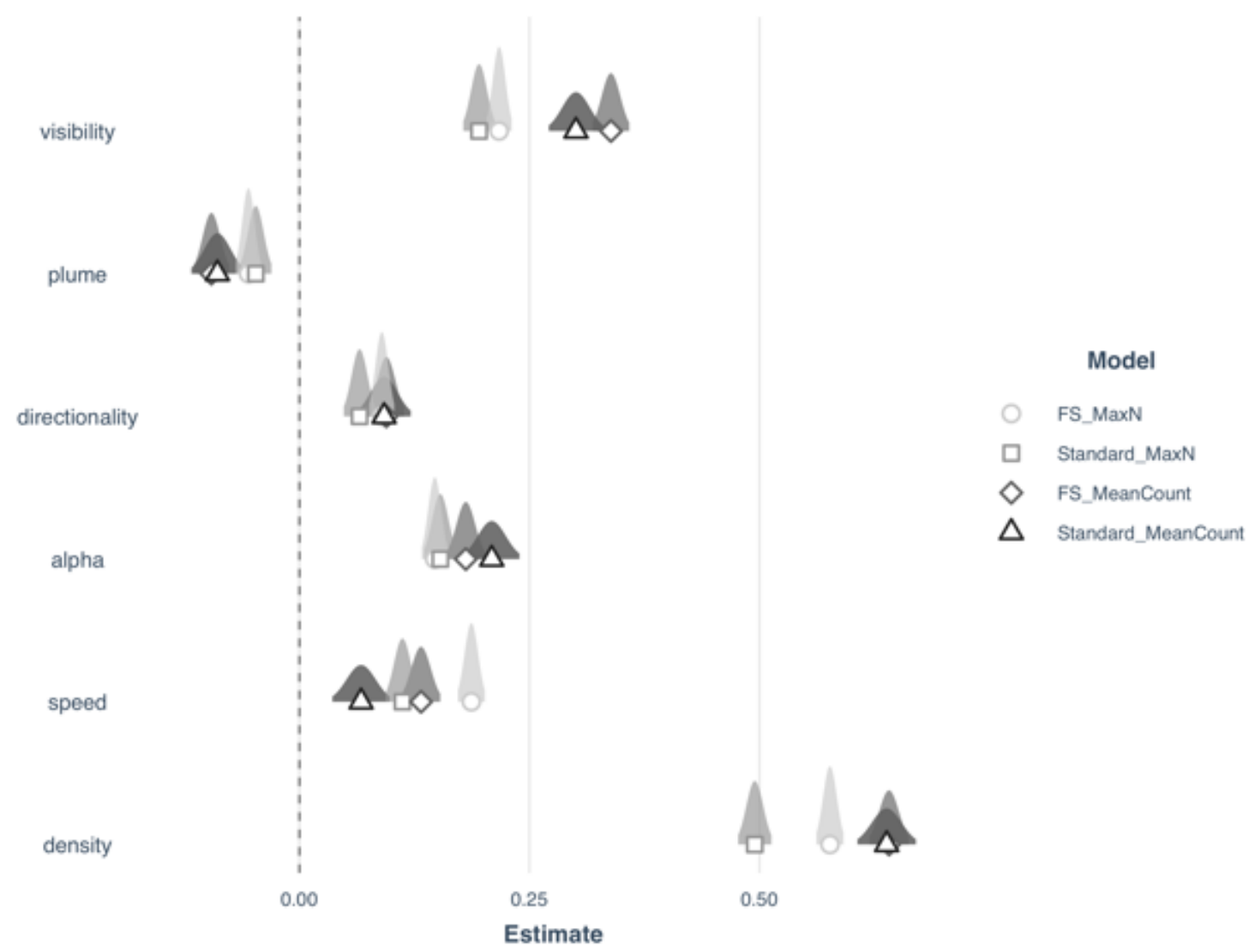

Figure 6. Standardized coefficient estimates for all highly significant factors in generalized linear models created for MaxN using full-spherical cameras (FS_MaxN; light-grey circle), MeanCount using full-spherical cameras (FS_MeanCount; mediumgrey diamonds), MaxN using standard cameras (Standard_MaxN; light-grey squares) and MeanCount using standard cameras (Standard_MeanCount; dard-grey triangles). Values have been scaled to their mean values to aid in comparison. Surrounding each parameter estimate is the assumed normal distribution with $95 \%$ confidence intervals. 


\begin{tabular}{|c|c|c|c|}
\hline Parameter & Fixed value & Value range & Description \\
\hline nsims & 1000 & & $\begin{array}{c}\text { The number of } \\
\text { simulation runs per } \\
\text { scenario } \\
\end{array}$ \\
\hline nsteps & 3600 & & $\begin{array}{c}\text { The number of } 1 \mathrm{~s} \mathrm{time} \\
\text { steps for each } \\
\text { simulation run }\end{array}$ \\
\hline$S_{0}$ & 5000000 & & $\begin{array}{l}\text { Initial number of bait } \\
\text { odor particles }\end{array}$ \\
\hline$\overline{D S P}$ & 1 & & $\begin{array}{c}\text { Displacement } \\
\text { parameter for random } \\
\text { particle movement }\end{array}$ \\
\hline$\overline{D F}$ & 0.0006 & & $\begin{array}{l}\text { Constant diffusion rate } \\
\text { for particle dispersal }\end{array}$ \\
\hline$\lambda$ & $0.00008 \mathrm{~s}^{-1}$ & & $\begin{array}{l}\text { Leaching rate of bait } \\
\text { odor particles from bait } \\
\text { bag per second }\end{array}$ \\
\hline $\bar{U}$ & $1.25 \mathrm{~ms}^{-1}$ & $0.1-25 . \mathrm{ms}^{-1}$ & Current speed \\
\hline$\mu$ Speed & $2.0 \mathrm{~ms}^{-1}$ & $0.0001-4.0 \mathrm{~ms}^{-1}$ & $\begin{array}{l}\text { Mean defining normal } \\
\text { distribution of possible } \\
\text { step length for sharks }\end{array}$ \\
\hline oSpeed & $0.2 \times \mu$ Speed & & $\begin{array}{c}\text { Variance defining } \\
\text { normal distribution of } \\
\text { possible step length for } \\
\text { sharks }\end{array}$ \\
\hline$T a b u$ & 25 & & $\begin{array}{c}\text { Number of most recent } \\
\text { cells visited shark will } \\
\text { not revisit }\end{array}$ \\
\hline Nmax & 4 & & $\begin{array}{c}\text { The maximum number } \\
\text { of sharks allowed in a } \\
\text { single cell }\end{array}$ \\
\hline DropThreshold & 0.95 & & $\begin{array}{l}\text { Value indicating what } \\
\text { percentage of current } \\
\text { cell heading options } \\
\text { must be not to elicit } \\
\text { movement in opposite } \\
\text { heading }\end{array}$ \\
\hline$a$ & 5 & $1-10$ & $\begin{array}{l}\text { Alpha. The relative } \\
\text { attraction strength to } \\
\text { bait }\end{array}$ \\
\hline$D S$ & 5 & $1-10$ & $\begin{array}{l}\text { Directionality. The } \\
\text { relative directness of } \\
\text { movement patterns }\end{array}$ \\
\hline$L V$ & $15 \mathrm{~m}$ & $1-15 \mathrm{~m}$ & $\begin{array}{l}\text { Distance within with } \\
100 \% \text { of sharks can be } \\
\text { detected within the } \\
\text { camera's field of view }\end{array}$ \\
\hline$U V$ & $1.5 \times L V$ & & $\begin{array}{c}\text { Distance outside of } \\
\text { which } 0 \% \text { of sharks can } \\
\text { be detected by the } \\
\text { camera }\end{array}$ \\
\hline Nsharks & 25 & $1-125$ & $\begin{array}{c}\text { The number of sharks } \\
\text { within the simulated } \\
1 \mathrm{~km}^{2} \text { area. }\end{array}$ \\
\hline
\end{tabular}

Table 1. Parameter description and value range when varied, as well as fixed value when not varied for each simulation scenario. 


\section{CHAPTER IV}

USING UNMANNED AERIAL VEHICLES AND MACHINE LEARNING TO IMPROVE SEA CUCUBMER DENSITY ESTIMATION IN SHALLOW HABITATS 


\section{Abstract}

Sea cucumber (Holothuroidea) populations across the globe have experienced dramatic declines caused by overexploitation and habitat loss. The status of populations and potential harvest levels are determined from fisheries-dependent and independent data sources, such as diver transect surveys. Though widely used, diving-derived data typically cover relatively small spatial scales and have a number of inherent biases that can reduce the accuracy of surveys. Unmanned aerial vehicles (UAVs) may offer a means to supplement current survey efforts while simultaneously overcoming several issues associated with traditional methods in shallow habitats. Here, we tested the potential of UAVs to estimate sea cucumber abundance in a shallow marine environment, while also exploring the potential of machine learning to automate sea cucumber counts. To evaluate this question, we conducted 24 diver belt transects paired with simultaneous UAV transect sampling of sea cucumbers in the small French Polynesian atoll of Tetiaroa, in July 2018. All UAV images were reviewed by three independent observers, as well as with a recently developed convolution neural network (CNN) model known as ResNet50. Comparison of counts derived from all three methods (divers, manual review of UAV data, and ResNet50) indicated no significant differences between any one method. Though regression of counts from manually reviewed UAV images were highly correlated with diver counts, CNN estimates appeared asymptotic at higher densities. Additionally, we estimated the spatial distribution of sea cucumbers using a UAVderived photomosaic of the study site. We then bootstrapped potential transect locations and determined that a minimum number of 25 samples is required to reduce sampling variance and reliably estimate sea cucumber density. Collectively, these results highlight 
the potential for UAVs to supplement current data collection efforts and would potentially enable surveys in regions previously inaccessible.

\section{Introduction}

Sea cucumbers (Holothuroidea) are marine benthic invertebrates that play an important role in coral reef ecosystems (Purcell et al. 2014a). Their digestion of organic matter associated with ingested coral sand and rubble results in the dissolution of acidic $\mathrm{CaCO}_{3}$ particulates and, consequently, increases local alkalinity in reef environments (Hammond 1981; Schneider et al. 2013; Purcell et al. 2016). Importantly, this digestive process may help to buffer against the effects of increasing ocean acidification (Schneider et al., 2013). As a digestive by-product, sea cucumbers also secrete ammonia $\left(\mathrm{NH}_{3}\right)$ that contributes to nutrient cycling and encourages productivity in coral systems (Uthicke and Klumpp 1998; Uthicke 2001). Furthermore, sea cucumbers directly increase oxygen levels in the sediment through bioturbation (Hammond 1982). By implication, the presence of sea cucumbers may improve reef resilience and stability under future anthropogenic stressors (Schneider et al. 2013), and it has been suggested that their removal can result in diminished ecosystem functionality (Purcell et al. 2016).

Many species of tropical sea cucumbers are commercially valuable (Conand 1998; Purcell et al. 2014b), with the majority harvested to produce bêche-de-mer products for consumption in Asian markets (Anderson et al. 2011; Eriksson and Clark 2015). Their ease of collection, low recruitment, slow growth, and high longevity makes them particularly vulnerable to overfishing (Conand 2001; Uthicke et al. 2004). These factors coupled with high global demand for sea cucumber products has resulted in $70 \%$ 
of tropical sea cucumber species being listed as exploited, over-exploited, or depleted (Anderson et al. 2011; Purcell et al. 2014b), with many local populations having already been extirpated (Purcell et al. 2014b). To determine optimal harvest levels, stakeholders must be able to assess the spatiotemporal population dynamics from a variety of data sources including fisheries-independent surveys.

To date, the majority of fisheries-independent surveys used to help sea cucumber management decisions comes from underwater visual censuses (UVCs), which provide density estimates over a small area using counts from SCUBA diver or snorkeler transects (e.g., Shepard et al., 2003; Leopold et al. 2013; Rehm et al. 2014; Wolfe and Bryne 2017; Idreesbabu and Sureshkumar 2017). Though important tools, these surveys have a number of shortcomings, including high costs, errors and bias owing to observer experience, low detection rates, and small spatial coverage (Shepard et al. 2003; Prescott et al. 2013). They are also time-consuming and logistically impractical in many of the shallow sand flat habitats where sea cucumbers are abundant (Mercier et al. 2000; Idreesbabu and Sureshkumar 2017). Given the limitations of current survey methods and an increasing need for accurate sea cucumber abundance estimates, it is critical to develop tools and techniques to better monitor these ecologically and economically important populations.

Unmanned Aerial Vehicles (UAVs) have rapidly developed over the last decade and have been increasingly used by ecologists as a wildlife monitoring tool (Ivošević et al. 2015). Their low cost, ease of use, relatively large spatial coverage, programmable flight paths, and ability to be deployed in remote locations, have enabled UAVs to be 
applied to a wide range of studies in both terrestrial and marine environments (Anderson and Gaston 2013; Colefax et al. 2017). The majority of work in marine population monitoring has focused on the application of UAVs to replace traditional manned aerial surveys of large vertebrates such as dugongs (Hodgson et al. 2013), cetaceans (Christansen et al. 2016), sea turtles (Rees et al. 2018) and elasmobranchs (Kiszka et al. 2016). More recently, UAVs have been used to examine aspects of species behavior (Rieucau et al. 2018) and to quantify changes in coral health (Parsons et al. 2018). An as yet unexplored potential application of UAVs, however, is their ability to provide density estimates for shallow water invertebrate species, for which remote underwater vehicles or diver transects may be impracticable.

In this study, we aimed to demonstrate how UAVs could provide a means to supplement current data collection efforts for sea cucumbers in shallow water environments, while also overcoming many issues associated with traditional diver surveys. Specifically, our objectives were to compare estimated counts and the time required to extract counts for sea cucumber transects using: 1) In-situ diver observations 2) UAV data manually generated by observers 3) UAV data generated using machine learning. Additionally, we explored how UAVs may be used to improve survey design and quantify required survey effort for diver transects.

\section{Methods}

\section{Data collection}

We conducted sea cucumber transect surveys over shallow $(<2 \mathrm{~m})$ sandflats of Tetiaroa, French Polynesia, a small atoll in the Society Archipelago (Fig. 1) from 22-24 
July 2018. In total, 24 paired diver transects were conducted, with a random starting and heading selected for each (Fig. 1). Prior to sampling, each survey location was verified using a Garmin eTrex 39x hand held GPS. Each transect covered a 4x10m area, and occurred between 08:00 to16:00 local time. To aid in observer counts (i.e., reduce double counting), each transect was subdivided into $1 \times 10 \mathrm{~m}$ areas by connecting two grey $1 \mathrm{~m}$ PVC tubes covered in red electrical tape using weighted 1/4" black line, each at $10 \mathrm{~m}$ in length (Fig. 2). Once the observers had deployed the transect grid, depth at both the starting and end points of each transect were measured using a weighted Komelon 6622 open reel measuring tape. Following these measurements, observers waited until all sediment had settled before beginning transect surveys (approximately 60s). Transects were conducted one at a time by two independent snorkelers, with their times required to complete each transect recorded in seconds. Following snorkel transects, each location was then surveyed using a DJI Mavic Air (168x83x49mm; 430g) equipped with a polarizing lens to reduce issues with sun glare. The UAV was flown directly over the center of the transect grid at an altitude of $7 \mathrm{~m}$ and all videos were shot in $4 \mathrm{k}$ resolution at 30 fps.

Manual review of $U A V$ data

Counts from snorkelers were recorded in-situ, whereas UAV video transects required additional steps to enumerate sea cucumbers. For each transect, a single image was selected from the video footage to be reviewed, using the ImageMagic package within a UNIX shell. Each image was then independently reviewed by two trained observers using the application Visual Counter (version 1.2; iVanya ${ }^{\mathrm{TM}} 2015$ ), with total time in seconds recorded for each observer to process an image. Visual Counter allowed 
observers to click on sea cucumbers present on an image, and provided a total count of marked objects, relieving observers from self-tracking raw counts (Fig. 2). After manual annotations of the sea cucumbers were completed by both observers, each pair of annotated images were compared to one another to by a third independent observer who provided the final count. To assist the third observer in comparing these two images, areas marked by both initial observers were converted to yellow, while areas of discrepancy (i.e., sea cucumbers marked by one observer but not the other) were converted to red. This colorization process was accomplished in MATLAB, by expanding the annotated pixel areas (to account for the same sea cucumber being marked in slightly different locations) and isolating marked pixels in the $\mathrm{L}^{*} \mathrm{a} * \mathrm{~b}$ colorspace. Automated UAV data review

To automate the process of identifying and enumerating sea cucumbers from UAV data, we elected to use ResNet50: a 50-layer Convolution Neural Network (CNN) that supports Residual Learning. Convolution Neural Networks are widely considered to be the current 'gold standard' for image classification, and function by transforming an input image through a specified number of hidden layers. Each layer type serves a different function in the network, from feature extraction (convolution), to dimensionality reduction (pooling), and final feature aggregation (fully connected). ResNet50 was developed and trained using ImageNet: a large database of over 14 million annotated images (Russakovsky et al. 2015). Using the pre-trained ResNet50 architecture, we constructed a faster-RCNN object detector for sea cucumbers. To train the faster-RCNN detector, we used 72 augmented images taken from our UAV transects (flipped vertically, horizontally, and both). Each image was annotated for 5 separate classifiers: small sea 
cucumbers, large sea cucumbers, rocks, detritus, and transect lines. Once trained, image classifiers were then used to predict the number of sea cucumbers present on the original (un-augmented) UAV transect images, with all proposed objects given probability of $90 \%$ or greater of being a sea cucumber, accepted in the final count.

\section{Comparing count estimates}

Counts generated for each estimation method were statically compared using a Kruskal-Wallis rank sum test. Additionally, we compared the resulting estimates of each UAV review method to diver transects using a simple linear model, whereby the mean value of the divers was assigned as the 'true count' for that transect. The time required to provide sea cucumber estimates for divers and manual review of UAV data was set as the sum of the individual times of each observer for any one transect. To determine if snorkelers or manual review of UAV data had significantly different time requirements, a Mann-Whitney-Wilcox test used. All data were analyzed in the $\mathrm{R}$ core environment $(\mathrm{R}$ Core Development Team, 2018), with significance accepted at a p-value of less than or equal to 0.05 .

\section{UAVs to improve diver survey designs}

Using the application Pix4DCapture (Version 4.6.0), we created a photomosaic of the entire study region using a series of 57 overlapping, geo-referenced images. The mosaic was then manually reviewed by a single observer using Visual Counter in the same manner as described for the manual review of UAV data, whereby all observed sea cucumbers were marked with a small, colored square (e.g., blue). The XY coordinates of these marker positions were then extracted via the same color channel filtering in $L^{*} a * b$ colorspace as previously described. We then randomly selected a 4x10m representative 
section of the mosaic, and provided the total number of marked sea cucumbers in this area. This procedure was then replicated for 2-100 simulated transects at a time, and was then repeated 1,000 times. Using these simulated samples, we then explored how total sample variance changed in relation to the simulated number of transects (1-100).

\section{Results}

Sea cucumber counts provided by divers varied broadly across transects (range $=0$ $111)$, with a mean of $53.6( \pm 79.9 ; \pm 2 S D)$. However, counts among divers were relatively precise, averaging a difference of only $2.25( \pm 6.0)$ with a maximum difference of 11. Difference in sea cucumber counts between divers was greatest for transects with the highest number of observed individuals (Fig. 3). Estimated counts from all three methods did not differ significantly $(\mathrm{p}=0.08, \mathrm{df}=2$, Kruskal-Wallis chi-squared $=4.96)$, though

estimates from the $\mathrm{CNN}$ were qualitatively lower than those from either divers or manual UAV counts (Fig. 3). Counts from manual review of UAV data were highly correlated with those from the diver surveys (adjusted $\mathrm{R}^{2}=0.94, \mathrm{p}<0.01$; Fig. 3). Although linear regression of CNN estimates against mean diver counts also yielded a significant relationship ( $\mathrm{p}<0.01)$, the correlation between the two variables was modest (adjusted $\mathrm{R}^{2}=0.54$ ), and visual inspection of the regression indicated an asymptotic relationship (Fig. 3).

Processing times for UAV images that were manually reviewed showed high variability from one image to another (range $=144-760 \mathrm{~s})$, averaging $380.6 \mathrm{~s}( \pm 156.1 \mathrm{~s})$. The amount of time required to process any one image was strongly related to the number of sea cucumbers estimated to be present, but did not appear to be influenced by transect depth. Processing times required by divers for each transect were significantly shorter 
than those by UAV review $(\mathrm{W}=170, \mathrm{p}=0.01)$, with an average time required of $275.5 \mathrm{~s}$ $( \pm 238.4)$. However, times also varied greatly between transects for divers (range $=92$ 456), and had a mean difference of less than two minutes as compared to manual review of UAV images.

Pix4D proved capable of generating a photomosaic of the entire surveyed area (Fig. 4). Furthermore, it was possible for observers to manually annotate sea cucumbers within these images using Visual Counter (Fig. 4). Visual inspection of simulation results indicated that sample variance dramatically declined once sample size reached at least 5 transects, but that decreases in variance began to plateau at approximately 25 transects (Fig. 5).

\section{Discussion}

In the present study, we have demonstrated how UAVs may be used in a new realm of marine research by highlighting their ability to monitor relatively small invertebrate communities. Specifically, we found that UAVs represent a viable option to assess the abundance of sea cucumber species in shallow marine environments. Importantly, counts estimated using manually processed UAV data did not differ significantly from estimates made by snorkelers in the field. Although the time required to manually extract counts was higher for UAVs than for snorkelers, this process represents a relatively small increase in effort, particularly when considering other time constraints that we did not address in this study (e.g., time spent deploying and retrieving transects, time moving between site locations). This is in contrast to many other video survey platforms, that are often rendered unusable for resource managers because of the elapsed time between collecting and extracting data (Harvey et al. 2013). Furthermore, 
we were able to demonstrate that by using CNNs, it may be possible to fully automate the process of extracting counts from UAV data, which could further reduce time requirements.

Our results indicate that manual reviewing UAV images, as well as automatically estimating counts with CNNs, does not differ significantly from traditional diver-derived counts. However, counts generated from CNNs data did tend to be lower, particularly in higher density areas. There are a number of factors that may have contributed to this lower than desired detection capability, but it was most likely driven by the small size of the dataset used to train the model. Numerous studies have shown that one of the most important factors for improving CNN model performance is to increase the size of the training dataset (Windrim et al. 2016; Ozbulk et al. 2016). As UAVs become more frequently used for this type of research, the amount of data available to develop these models will likely increase exponentially.

When considering the potential of CNNs to automatically enumerate sea cucumbers from image data, coupled with the relatively low cost of UAVs $(\sim \$ 1000$ USD) and their ability to be deployed in remote regions, UAVs become an obvious choice to supplement current UVC techniques as a research tool, and may even facilitate the gathering of data where none currently exist. The utility of UAVs may be particularly high in areas where UVC techniques are too expensive or logistically unrealistic to be implemented. Given the increasing popularity of UAVs in the public sector, it is also feasible that UAVs could be a source of large-scale citizen science data in the future. Though identifying sea cucumbers and other invertebrates from UAV data requires extensive training, it would be relatively simple to establish a repository where citizen 
scientists could contribute UAV images to be later reviewed by scientist, or ideally by machine learning methods such as CNNs. Similar citizen scientist image databases already exist, such as eBird (https://ebird.org/home), eMammal (https://emammal.si.edu), and Reef Vision (https://recfishwest.org.au/our-services/research/reef-vision-artificialreef-monitoring/).

Importantly, our results build on previous work (e.g., Shepard et al. 2003) to indicate that sea cucumbers do not distribute uniformly or even randomly throughout their environment, but instead cluster in large groups. Therefore, UAVs may be particularly well-suited to study these communities because they can cover a much larger area in a shorter timeframe than is typical of UVC techniques. By mapping the study region ahead of deploying diver transects, researchers may be able to quantify the general spatial distribution of their target species, and potentially identify what physical characteristics of the environment may be driving these observed distributions (e.g., distance to coral, tidal state). Furthermore, using photomosaic mapping could enable researchers to determine what survey effort is required to accurately and precisely estimate species densities. In the present study we demonstrated how this technique could be used to determine the number of samples required to reliably estimate sea cucumber density within a study site. Using this same approach, researchers could determine how different sampling designs (e.g., random, stratified-random, systematic, or adaptive) and chosen transect sizes (i.e., better to have many small transects, or fewer large transect) may impact their resulting count estimates. Given the potential limitations of UAVs to identify sea cucumbers to the species level, coupled with depth restrictions of the 
technique, UAVs may be best served as a tool for improving diver transects until these limitations can be addressed.

As UAVs continue to advance and drop in price, they will undoubtedly be used increasingly by researchers and conservation managers. Here we have presented how this innovative technology can be used in the marine environment to enumerate small marine invertebrates such as sea cucumbers. Given the ecological importance of sea cucumbers (particularly in the face of increasing ocean acidification due to climate change) as well as their massive global economic importance, it is imperative that we have reliable fisheries-independent data to help inform fisheries management as well as potential conservation measures. This data need is made all the more crucial by the fact that many sea cucumber species are undergoing dramatic declines in the face of overexploitation and other anthropogenic stressors (Purcell et al. 2014a). Although UVC techniques such as diver transects will continue to play an important role in quantifying marine invertebrate communities, the reliability and numerous advantages of UAV surveys demonstrated in this study highlight their likely future role in describing spatiotemporal changes of shallow water coral reef communities.

\section{Acknowledgements}

The authors would like to thank the Seeley family, J. Hirota, and the Florida International University Dissertation Year Fellowship for generously funding this research. We would also like to extend our gratitude to the Tetiaroa Society and the Centre de Rechereches Insulaires et Observatoire de l'Environnement (CRIOBE) for all of their help in the field and providing logistical support. Lastly, we would like to thank Florida International University Fisheries and Ecosystem Assessment Lab interns A. 
Bass, D. De Mello, B. Markley, and M. Schlegel for providing sea cucumber counts from survey images.

Literature cited

Anderson, K., Gaston, K. J. 2013. Lightweight unmanned aerial vehicles will revolutionize spatial ecology. Frontiers in Ecology and the Environment, 11:138146.

Anderson, S. C., Flemming, J. M., Watson, R., Lotze, H. K. 2011. Rapid global expansion of invertebrate fisheries: trends, drivers, and ecosystem effects. PLoS One, 6:e14735.

Christiansen, F., Dujon, A. M., Sprogis, K. R., Arnould, J. P., Bejder, L. 2016. Noninvasive unmanned aerial vehicle provides estimates of the energetic cost of reproduction in humpback whales. Ecosphere, 7.

Colefax, A.P., Butcher, P.A., Kelaher, B.P. and Handling editor: Howard Browman. 2017. The potential for unmanned aerial vehicles (UAVs) to conduct marine fauna surveys in place of manned aircraft. ICES Journal of Marine Science, 75: 18.

Conand, C. 1998. Overexploitation in the present world sea cucumber fisheries and perspectives in mariculture. Echinoderms 1998: Proceedings of the 9th International Echinoderm Conference, San Francisco, CA, USA. A.A. Balkema, Rotterdam, pp 449-454.

Conand, C. 2001. Overview of sea cucumber fisheries over the last decade-what possibilities for a durable management? Echinoderms 2000: Proceedings of the $10^{\text {th }}$ International Conference, Dunedin, New Zealand. Swets and Zeitlinger, Lisse, pp 339-344.

Eriksson, H., Clarke, S. 2015 Chinese market responses to overexploitation of sharks and sea cucumbers. Biological Conservation, 184:163-173.

Hammond, L. S.1981. An analysis of grain size modification in biogenic carbonate sediments by deposit-feeding holothurians and echinoids (Echinodermata). Limnological Oceanography, 26:898-906.

Hammond, L. S. 1982. Patterns of feeding and activity in deposit feeding holothurians 
and echinoids (Echinodermata) from a shallow back-reef lagoon, Discovery Bay, Jamaica. Bulletin of Marine Science, 32:549-571.

Harvey, E., Fletcher, D., Shortis, M. R., Kendrick, G. A. 2004. A comparison of underwater visual distance estimates made by scuba divers and a stereo-video system: implications for underwater visual census of reef fish abundance. Marine and Freshwater Research, 55:573-580.

Harvey, E. S., McLean, D., Frusher, S., Haywood, M. D. E., Newman, S. J., Williams, A. 2013. The use of BRUVs as a tool for assessing marine fisheries and ecosystems: a review of the hurdles and potential. Fisheries Research and Development Corporation and The University of Western Australia, Perth.

He, K., Zhang, X., Ren, S., and Sun, J. 2016. Deep Residual Learning for Image Recognition. IEEE Conference on Computer Vision and Pattern Recognition (CVPR), pp. 770-778. IEEE, Las Vegas, NV, USA.

Hodgson, A., Kelly, N., Peel, D. 2013. Unmanned aerial vehicles (UAVs) for surveying marine fauna: a dugong case study. PloS One, 8: e79556.

Idreesbabu, K. K., Sureshkumar, S. 2017. Distribution pattern and community structure of sea cucumbers (Class: Holothuroidea) in different biogeographic regions of the selected Islands of Lakshadweep Archipelago, India.

Ivošević, B., Han, Y., Cho, Y., Kwon, O. 2015. The use of conservation drones in ecology and wildlife research. Ecology and Environment, 38: 113-188.

Kiszka, J. J., Mourier, J., Gastrich, K. R., Heithaus, M. R. 2016. Using unmanned aerial vehicles (UAVs) to investigate shark and ray densities in a shallow coral lagoon. Marine Ecological Progress Series, 560:237-242.

Léopold, M., Cornuet, N., Andréfouët, S., Moenteapo, Z., Duvauchelle, C., Raubani, J., Ham, J., Dumas, P. 2013. Comanaging small-scale sea cucumber fisheries in New Caledonia and Vanuatu using stock biomass estimates to set spatial catch quotas. Environmental Conservation, 40:367-379.

Mercier, A., Battaglene, S. C., Hamel, J. F. 2000. Periodic movement, recruitment and size-related distribution of the sea cucumber Holothuria scabra in Solomon Islands. Hydrobiologia, 440: 81-100.

MATLAB and Statistics Toolbox Release, 2018. The MathWorks, Inc., Natick, Massachusetts, United States.

Ng, H., Nguyen, V., Vonikakis, V., Winkler, S. 2015. Deep Learning for Emotion Recognition on Small Datasets using Transfer Learning. Proceedings of the 2015 
ACM on International Conference on Multimodal Interaction - ICMI '15, pp. 443-449. ACM Press, Seattle, Washington, USA.

Ozbulak, G., Aytar, Y., Ekenel, H. 2016. How transferable are CNN-based features for age and gender classification? 2016 International Conference of the Biometrics Special Interest Group (BIOSIG) pp. 1-6. IEEE.

Parsons, M., Bratanov, D., Gaston, K., Gonzalez, F. 2018. UAVs, hyperspectral remote sensing, and machine learning revolutionizing reef monitoring. Sensors, 18: 2026.

Perez, L., Wang, J. 2017. The Effectiveness of Data Augmentation in Image Classification using Deep Learning. arXiv:1712.04621.

Prescott, J., Vogel, C., Pollock, K., Hyson, S., Oktaviani, D., Panggabean, A.S. 2013. Estimating sea cucumber abundance and exploitation rates using removal methods. Marine and Freshwater Research. 64: 599-608.

Purcell, S. W., Lovatelli, A., Pakoa, K. 2014a. Constraints and solutions for managing Pacific Island sea cucumber fisheries with an ecosystem approach. Marine Policy, 45:240-250.

Purcell, S. W., Polidoro, B. A., Hamel, J. F., Gamboa, R. U., Mercier, A. 2014b. The cost of being valuable: predictors of extinction risk in marine invertebrates exploited as luxury seafood. Proceedings of the Royal Society B: Biological Sciences, 281:20133296.

Purcell, S. W., Conand, C., Uthicke, S., Byrne, M. 2016. Ecological roles of exploited sea cucumbers. Oceanography and Marine Biology: An Annual Review, 54:367-386.

R Core Team. 2018. R: A language and environment for statistical computing. R Foundation for Statistical Computing, Vienna, Austria. URL http://www.Rproject.org/

Rees, A. F., Avens, L., Ballorain, K., Bevan, E., Broderick, A. C., Carthy, R. R., Christianen, M. J., Duclos, G., Heithaus, M. R., Johnston, D. W., Mangel, J. C., Paladino, F., Pendoley, K., Reina R. D., Robinson, N. J., Robert, R., SykoraBoide, S. T., Tilley, D., Varela, M.R., Whitman, E. R., Whittock, P. A., Wibbels, T., Godley, B. J. 2018. The potential of unmanned aerial systems for sea turtle research and conservation: a review and future directions. Endangered Species Research, 35:81-100.

Rehm, L., Koshiba, S., Mereb, G., Olsudong, D., Seksei, F., Remeliik, K. 2014. Status of sea cucumber populations inside and outside a Marine Protected Area in Ngardmau State, Palau. 
Ren, S., He, K., Girshick, R., Sun, J. 2017. Faster R-CNN: Towards Real-Time Object Detection with Region Proposal Networks. IEEE Transactions on Pattern Analysis and Machine Intelligence, 39: 1137-1149.

Rieucau, G., Kiszka, J., Castillo, J., Mourier, J., Boswell, K., Heithaus, M. 2018. Using unmanned aerial vehicle (UAV) surveys and image analysis in the study of large surface-associated marine species: a case study on reef sharks Carcharhinus melanopterus shoaling behavior. Journal of fish biology, 93: 119-127.

Russakovsky, O., Deng, J., Su, H., Krause, J., Satheesh, S., Ma, S., Huang, Z., Karpathy, A., Khosla, A., Bernstein, M., Berg, A. 2015. ImageNet Large Scale Visual Recognition Challenge. International Journal of Computer Vision, 115: 211-252.

Schneider, K., Silverman, J., Kravitz, B., Rivlin, T., Schneider-Mor, A., Barbosa, S., Byrne, M., Caldeira, K. 2013. Inorganic carbon turnover caused by digestion of carbonate sands and metabolic activity of holothurians. Estuarine, Coastal, and Shelf Science, 133:217-223.

Shepherd, S., Toral-Granda, V., Edgar, G. J. 2003. Estimating the abundance of clustered and cryptic marine macro-invertebrates in the Galápagos with particular reference to sea cucumbers. Noticias de Galápagos, 62:36-39.

Uthicke, S., Klumpp, D. W. 1998. Microphytobenthos community production at a nearshore coral reef: seasonal variation and response to ammonium recycled by holothurians. Marine Ecological Progress Series, 169:1-11.

Uthicke, S. 2001. Nutrient regeneration by abundant coral reef holothurians. Journal of Experimental Marine Biology and Ecology, 265:153-170.

Uthicke, S., Welch, D., Benzie, J. H. 2004. Slow growth and recovery in overfished holothurians on the Great Barrier Reef: evidence from DNA fingerprints and repeated large-scale surveys. Conservation Biology, 18:1395-1404.

Windrim, L., Ramakrishnan, R., Melkumyan, A., Murphy, R. 2016. Hyperspectral CNN classification with limited training samples. arXiv preprint arXiv:1611.09007.

Zhuang, F., Qi, Z., Duan, K., Xi, D., Zhu, Y., Zhu, H., Xiong, H., He, Q. 2019. A Comprehensive Survey on Transfer Learning. arXiv:1911.02685. 
Figures

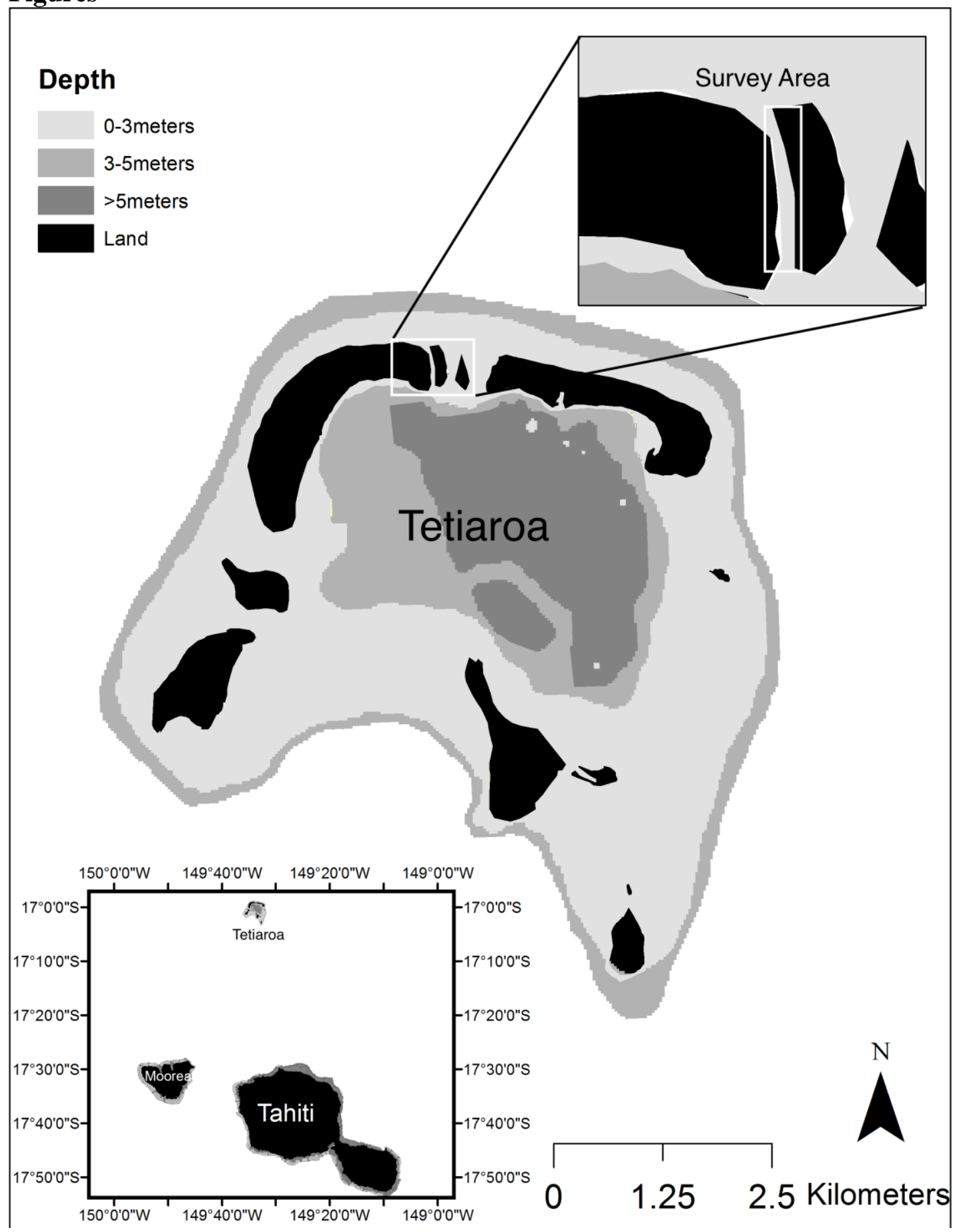

Figure 1. All unmanned aerial vehicle (UAV) transects for this study were flown in sandflat habitats of Tetiaroa (French Polynesia) of less than 2 meters in depth, from 2225 July 2018. Lower inset depicts nearby islands of the Society Archipelago; Tahiti and Moorea. Upper inset highlights northern region of lagoon where UAV transects were flown. 


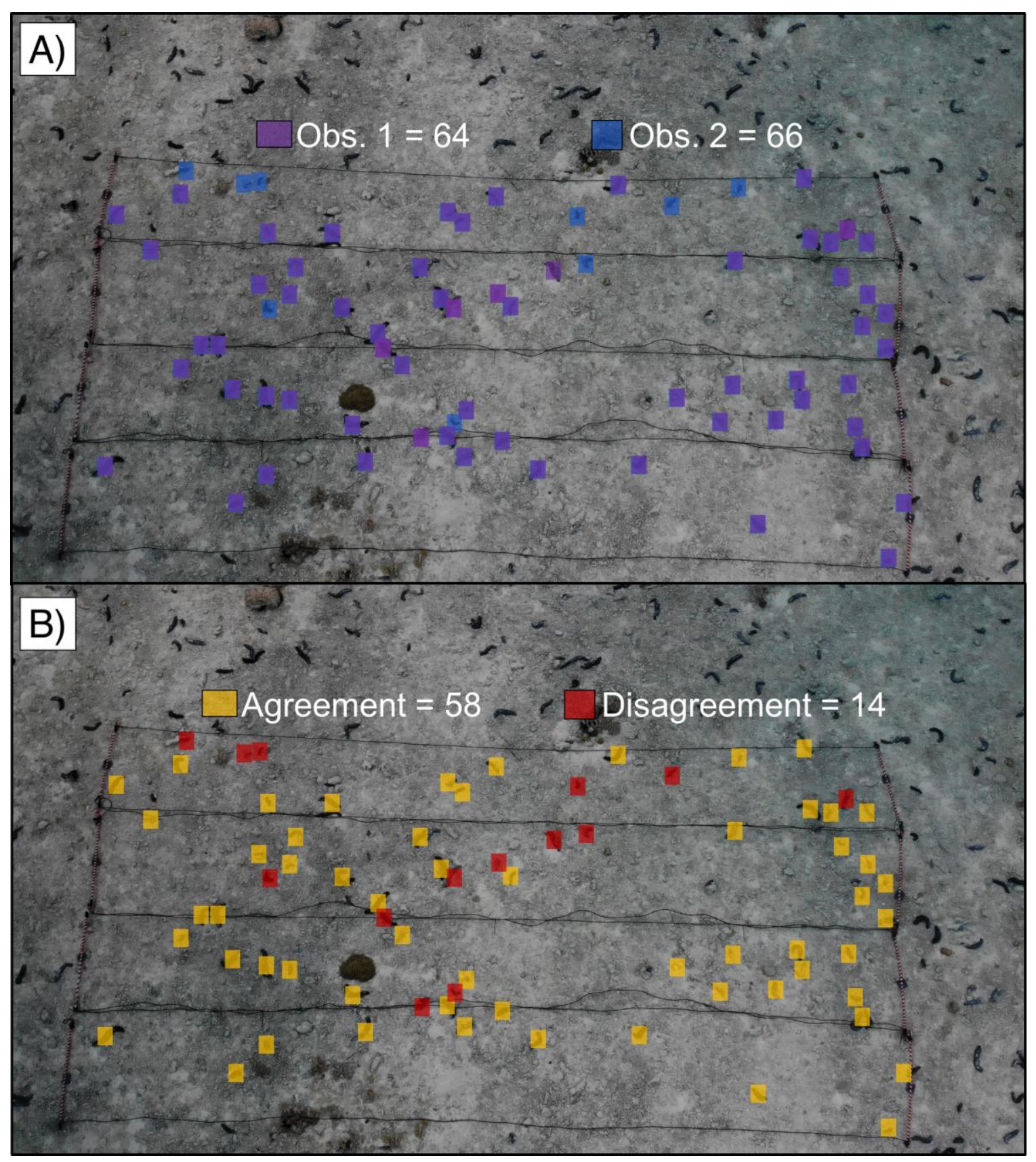

Figure 2. Example images of UAV data flown over snorkeler transects used in Tetiaroa, French Polynesia. Snorkeler transects are highlighted by weighted PVC and connected lines to ease comparison between divers and UAV. A) Image after being processed by observer using Visual Counter software. Sea cucumbers identified by the observer one are represented by small purple squares, while observer two markings are indicated in blue. B) Image of sea cucumber counts processed by two independent observers, with areas of agreement (represented by small orange squares) and disagreement (represented by small red squares) identified using MATLAB color channel filtering in the L*a*b color space. 


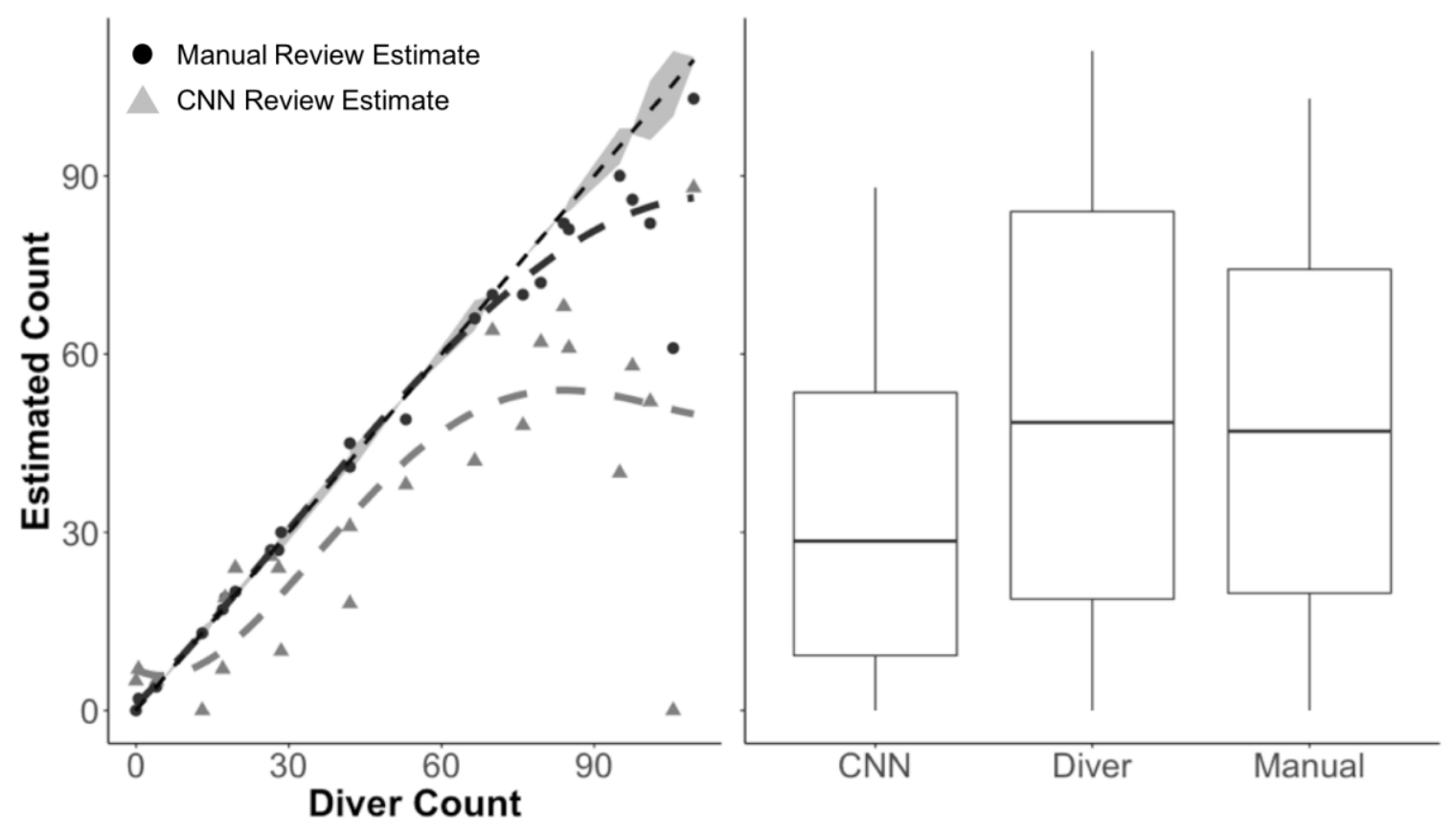

Figure 3. Left panel: Results from linear regression of sea cucumber counts estimated by manual review of UAV images (black circles) and via the employed convolution neural network model (CNN; grey triangles) as compared to mean count obtained by divers for the same transect. Small dashed line represents a perfect correlation, with the range in diver estimates illustrated by grey shadowing. Larger dashed lines represent an fitted polynomial of the manual review (black) and $\mathrm{CNN}$ (grey) estimates to aid in pattern visualization using the geom_smooth function in ggplot. Right panel: Boxplot for counts estimates derived from CNN, Divers, and Manual review of UAV data. Median values are indicated by center box line, with the integral quartile range represented by boxes, and minimum/maximum quartile ranges indicated by extended lines. 


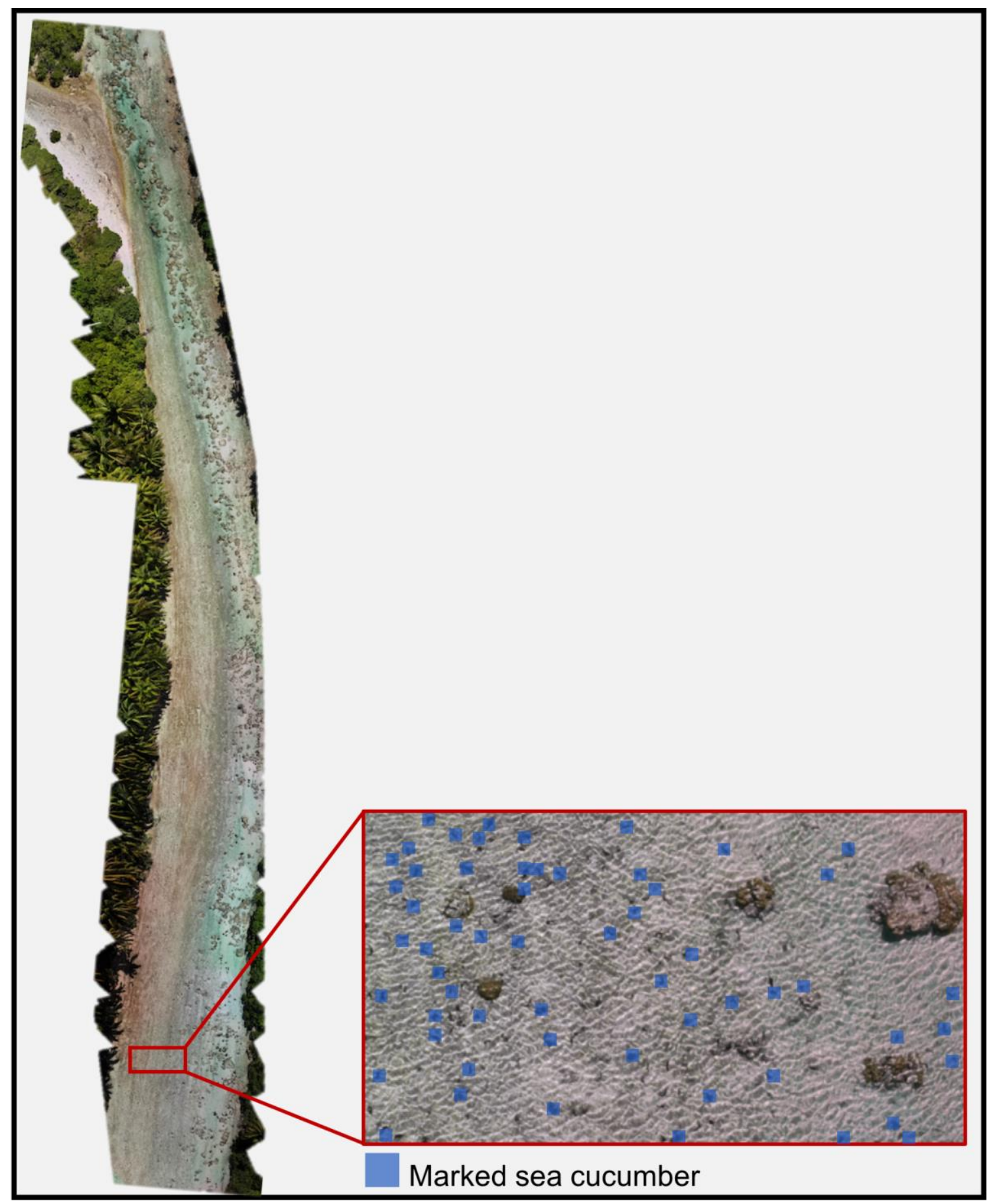

Figure 4. Photomosaic map of study region in Tetiaroa, French Polynesia generated by stitching 56 overlapping, geo-referenced images using the application Pix4DCapture. Inset highlights zoomed in portion of image with sea cucumbers manually marked using Visual Counter. 


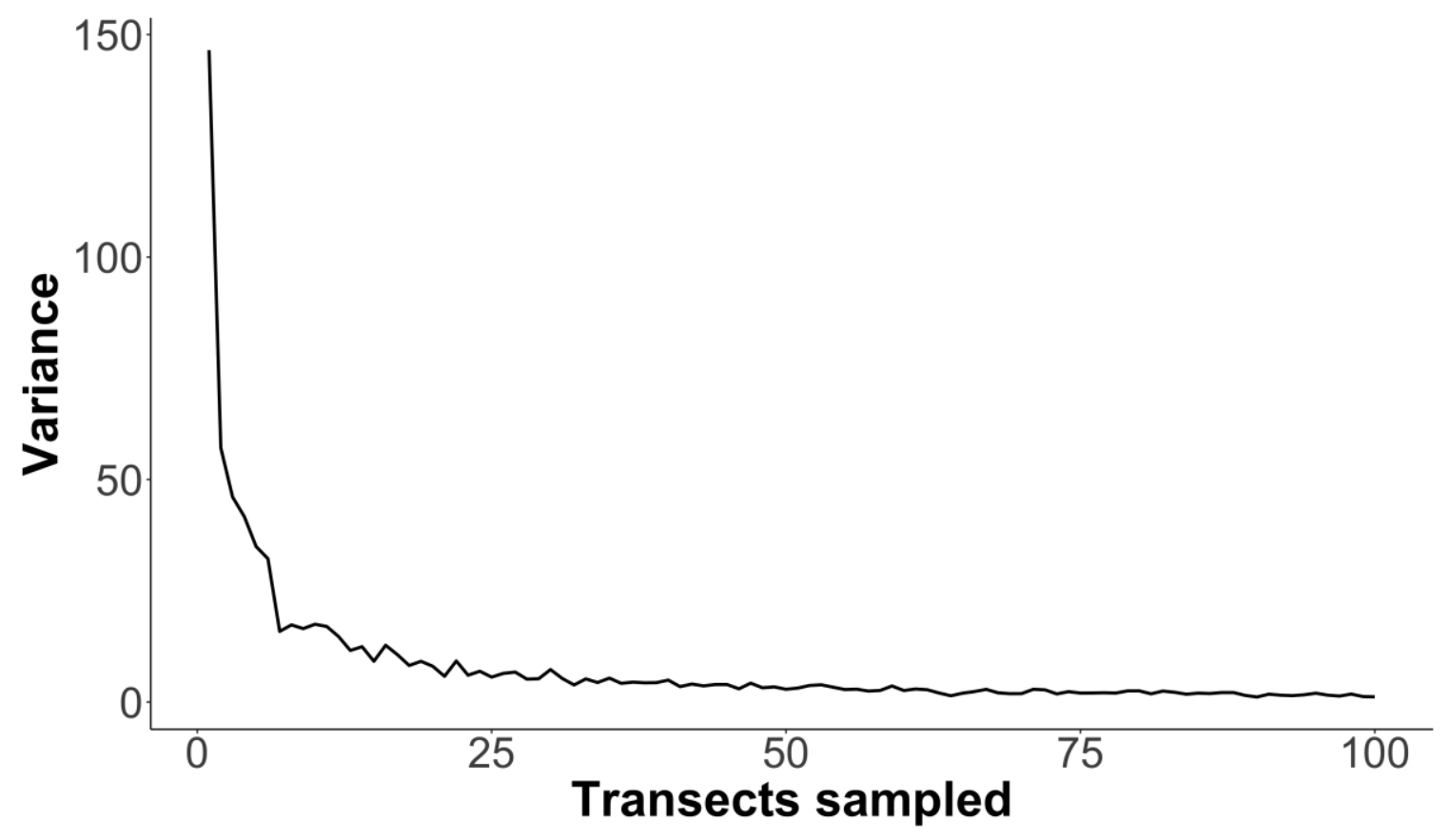

Figure 5. Sample variance from simulated transects (1-100) in relation to the number of transects sampled, based on sea cucumber locations taken from UAV generated photomosaic of the study region in Tetiaroa, French Polynesia. A total of 1,000 simulations were run for each number of simulated transects sampled. 
CHAPTER V

CONCLUSIONS AND FUTURE DIRECTIONS 
Nearly all branches of applied ecology have their foundation rooted in a simple objective; providing counts of organisms. Estimating population size is fundamental for conservation planning, establishing sustainable harvest practices, elucidating community dynamics, understanding trophic interactions, and predicting how these dynamics may change under future conditions. Though providing accurate species counts is vital to the field of ecology, it is also inherently difficult. This is especially true in fisheries research, where species are often highly mobile, cryptic, capable of actively avoiding detection, and inhabit an environment not readily accessible to human observers. As fisheries scientist John Shepard aptly summarizes, "Managing fisheries is hard. It's like managing a forest, in which the trees are invisible and keep moving around." An obvious question facing fisheries scientists is how can we overcome these challenges to improve the way in which we survey abundance and biodiversity? Often our greatest leaps forward in this realm come from technological advances. From acoustic telemetry, to global positioning devices, remote sensing, to hydroacoustics, innovations in technology continue change the way in which we survey the marine environment. In the last two decades, one of the greatest such advances has been the integration of various optical technologies into survey platforms. Small, inexpensive cameras are now capable of counting organisms for durations and depths well beyond human capabilities, and are becoming common place in fisheries research. While these technologies offer numerous advantages over invasive fishing-based survey methods, their novelty also means they have not yet undergone extensive scrutiny for potential biases and sources of error. Understanding, quantifying, 
and (if possible) mitigating against these biases is critical to insuring that data gathered using these methods are correctly interpreted and utilized for conservation planning.

In this dissertation, I investigated potential biases for two of the most commonly used camera based survey methods in fisheries research today; Baited Remote Underwater Video Systems (BRUVs) and Unmanned Aerial Vehicles (UAVs). In Chapter Two, I examined the relationship between common metrics of relative abundance derived from BRUVS and 'true' changes to local populations for two different reef shark species. Results from this chapter indicated that current relative abundance metrics likely undercount sharks in high density environments, which could lead to hyperdepleted or hyperinflated estimates of abundances, and thus mislead management decisions based on these data. Additionally, in this chapter we found that detection probability for standard BRUVS, which are often assumed to be $100 \%$, was relatively low as compare to newly developed full-spherical cameras that are capable of recording in $360^{\circ}$ horizontal by $360^{\circ}$ vertical fields-of-view. Chapter Three builds off of these initial findings using a spatially-explicit individual-based-model to test if these same metrics of relative abundance were sensitive to changes in density-independent factors such as species speed, movement pattern, attraction strength to bait, and environmental considerations such as bait plume size and water clarity. Results from this chapter provided empirical support for what is often suspected of baited surveys such as BRUVS, in that the metrics derived from these data were highly sensitive to changes in factors unrelated to local densities. Cumulatively, these chapters highlight the limitation of 
current relative abundance metrics derived from BRUV data, and suggests that researchers and conservation managers should carefully consider survey results before translating them into management actions. The goal of Chapter Four was to see if UAVs could be use as a means to supplement data collection for small invertebrate species such as sea cucumbers in shallow marine environments. Results from this chapter indicate that UAVs provide similar density estimates as compared to widely used diver transects, and can be utilized to survey a much greater area with far less effort (and thus lower cost). Furthermore, it is possible to automate the process of extracting count data from UAV footage, which could facilitate the collection and analysis of UAV data gathered by citizen scientists, and thus exponentially increase the amount of data available to inform management for these depleted populations. Together, these chapters advance our understanding on the limitations of current optical technologies used in fisheries research, and offers insights on how to account for, and diminish, their impact on survey results.

This dissertation adds to a growing body of work in methods research which strives to improve the accuracy and interpretation of various surveys. However, as is often the case in science, the answers uncovered in this work naturally have lead to more questions which need to be explored. For example, expanding on Chapter Three, is it possible that density-independent factors such as speed and bait plume size interact to impact estimates of species counts in a different way? Or do these factors have different impacts depending on the density of the target species? Similarly, from Chapter Two, would we get the same answers if we used a large-scale enclosure experiments rather than assuming full-spherical cameras represented a 'true' abundance? Furthermore, could 
we expand off these works and develop a more robust metric of relative abundances for BRUVS? When looking at the ability of UAVs to survey the marine invertebrates, a logical next step would be to investigate potential depth limitations of this method, and to see if other technologies such as multispectral imaging could improve their capabilities. There is obviously still much work to be done in these areas of research, but with each step, with every new question explored, we improve our understanding of the marine world, and perhaps just as importantly, how that view may be skewed by the very tools we use to explore it. 
VITA

JAMES PATRICK KILFOIL

2005-2009

B.Sc., Nutrition and Physiology

University of Missouri

Columbia, Missouri

2012-2014

M.Sc., Natural Resources

Delaware State University

Dover, Delaware

\section{PUBLICATIONS AND PRESENTATIONS}

Lagabrielle E., A. Allibert, J. Kiszka, N. Loiseau, J.P. Kilfoil*, and A. Lemahieu. 2018. Socioecological changes increase the probability of shark-human interactions around a fast-developing Indian Ocean island. Scientific Reports. 8: 3676.

Campbell, M.D., J. Salisbury, R. Caillouet, W.B. Driggers, and J.P. Kilfoil*. 2018. Camera field-of-view and fish abundance estimation: a comparison of individual-based model output and empirical data. Journal of Experimental Marine Biology and Ecology. 501: 46-53.

Kilfoil, J.P.*, A. J. Wirising, M.D. Campbell, J.J. Kiszka, K. R. Gastrich, M. R. Heithaus, Y. Zhang, and M. E. Bond. 2017. Baited Remote Underwater Video surveys undercount sharks at high densities: Insights from full-spherical camera technologies. Marine Ecological Progress Series. 585: 113-121.

Kilfoil, J.P.*, B.M Wetherbee, J.K. Carlson, and D.A. Fox. 2017. Targeted catch and release angling of prohibited sharks: Sand Tigers (Carcharias taurus) in coastal Delaware waters. Fisheries. 42: 281-287.

Fox, D.A., B.M. Wetherbee, S. Johnson, J.P. Kilfoil*, and S. Michels. 2015. Conservation of the Sand Tiger shark (Carcharias taurus) in the waters of Delaware Bay and nearshore coastal habitats. Final Report for NOAA-NMFS Proactive Species Conservation Program. Award Number: NA09NMF4720365.

Kilfoil, J.P.*, M.R. Heithaus, M.M. Campbell, Y. Zhang. 2019. Seeing the bigger picture: Using full-spherical cameras to reduce the influence of density independent factors on video survey metrics of relative abundance. Data monitoring session, $70^{\text {th }}$ Annual Tuna Conference, Lake Arrowhead, CA. Oral presentation. 
Kilfoil, J.P.*, M.R. Heithaus, Y. Zhang, Tristan Guttridge, M.E. Bond. 2018. Validating the use of unmanned aerial vehicles (UAVs) to study the endangered smalltooth sawfish (Pristis pectinata) in The Bahamas. Watching the submarine races: AUVs and Drones in Fisheries Research Symposium, Annual Meeting of the American Fisheries Society, Atlantic City, NJ. Oral presentation.

Kilfoil, J.P.*, I. Pinto, J.J. Kiszka, M.R. Heithaus, Y. Zhang, A.J. Wirsing. 2018. Eye in the sky: using unmanned aerial vehicles (UAVs) to quantify both coral structure and invertebrate density in shallow water marine environments. Florida International University Graduate Student Appreciation Week Symposium. Oral presentation.

Kilfoil, J.P.*, M.R. Heithaus, Y. Zhang, Tristan Guttridge, M.E.Bond. 2018. Experimental validation of unmanned aerial vehicles to survey smalltooth sawfish (Pristis pectinata) in the Bahamas. Research Experiences Expert Talk, Bimini Biological Field Station. Oral presentation.

Kilfoil, J.P.*, I. Pinto, J.J. Kiszka, M.R. Heithaus, Y. Zhang, A.J. Wirsing. 2017. Moving beyond diver surveys: Automated UAV survey data extraction to quantify coral and invertebrate density in shallow-water marine environments. Ecosystem in Monitoring Practice Session, Annual Meeting of the International Council for the Exploration of the Sea, Fort Lauderdale, FL, USA. Oral presentation.

Kilfoil, J.P.*, M. Campbell, M. Heithaus, K. Gastrich, J. Kiszka, A. Wirsing, M. Bond, Y. Zhang. 2017. Are limited field of views limiting elasmobranch conservation efforts? Implications for baited remote underwater video surveys. Integration of technologies for the next generation of marine observation systems and fisheries independent surveys II symposium, Annual Meeting of the American Fisheries Society, Tampa, FL, USA. Oral presentation.

Kilfoil, J.P.*, I.R. Pinto, J.J. Kiszka, J. Mourier, A.J. Wirsing, M.R. Heithaus, Y. Zhang. 2016. To catch a predator: Using unmanned aerial and underwater video technologies to estimate reef shark populations in French Polynesia. Florida International University Biological Sciences Symposium. Oral presentation.

Kilfoil, J.P.*, J.J. Kiszka, J. Mourier, A.J. Wirsing, M.R. Heithaus, Y. Zhang. 2015. Unmanned aerial drone and stationary video surveys to estimate reef shark densities in shallow nursery habitats. Ecosystem in Monitoring Practice Session, Annual Meeting of the International Council for the Exploration of the Sea, Copenhagen, Denmark. Oral presentation.

Kilfoil, J.P.*, Y. Zhang, K.M. Boswell. 2015. Spatial-temporal distributions of dominant estuarine species along the Texas coast. Annual Meeting of the American Fisheries Society, Portland, OR. Oral presentation. 